\title{
EIN OSTEUROPÄISCHER SCHNALLENTYP AUS DEM 7. JAHRHUNDERT \\ IM KARPATENBECKEN. PERIPHERIALE VERBINDUNGEN ZUR ZEIT DER BYZANTINISCHEN DOMINANZ
}

\author{
GERGELY SZENTHE \\ Ungarisches Nationalmuseum \\ H-1370 Budapest, Múzeum krt. 14-16, Ungarn \\ szenthe.gergely@hnm.hu
}

\begin{abstract}
The present study discusses a single buckle type, namely the variant that has the loop and plate cast in one and is provided with an attachment spike, representing a separate technological group within consciously employed forms. Assigned to the heraldic style in the Martinovka group, these buckles enjoyed a long use. The distribution and chronology of this buckle type shed light on the cultural contacts between the territories (cultural peripheries) on the northern fringes of the Mediterranean.

Keywords: Early Avar Period, Eastern European contacts of the Carpathian Basin, centre-periphery cultural contacts, Martinovka group, pseudo-buckles in the Carpathian Basin, early and Middle Avar continuity
\end{abstract}

\section{EINLEITUNG: ZU DEN ASPEKTEN DER ANALYSE}

Das Ziel dieser Arbeit ist die Analyse einer technischen Variante eines einzigen awarenzeitlichen Gegenstandstyps, der Schnallen mit festem schildförmigem Beschlag und mit unverzierter Oberfläche. Die meisten Exemplare des in der Früh- und Mittelawarenzeit in weitem Kreis benutzten Gegenstandstyps wurden am Riemen mit Hilfe von mitgegossenen Nieten befestigt (Abb. 1.1-4). Die Methode, nämlich die Inbetrachtnahme eines technischen Details neben formell-typologischen Aspekten bei der Auswahl der analysierenden Gegenstände, ist natürlich bestreitbar, aber - wie ich es durch die nachstehenden theoretischen Überlegungen beweisen möchte begründbar. Wie es aus der nachfolgenden Analyse hervorgeht, macht es auf solche typologischen Verbindungen des Gegenstandstyps (praktisch auf seine Herkunft bzw. Verbindung mit dem Martinovka-Typ) aufmerksam, die ohnedem unbemerkt bleiben könnten. Obwohl der Schnallentyp im Vergleich zum variationsreichen Fundmaterial des Zeitalters weniger sehenswürdig ist, sind gewisse Ergebnisse hinsichtlich der kulturhistorischen Prozesse des 7. Jahrhunderts von der gezielten Analyse der technischen Variante zu erwarten: Dadurch kann das Bild über die Verbindungen der umgebenden Welt und des Karpatenbeckens ergänzt werden.

Die formalen Kennzeichen eines Gegenstandes werden durch das stilare Wissen der schaffenden Kultur geformt. Außer dem funktionellen Wert tragen alle Gegenstände auch visuelle Aussage, die die in der Gruppe der Hersteller oder Benutzer angehäuften Kenntnisse passiv spiegeln. Diese Aussage hat auch eine aktive Rolle durch bewusste Entscheidungen und Wahlen zwischen parallelen Möglichkeiten in der Gestaltung der Identität der Gruppe. ${ }^{1}$ Die nach ihrer visuellen Rolle bewusst gestalteten formalen, ornamentalen und ikonographischen Elemente spiegeln gewisse Aspekte der Identität der herstellenden Gruppe (oder der Gruppe, die die Gegenstände

${ }^{1}$ SHEnNAn 1989, 3-14. Zur aktiven Rolle des Stils in der Formung der Identität bzw. zur passiven Rolle bei deren Äußerung s. SACKETT 1990 


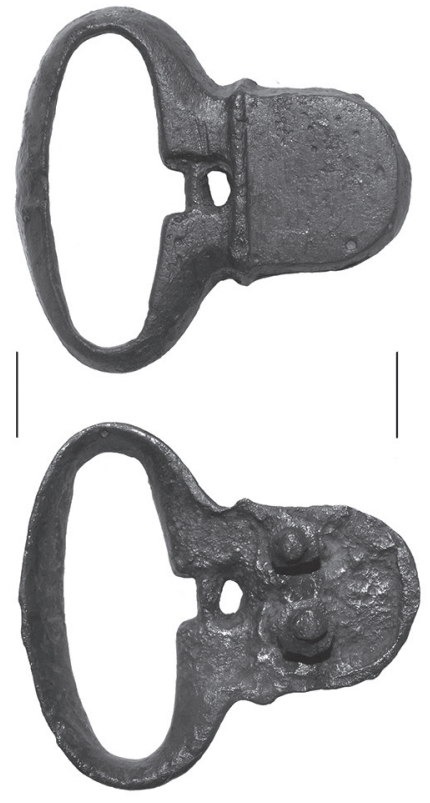

1
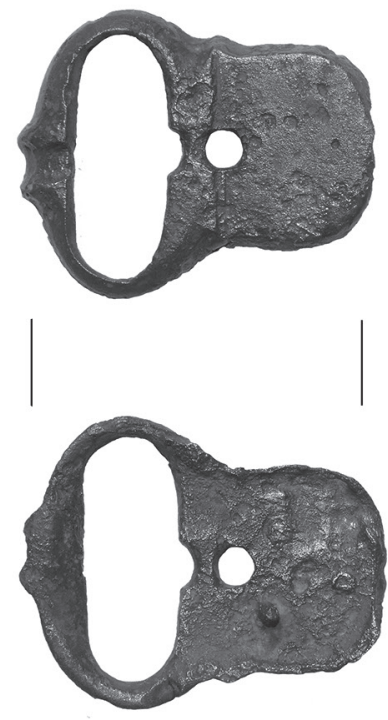

2
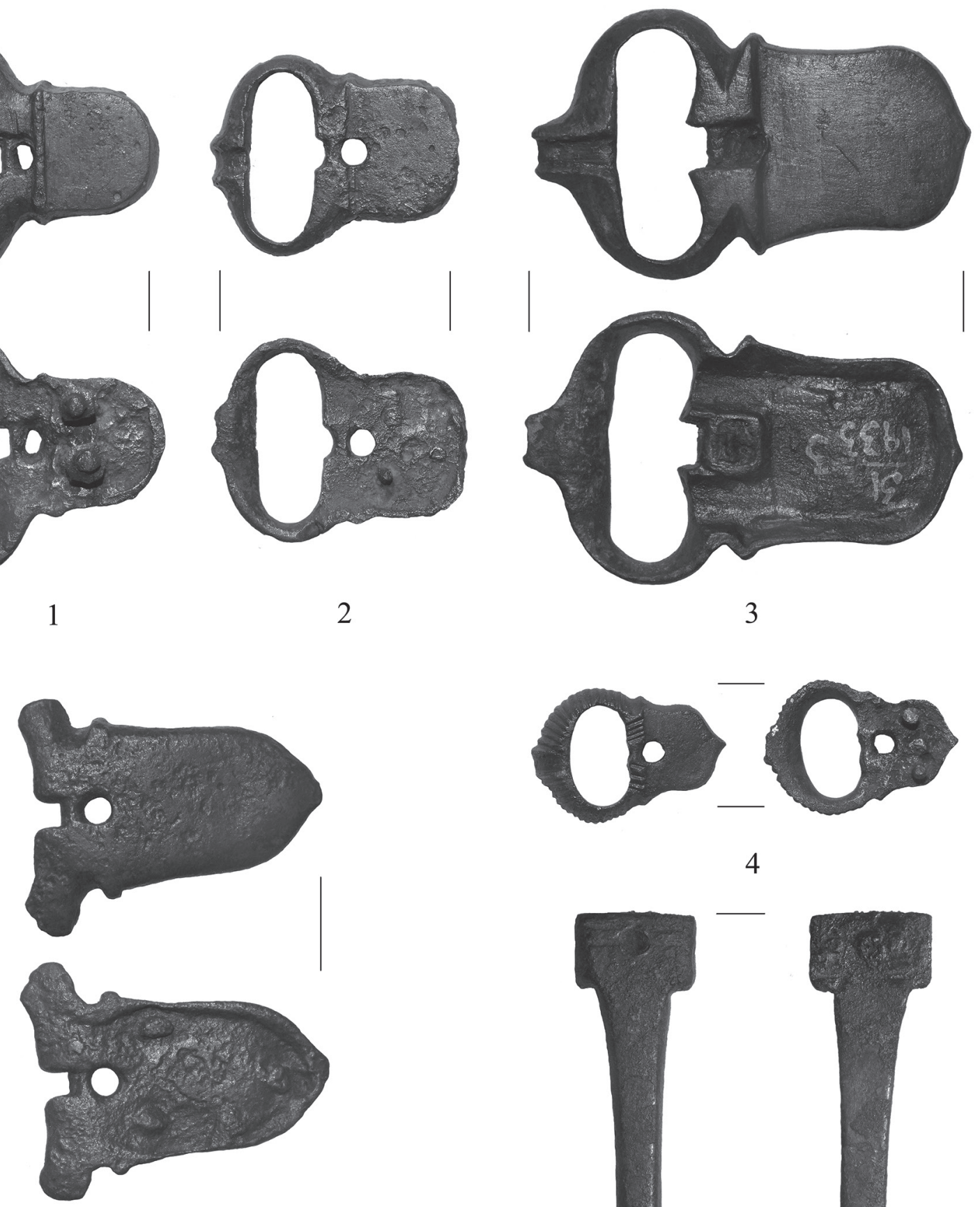

4
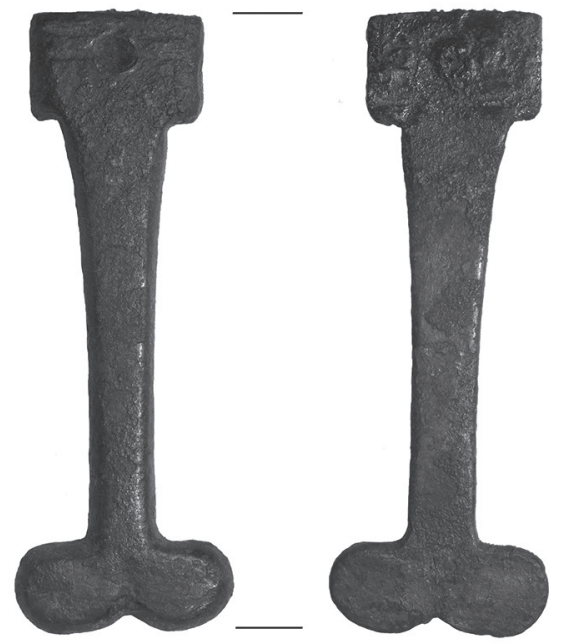

6

Abb. 1. 1: Gürtelschnalle, Pápa-Úrdomb Grab 1; 2: Gürtelschnalle, Törökbálint Grab 2; 3: Schnalle ohne Befestigungselemente, Kiskőrös-Pohibuj Mackó-dűlő Grab 31; 4: Fehlguss oder beschädigter Gegenstand mit fehlerhafter Niete, Jánoshida-Tótkérpuszta Grab 173; 5: Schwertriemenschnalle, Kecel, Grabfund; 6: Aufhängerbeschlag mit langem Hals, Törökbálint Grab 2 
machen ließ). Deswegen sind sie situativ, indem sie sich den aus den jeweiligen gesellschaftlichen Verhältnissystemen hervorgehenden, sich schnell verändernden, aktuellen Forderungen anpassen. Einen anderen Teil des stilaren Wissens der Kultur bilden Elemente, die über keine visuelle Aussage verfügen - oder solche nur in beschränktem Maße aufweisen - und die durch praktische Funktionen bestimmt sind. Auch in diesen Elementen offenbaren sich jedoch gewisse, von der Identität passiv bezeugende Komponenten der Gruppentraditionen. Sie gehören zu jenem Teil des Wissensgutes der Hersteller, der sich erst infolge tiefgehender Wandlungen des Wirtschaftssystems (und der Kultur) verändert. (Zum Beispiel die benutzten Gefäßtypen als Folge des Wechsels der Ernährungskultur; im Gegensatz dazu kann die aktuelle Ausführung gewisser Keramiktypen im Zusammenhang mit visuellen Trends auch bei der Beständigkeit der Ernährungskultur verändern.)

Dieser Teil des stilaren Wissens einer Kultur ist relativ statisch, inwiefern der Hersteller eine neue morphologische Lösung - wenn sich dadurch die absichtliche visuelle Bedeutung des Gegenstandes nicht verändert - möglicherweise mit Hilfe von schon bekannten Verfahren und technischen Details auszuführen strebt. Die angewandten Technologien und technischen Elemente ${ }^{2}$ können - vom kulturellen und gesellschaftlichen Milieu, von der bei der Herstellung investierten Energie abhängig - eine bedeutende visuelle, wertmessende Rolle spielen. Die Symbolik einer vertikal gegliederten materiellen Kultur, die Verhältnissysteme einer stark hierarchisierten (wie z. B. der byzantinischen) Gesellschaft, durch technologische, technische bzw. formale Lösungen und durch die Grundstoffe oder kann im Großen und Ganzen für eine weniger hierarchisierte - „barbarische“ - Gesellschaft unverständlich sein. Auch noch in dem Fall, wenn die Gegenstände aus den ursprünglichen Zusammenhängen herausgegriffen, mit einer neuen Prestigerolle aufgeladen benutzt werden.

Die Anwendung von Technologien und technischen Lösungen setzt ein zusammengesetztes Wissenssystem voraus, zu dessen Veränderung ein längerer Lernprozess als zur Aneignung (Kopierung und Adaptation) eines formalen Trends notwendig ist. Während eine - im Allgemeinen technologische - Vereinfachung/Degradation, die durch einen neuen formalen Trend erfordert ist, schnell wirken kann (siehe die explosionsartige Verbreitung des Buntmetallgießens am Anfang der Spätawarenzeit nach der Vielfältigkeit der Goldschmiedetechnik im 7. Jahrhundert), ${ }^{3}$ ist die Innovation, die Anwendung einer neuen Technologie oder eines vom Gewöhnlichen abweichenden technischen Elements ein seltener und große Energieverwendung beanspruchender Prozess. ${ }^{4}$

Der Begriff „Technologie“ ist selbstverständlich. Es ist aber wichtig zu klären, was tatsächlich für eine technische Lösung zu halten ist. Technische Elemente verfügen über eine praktische Funktion, die als ein direkter Grund für ihre Anwendung am Gegenstand dient. Die Kennzeichen, deren Erscheinen - mindestens aufgrund der heutigen Kenntnisse - nur ihre visuelle Wirkung begründet, sind keine technischen Elemente, sondern primäre morphologische Kennzeichen bzw. Verzierungselemente. (Ein solches Element ist z. B. der zwischen der oberen, für die Anbringung verantwortlichen, tatsächlich als technisches Element dienenden Tülle und dem Körper der Riemenzunge befindliche Scharnier, der von der Römerzeit an in den unter direktem mediterranem Einfluss stehenden Kulturen erschien, ${ }^{5}$ da der Scharnier hier keine praktische Funktion hat, kann man in diesem Fall über kein ,technisches Element" sprechen.) Bei der Ausformung der Verzierungselemente wird der Hersteller durch den Anspruch motiviert, sich den morphologischen Tendenzen, Trends anzupassen. Im Gegensatz dazu hat die praktische Rolle immer eine determinierende Kraft, auch wenn eine technische Lösung sich sonst den visuellen Erfordernissen des Gegenstandes, dessen formaler Funktionalität immer anpassen soll.

Bei den Schnallen, die im Fokus der vorliegenden Arbeit stehen, verfügt die Befestigungsweise nur über einen minimalen visuellen Wert (Nietköpfe auf der Oberfläche der Gegenstände oder umgekehrt: die unsichtbare Befestigungsweise). Sie wurde deshalb durch formale Trends nur wenig oder kaum beeinflusst. Mit großer Wahrscheinlichkeit setzten sich also solche Automatismen im Laufe der Herstellung durch, die unabhängig von der bewussten Ausformung der formalen Elemente funktionierten. Die mit der Rückplatte des Gegenstandes mitgegossenen, zur Befestigung dienenden Dorne, die Lochzapfen bzw. die durch Löcher durchgehenden Nieten gehören deswegen - wie die Herstellungstechniken - zum relativ ständigen bzw. sich langsam verändernden Teil des stilaren Wissens der Kultur.

In dem Fundmaterial byzantinischen Ursprungs, der mit der Elite des Karpatenbeckens im 7. Jahrhundert verbunden werden kann, für das die komplizierten Goldschmiedetechniken im Allgemeinen kennzeichnend sind,

\footnotetext{
${ }^{2}$ Z. B. bei den im spätantiken Milieu angewandten Schraubenverschlüssen: THEUNE-GROSSKOPF 1995, 93-95.

${ }^{3}$ SZENTHE $2013 b$.
}

\footnotetext{
${ }^{4}$ Zum Begriff „technologische Innovation“ und zu deren Funktionsmechanismen s. GREENE 1994; SHORTLAND 2004.

${ }^{5}$ Siehe dazu für die Spätawarenzeit: SzENTHE 2013b.
} 
können die Einfachheit des ausgewählten Schnallentyps und die vom Byzantinischen abweichende technische Lösung der Befestigung die Aufmerksamkeit der Forscher vor allem im Licht der obigen Überlegungen erwecken. In der Frühmittelalterforschung kann der Untersuchung der Technologien und technischen Elemente wegen des Charakters des Fundmaterials und der großen Menge der Kleingegenstände-eine besondere Bedeutung zugeschrieben werden. Außer der technologiehistorischen Analyse ${ }^{6}$ wurde deshalb die Untersuchung gewisser technischen Einzelheiten - so die Untersuchung der bei der Befestigung der Gegenstände angewandten Techniken - zur selbstständigen neuen Richtung. ${ }^{7}$ In dieser Richtung möchte auch der Verfasser einen neuen Schritt machen.

\section{SCHNALLEN MIT FESTEM SCHILDFÖRMIGEM BESCHLAG UND BEFESTIGUNGSDORNEN IM 7. JAHRHUNDERT}

Außer den behandelten Stücken sind noch zahlreiche Exemplare des Gegenstandstyps mit durch den durchbohrten Körper durchgeschlagenen Nieten bekannt. Sie unterscheiden sich weder typologisch noch hinsichtlich der Anwendung von der erörterten Variante und kommen damit in den gleichen Grabkomplexen vor. Die Verwendung von Drahtnieten ist in einigen Fällen daran zurückzuführen, dass die Herstellung einer mitgegossenen Niete ein Problem beim Gießen bedeuten kann, das man nicht - oder nicht in jedem Fall - lösen konnte. ${ }^{8}$

Es ist zu betonen, dass die überwiegende Mehrheit der Dorne wirklich mit dem Körper des Gegenstandes mitgegossen wurde. Die von mir analysierten Stücke, mindestens die aus Kupferlegierung produzierten Exemplare, weisen außer einer einzigen Ausnahme keine Spuren nachträglichen Lötens auf (Abb. 2.1-2). ${ }^{9}$ Dass die mit dem Körper des Gegenstandes in einem gegossen wurde, diente zur Vereinfachung der Arbeit des Herstellers. Die Modellierung des Dorns ist ein energiesparendes Verfahren im Vergleich zur Herstellung des zur Niete nötigen Drahtes (Gießen, dann Ziehen) bzw. - wenn das Nietloch nicht an dem Wachsmodell des Gegenstandes zusammen modelliert ist - angemessen zum Lochbohren mit einem dünnen, gehärteten Bohrer. Diese Lösung hat sonst technisch gegen die separaten Nieten oder eine trennbare Befestigung mit Lochzapfen keinen Vorteil. Im Gegensatz: Die Legierung des Gegenstandes ist im Allgemeinen steif, sie ist nicht so gut dehn- und schmiedbar ${ }^{10}$ wie das zur Herstellung der Nieten verwandte pure Kupfer oder die meistens leicht legierte Bronze. ${ }^{11}$ Die Anwendung des mit dem Körper des Gegenstandes mitgegossenen Befestigungsdorns war also primitiver und schwerfälliger als die beiden im Frühmittelalter parallel angewandten Verfahren.

Wenn die mit dem Körper des Gegenstandes mitgegossene Niete nicht ausfloss oder der Beschlag auch ein zweites Mal angebracht wurde, wurde der Gegenstand sekundär durchbohrt und eine Draht durch das Loch geschlagen. Die Schnallenkörper zeigen in mehreren Fällen die Zeichen des nachträglichen Durchbohrens. In einigen Fällen können aber keine, zum Anbringen dienenden technischen Elemente beobachtet werden (Abb. 1.3). ${ }^{12}$ Da es technisch unmöglich ist, dass die an dem Modell des Gegenstandes modellierte Niete oder das Nietloch ${ }^{13}$ keine Spur auf der Oberfläche des Gusses gelassen hätten, rechnete der Hersteller - wenn er tatsächlich einen als Schnalle benutzbaren Gegenstand produzieren wollte - mit dem nachträglichen Durchbohren des fertiggestellten Gegenstandes wahrscheinlich bewusst. Für die vorliegende Studie ist aber das konsequente und durch zahlreiche Exemplare vertretene Erscheinen des mitgegossenen Befestigungsdorns als selbstständige Anbringungstechnik interessant. Die oben erwähnten Varianten können das Bild nur mit kultur- und technologiehistorischen Details bereichern.

${ }^{6}$ Z. B. BÜHLER 1999; BÜHLER 2010. Zur frühbyzantinischen gegenständlichen Kultur ist TóTH 2010 besonders bedeutend.

${ }^{7}$ DAIM 2000; ZÁBOJNíK 2000.

${ }^{8}$ Die Gasableitung der langen Löcher mit kleinem Durchschnitt, die sich in einem Raum mit dem Körper des Gegenstandes befanden, ist in der Gussform problematisch. Ihre Auffüllung mit Metall ist nie völlig gesichert; es hängt auch von der Richtung der Löcher im Inneren der Gussform und den Fließeigenschaften der Legierung ab.

${ }^{9}$ Bei der Schnalle von Hidashát (Tabelle Nr. 16) sitzen drei halbkugelige Eintiefungen in der Rückseite des Schnallenkörpers, in denen die Nieten eingelötet wurden. Der Dorn wurde in den anderen analysierten Fällen aus demselben Material hergestellt wie der Schnallenkörper. Siehe die Ergebnisse der Metallanalyse im vorliegenden Band: MAY-SZENTHE 2015.
${ }^{10} \mathrm{Zu}$ den awarenzeitlichen Legierungen s. DAIM 1987; DAIM 2000; KÖLTŐ 1982

${ }^{11}$ Zur Materialzusammensetzung der Niete s. KöLTő 1982, $25-27$.

12 Kiskőrös-Pohibuj Mackó-dülö Grab 31: TöRÖK 1975, 294, Fig. 3, ohne eine ausführliche Beschreibung der Schnalle und ohne die Veröffentlichung ihrer Rückseite.

${ }^{13}$ Die Bohrungen an den massenhaft hergestellten Gegenständen der Spätawarenzeit wurden in den dokumentbaren Fällen-d.h. wenn das Nicht fehlt-schon auf dem Wachsmodell modelliert; s. BíRÓ-SZENTHE 2011, 157. 
DER UNTERSUCHTE SCHNALLENTYP IM KARPATENBECKEN

\section{Funktion}

Etwa die Hälfte der Fälle gilt als Gürtelschnalle bzw. der Größe nach entsprechen sie dieser Funktion. Die die andere Hälfte vertretenden kleinen Exemplare wurden im Karpatenbecken meistens paarweise zur Aufhängung von Schwertern (Säbeln) oder Köchern benutzt (s. die sämtlichen Beispielen Nicht datierbar in der Tabelle).

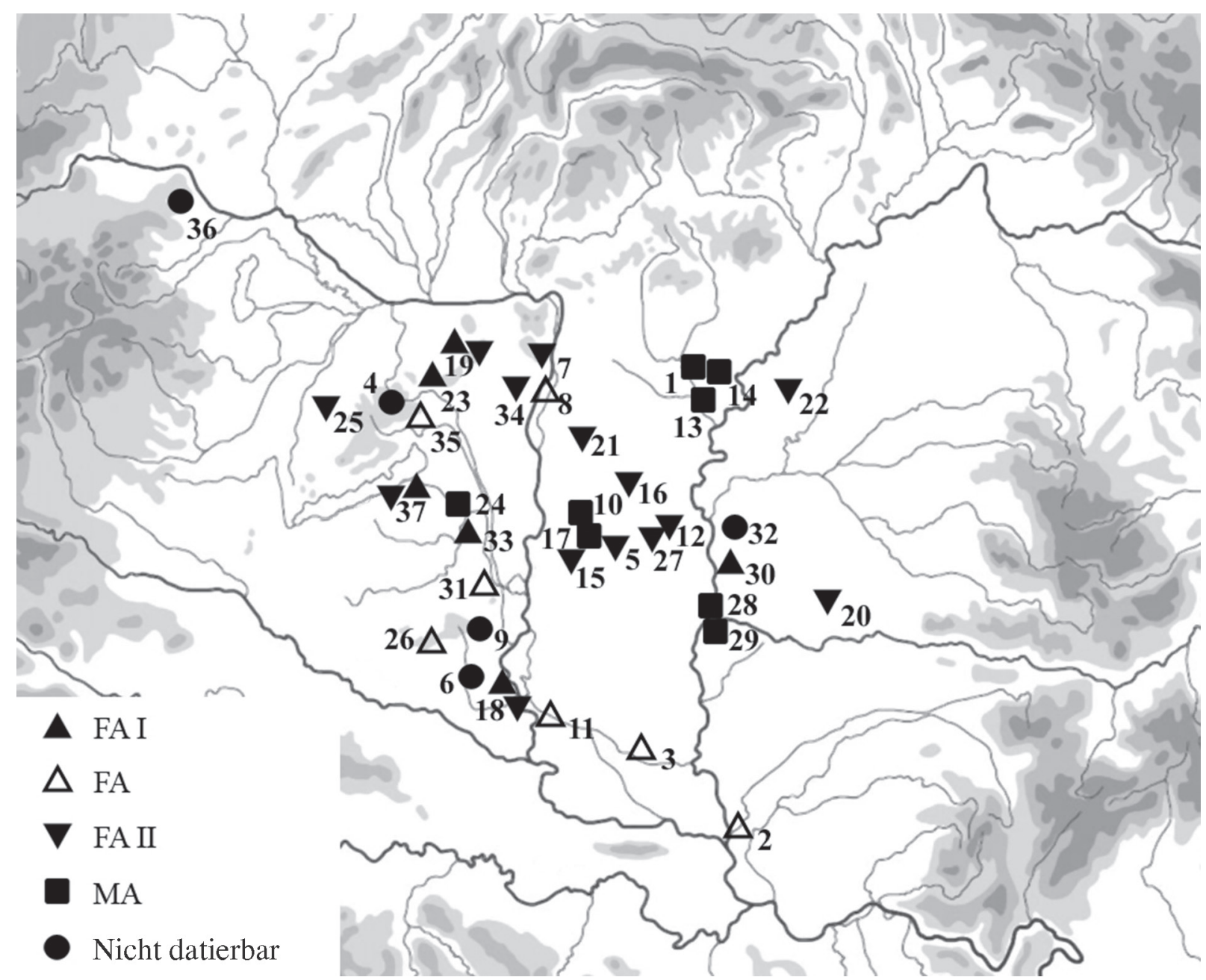

Abb. 2. Schnallen mit festem Beschlag und mitgegossenen Nieten im früh- und mittelawarenzeitlichen Karpatenbecken. 1: Alattyán; 2: Aradac; 3: Feketić; 4: Bakonytamási; 5: Bócsa; 6: Bóly; 7: Budapest, XII; 8: Budapest, XXI; 9: Cikó; 10: Csengőd; 11: Čik; 12: Gátér; 13: Jánoshida; 14: Jászapáti; 15: Kecel; 16: Kecskemét; 17: Kiskőrös; 18: Kölked; 19: Környe; 20: Kunágota; 21: Kunbábony; 22: Kunmadaras; 23: Mór; 24: Ozora; 25: Pápa; 26: Pécs; 27: Petőfiszállás; 28: Szeged-Fehértó; 29: Szeged-Kundomb; 30: Szegvár; 31: Szekszárd; 32: Szentes; 33: Tolnanémedi; 34: Törökbálint; 35: Várpalota; 36: Wien; 37: Zamárdi 


\section{Chronologie}

Aufgrund der Begleitfunde können die Schnallen in die Frühawarenzeit und in die erste Hälfte der Mittelawarenzeit datiert werden. ${ }^{14}$ Aufgrund der häufigen Korrelation mit gewissen Fundtypen gruppiert sich ihr Erscheinen innerhalb dieser längeren Periode um zwei Schwerpunkte. Der erste Schwerpunkt der Verbreitung ist an den Anfang bzw. in die erste Hälfte der Frühawarenzeit zu datieren. In dieser Gruppe gilt der Aufhängerbeschlag mit langem Hals und mit zwei passförmigen Gliedern am unter Ende als ein Leitfund. ${ }^{15}$ Wie die Schnallen, wurden auch diese Gegenstände in mehreren Fällen mit mitgegossenen Nieten hergestellt. (Die nachträgliche Bohrung hat bei diesem Gegenstandstyp einen ähnlichen Charakter wie bei den Schnallen. Der Beschlag des Fundes von Mór wurde z. B. nach dem Abfeilen der Dorne durchbohrt: Abb. 1.6.) Charakteristische Grabfunde sind die für

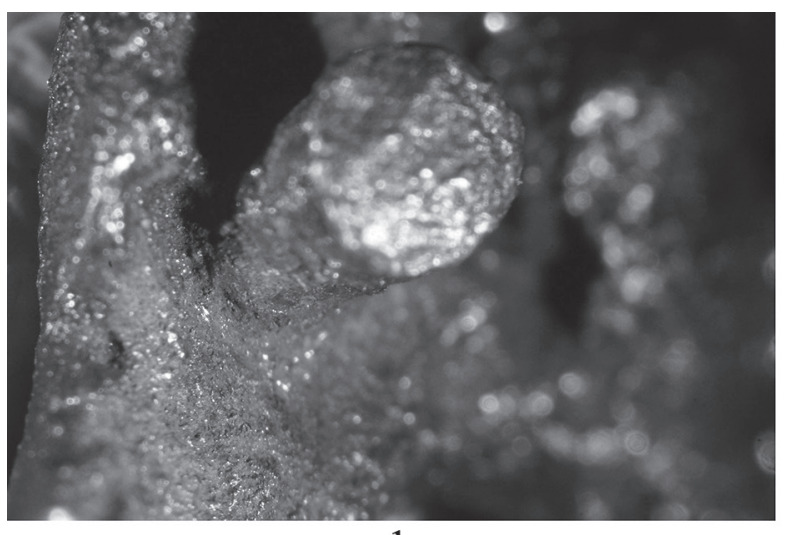

1

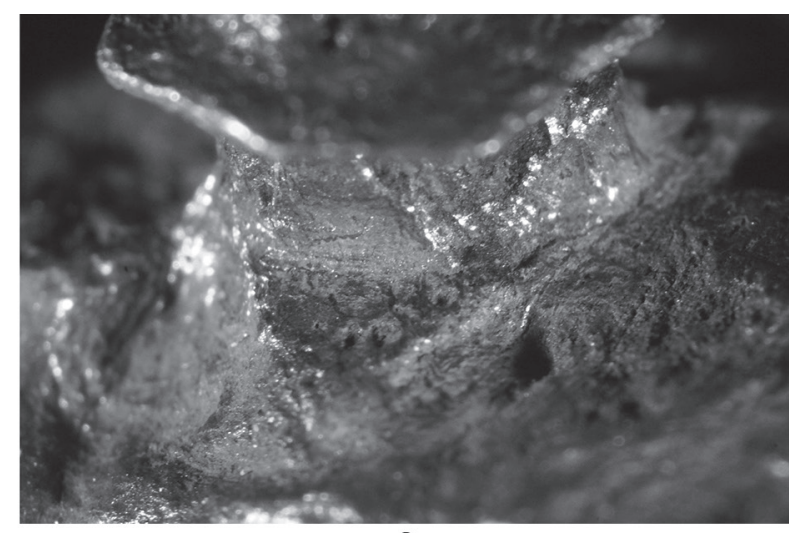

2

Abb. 3. Mitgegossene Niete auf dem Schnallenkörper. 1: Schwertriemenschnalle, Kecel; 2: Gürtelschnalle, Pápa-Úrdomb Grab 1

die frühesten vielteiligen Gürtel kennzeichnenden runden Nietköpfe mit Bleiauskleidung ${ }^{16}$ und die zumeist aus dünnem Silberblech gepressten, riemenzungenförmigen Gürtelbeschläge ebenfalls mit Bleiauskleidung und Befestigungsband oder kleine Riemenzungen des gleichen Formats. ${ }^{17}$ Seltene Begleitfunde der frühen Gruppe sind gegossene Beschläge des Martinovka-Typs mit mitgegossenen Nieten, ${ }^{18}$ bis Anfang des 7. Jahrhunderts datiert. ${ }^{19}$ Die Blechbeschläge oder Riemenzungen mit graviertem geometrischem Muster ${ }^{20}$ können aufgrund von gewissen formalen Merkmalen im Großen und Ganzen unter die Gegenstände des Martinovka-Typs eingereiht werden. Die etwa gleichzeitigen Schwerter mit P-förmigen Hängeösen ${ }^{21}$ sind häufige Begleitfunde der frühawarenzeitlichen Schnallen. Im Allgemeinen werden alle in die erste Hälfte des 7. Jahrhunderts datiert. Obwohl diese Fundtypen nur innerhalb von weiten Rahmen datierbar sind bzw. in gewissen Fällen aus der zweiten Hälfte der Frühawarenzeit

${ }^{14}$ Was die Datierung der herausragenden Komplexen betrifft, zu den frühen Gräbern von Környe s. MARTIN 1990, $70-75$ (bis zur Wende des 6. und 7. Jahrhunderts); zu den Beschlägen mit Pseudoschnalle des Kunbábony-Kreises: H. TótH-HoRváth 1993, 113119; BALOGH-WICKER 2012, 573 (höchstwahrscheinlich gelangten sie im mittleren Drittel des 7. Jahrhunderts ins Grab); zum Grab von Kunágota: RÁcz 2001, 488-489 (zweites Viertel des 7. Jahrhunderts, aus morphologischem Grund früher datiert als das Grab von Ozora); der Komplex von Ozora wird durch die Münze des Constantinus IV. (669-674) post quem datiert (Somogyi 1997, 71). Da das Fundmaterial mit den Garnituren des Typs Kunágota, Kecskemét-Sallai-Str. eine Verwandtschaft zeigt, kann die Bestattung in diesem Fall kurz nach der Prägung der Münze datiert werden. Die mit den PseudoschnallenGarnituren vorkommenden Rosetten mit Einlage sind auch aus Grab I des Gräberfeldes von Kiskőrös-Vágóhíd bekannt (LÁsZLó 1955,
Taf. I). Das benachbarte Mädchengrab mit einer Schnalle mit festem Beschlag konnte deswegen kurze Zeit darauf, wahrscheinlich im dritten Viertel des 7. Jahrhunderts, ausgegraben werden. Die chronologische Lage der anderen, nach morphologischen Kriterien gut datierbaren Parallelen ist durch diese Rahmen bestimmt.

${ }^{15}$ Tabelle Nr. 6, 8, 52, 60, 68, 79-80, 81, 88, 98

${ }^{16}$ Környe, Mór, Zamárdi: Tabelle Nr. 45, 52, 60-61, 89, 97. Zu ihrer Datierung s. MARTIN 1990.

${ }^{17}$ Környe, Törökbálint, Zamárdi: Tabelle Nr. 32, 35, $37-$

39, 43, 47, 78, 90, 93, 96-98, 100-101.

${ }^{18}$ Kiskőrös-Városalatt, Tolnanémedi: Tabelle Nr. 28, 76-77.

${ }^{19}$ BALOGH 2004.

${ }^{20}$ Tabelle Nr. 31, 40, 42, 67, 93, 96, 102, 104, 107-108.

${ }^{21}$ Tabelle Nr. 9, 44, 49, 59, 62, 71, 78-80. 
stammen, ${ }^{22}$ ist es doch kennzeichnend, dass sie in denjenigen transdanubischen Gräberfeldern vorkommen, in denen auch die frühesten Exemplare des Schnallentyps im Karpatenbecken zu finden sind. ${ }^{23}$

Zwar überwiegend in Männergräbern gefunden, kommt der untersuchte Schnallentyp in der Frühawarenzeit in Transdanubien recht häufig auch in Frauengräbern vor. Im Gegensatz zu den Bestattungen von Szekszárd, ${ }^{24}$ Környe ${ }^{25}$ und Várpalota, ${ }^{26}$ die in die frühere Periode der Frühawarenzeit datiert werden können, hatten diese Gräber meistens ein ärmliches Fundmaterial und sind nur zwischen weiten chronologischen Rahmen oder aufgrund ihrer Horizontal-stratigraphie im Gräberfeld zu datieren. Der Schwerpunkt der Verbreitung westlich der Donau ${ }^{27}$ ist jedoch ein Faktor, mit dessen Hilfe diese Frauengräber in die frühe transdanubische Gruppe einzuordnen sind und der diese Funde zugleich vom späteren, überwiegend in der Großen Ungarischen Tiefebene bekannten Horizont der fundreichen bewaffneten Männergräber unterscheidet.

Die spätere, parallele Gruppe der chronologisch zwar mit der Schnallen mit schildförmigem Körper und Befestigungsdornen kann chronologisch zwar mit der Transdanubischen durch die Pseudoschnallen, durch gepresste Garnituren mit schildförmigen Beschlägen und Zahnschnittornamentik in einen Horizont in die zweite Hälfte der Frühawarenzeit und an den Anfang der Mittelewarenzeit datiert werden. Der behandelte Schnallentyp ist in den hervorragendsten Fundverbänden vom Ende der Frühawarenzeit als ein Element der Waffenaufhängung ${ }^{28}$ - bzw. in mehreren Fällen auch als Gürtelschnalle - regelmäßig aufzufinden. ${ }^{29}$ Durch die gepresste Variante der Pferdegeschirrbeschläge vom Malaja Pereščepina-Typ ${ }^{30}$ können die Komplexe des Grabes 193 von Gátér-Vasútállomás und des Grabes 2 von Törökbálint in das unmittelbare Milieu des Pseudoschnallenkreises eingereiht werden. Im Waffengrab von Gátér, in dem Amphore und auch Pferd begraben wurden, war der untersuchte Schnallentyp wahrscheinlich eine Gürtelschnalle. ${ }^{31}$

Die Schnalle von Kunmadaras und von Petőfiszállás weisen Zahnschnittornamentik auf. ${ }^{32}$ Schnallen mit mitgegossenen Nieten tauchen mehrmals in solchen Grabinventaren auf, in denen bestimmte Gegenstände mit den Motiven des gezähnten Tierstils oder mit gezähntem Bandgeflecht verziert sind. ${ }^{33}$ Unter den Funden des Grabes Nr. 1377 von Zamárdi gibt es einen Aufhängerbeschlag mit gezähntem Bandgeflecht. ${ }^{34}$ Mehrere Funde des Grabes von Kunbábony, so auch der Aufhängerbeschlag mit Befestigungsd, wurden mit Zahnschnittmuster verziert. ${ }^{35}$

Im Gegenstandshorizont mit Pseudoschnallen und mit Zahnschnittornamentik kommen gepresste Rosetten mit glattem Rand und vergoldeter oder goldener Blech- und Steineinlage mehrmals vor. ${ }^{36}$ Dieser Rosettentyp erscheint auch im klassischen „mittelawarenzeitlichen“ Fundhorizont, was ein enges chronologisches Nacheinander der Funde der beiden chronologischen Gruppen beweist. ${ }^{37}$

${ }^{22}$ Siehe unten: wegen der für den Pseudoschnallenkreis und in der ersten Hälfte der Mittelawarenzeit kennzeichnenden Rosetten mit Blecheinlage und eingelegter Mitte (Anm. 36). Der gekerbte Ring der im Grab 78 von Környe gefundenen Schnalle mit festem Beschlag (Tabelle Nr. 42) ist eine für den Bócsa-Kunbábony-Kreis charakteristische Formvariante.

${ }^{23}$ Környe und Zamárdi: ausführlicher siehe unten, in Verbindung mit der geographischen Verbreitung.

${ }^{24}$ Grab 108, erste Hälfte des 7. Jahrhunderts (RosNER 1999, 123).

${ }^{25}$ Grab 32. Die Analogien der Beschläge des Aufhängerbeschlag in Kölked wurden von Zs. Hajnal in die Phase 2 datiert (HAJnAL 2012, 626-627). Aufgrund der im Grab II von KiskőrösVágóhíd vorgekommenen Analogien der blechernen Fingerringe mit Kopf (s. Anm. 14) ist eine spätere Datierung möglich (im Allgemeinen in die erste Hälfte des 7. Jahrhunderts).

${ }^{26}$ Gräber 208, 220 und 227 mit kennzeichnenden frühawarischen Funden. Die gegossenen Scharnierriemenzungen datieren in die Phase 2 der Gräberfelder von Kölked (Ende des 6. Jahrhunderts, erstes Viertel des 7. Jahrhunderts). Die Analogien der Perlen und der Nadel mit Löffelkopf werden im Allgemeinen in die erste Hälfte des 7. Jahrhunderts datiert: HAJNAL 2012, 626-627, Abb. 9-11.

${ }^{27}$ Im Gegensatz zum einzigen Mädchengrab von KiskőrösVágóhíd (Tabelle Nr. 27). Es ist zu bemerken, dass das erwähnte Grab - im Gegensatz zu den frühawarenzeitlichen Komplexen Transdanu- biens - eines der wertvollsten Ensembles der Mittelawarenzeit ist (Datierung wahrscheinlich MA I).

${ }^{28}$ Bócsa, Kunbábony, Kecel, Petőfiszállás: Tabelle Nr. 6, $23,54-58,68$.

29 Kecel, Kunmadaras, Pápa-Úrdomb, Petőfiszállás, Zamárdi: Tabelle Nr. 21, 59, 65, 67, 107.

${ }^{30}$ Werner 1984, Taf. 16, 52.

${ }^{31}$ Unter die Funde wurden um hundert Jahre jüngere gegossene Gürtelbeschläge gemischt und sie wurden zusammen veröffentlicht. Diese Funde stammen wahrscheinlich aus einer anderen, das Grab 193 zerstörenden Bestattung. An der Stelle der Gürtelschnalle des Grabes 193 wurde eine spätawarenzeitliche gegossene Schnalle mit Pflanzenmotiv (zweite Hälfte des 8. Jahrhunderts) beschrieben. Aufgrund der Fundzusammenhänge gehört zum Inventar eine Schnalle mit mitgegossenen Nieten, die in der Beschreibung anderswo erwähnt wurde (s. KADA 1906, 208-210).

32 Tabelle Nr. 59 und 67.

${ }^{33}$ Budapest, Csengőd-Péterhalom, Kunbábony, ZamárdiRétiföldek: Tabelle Nr. 8, 11, 54-58, 100-101.

${ }^{34}$ BÁRdos-GARAM 2009, Taf. 156.

${ }^{35}$ H. Tóth-Horváth 1993, Taf. XVII. 2, Taf. XXI. 5.

${ }^{36}$ Bócsa, Környe, Kunbábony, Petőfiszállás, Zamárdi: Tabelle Nr. 6, 42, 67, 93, 107-108; s. auch Anm. 14.

${ }^{37}$ Kiskőrös-Vágóhíd Grab I: Tabelle Nr. 26. 


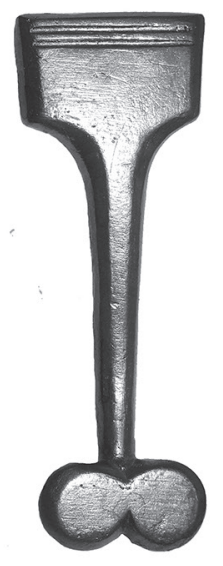

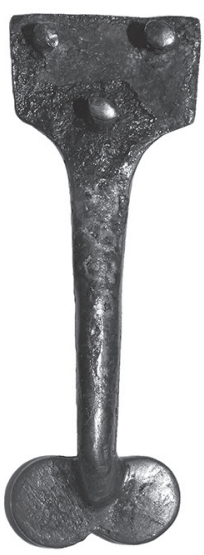

1
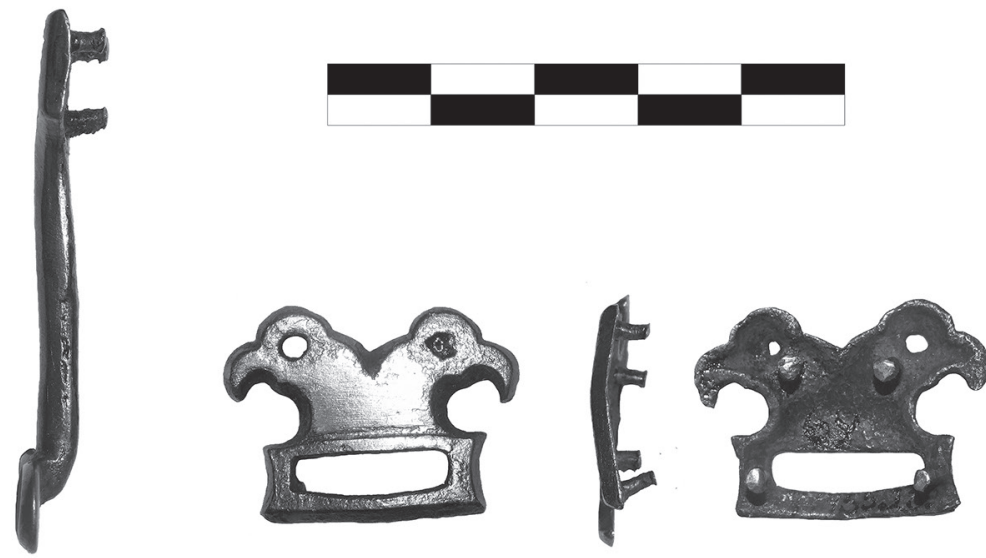

2
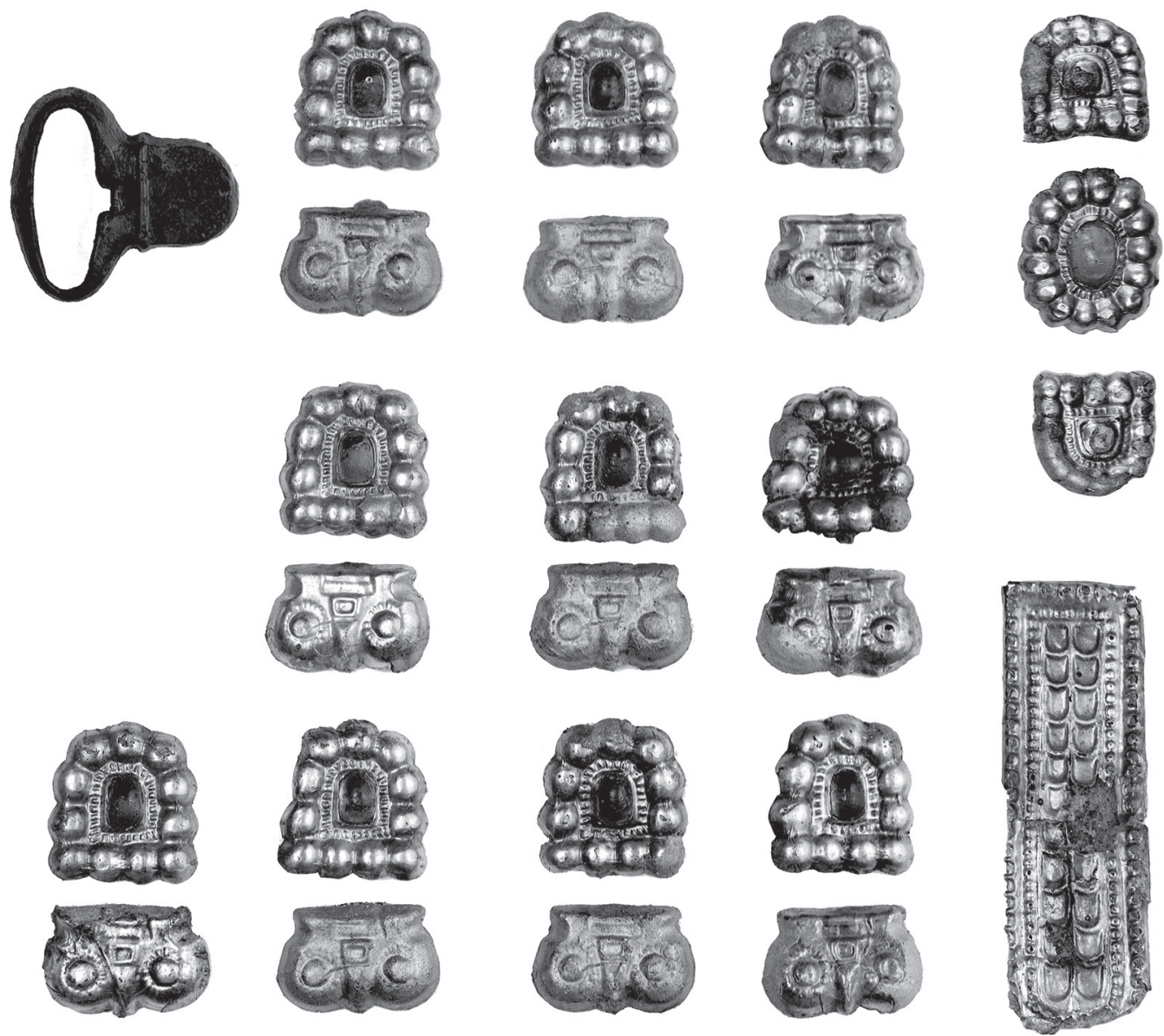

3

Abb. 4. 1: Silberner Aufhängerbeschlag mit langem Hals, Bócsa; 2: Aufhängerbeschlag mit Raubvogelköpfen, Bócsa; 3: Gürtelgarnitur mit gepressten Pseudoschnallen, Pápa-Úrdomb Grab 1 

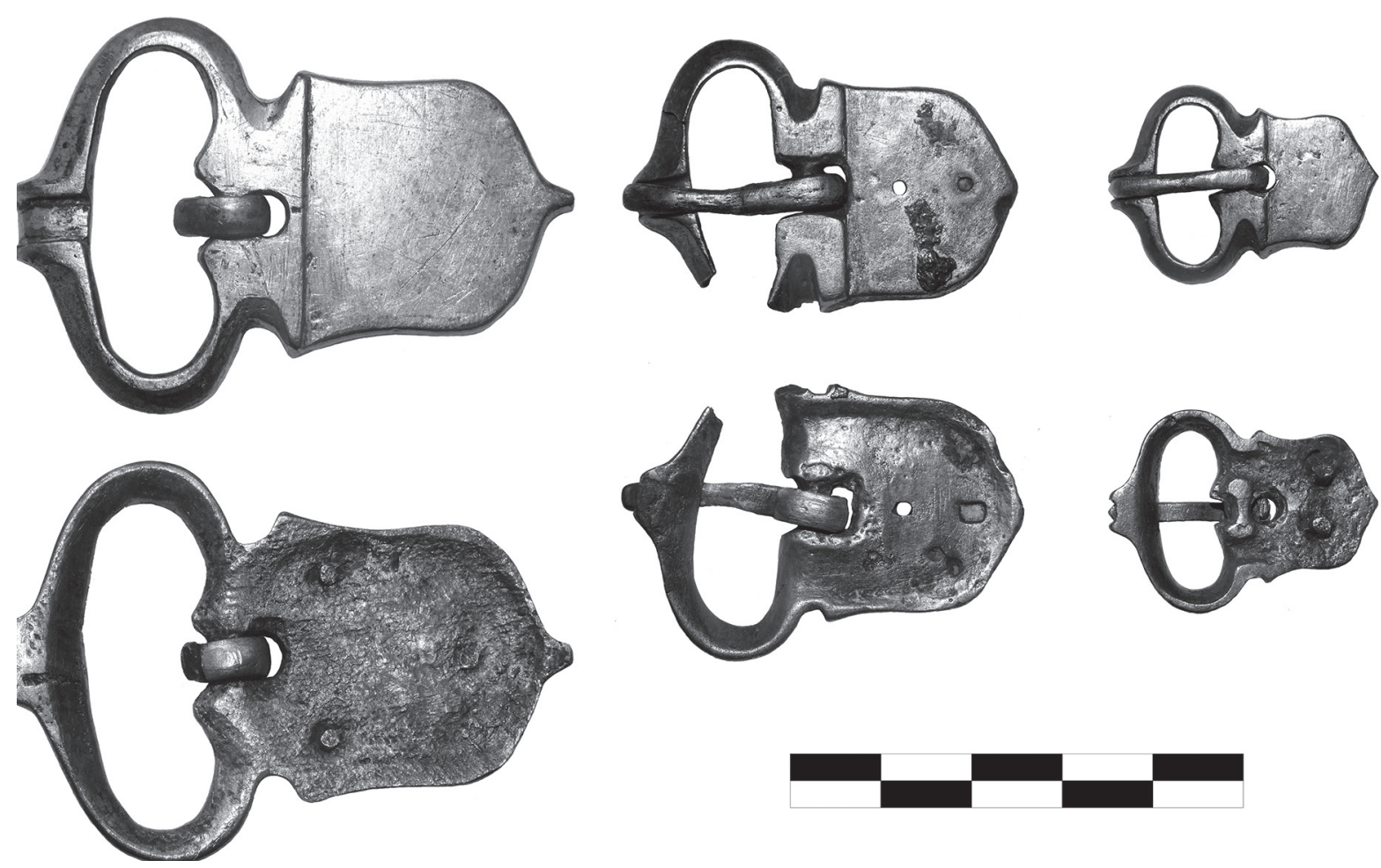

Abb. 5. Silberschnallen mit mitgegossenen Nieten, Ozora

Eine Gruppe von Grabinventaren mit gepressten Gürtelgarnituren bildet einen einzigen, ans Ende der Frühawarenzeit, an den Anfang der Mittelawarenzeit datierbaren Horizont („Kunágota-Mersin-Typ“, Kunágota (Abb. 6); große Riemenzungen mit Tiergestalt, ${ }^{38}$ Környe, Grab 24; Pancsova-Typ, ${ }^{39}$ Jászapáti, Grab 264; Tarnaméra-Typ, ${ }^{40}$ Kecskemét-Sallai-Straße; gepresstes geometrisches Muster auf der Gürtelgarnitur des Grabes 202 von Jánoshida). An das Ende dieser Reihe kann auch das Grab von Ozora wegen der Schnalle und der schildförmigen Beschläge der Gürtelgarnitur gestellt werden, obwohl es traditionell in die Mittelawarenzeit datiert wird (Abb. 5). Die typologische Kontinuität zwischen der Gruppe vom Ende der Frühawarenzeit und der vom Anfang der Mittelawarenzeit ${ }^{41}$ wird durch die Ähnlichkeit der Männergräber von Kunágota und Ozora weiter betont. Im Grab von Kunágota kamen eine verzinnte ${ }^{42}$ Bronzeschnalle und typologisch identische Schwertriemenschnallen mit gepressten schildförmigen Goldbeschlägen vor, während in Ozora eine einzige silberne (silbervergoldete) Gürtelschnalle mit mitgegossenen Nieten bzw. den Silberschnallen von Bócsa ähnliche, kleine Schnallen des Waffengürtels gefunden wurden.

Die chronologische Kontinuität zwischen den Fundkomplexen mit dem analysierten Schnallentyp aus der zweiten Hälfte der Frühawarenzeit und aus der ersten Hälfte der Mittelawarenzeit wird einerseits durch das Aufkommen der Gegenstände des Pseudoschnallenkreises und der Zahnschnittornamentik, andererseits durch die Gürtelgarnituren mit verschiedenen gepressten Beschlagtypen betont. Von dieser typologischen und chronologischen Gruppe sondern sich die aus Silberblech gefertigten, in die Mittelawarenzeit datierbaren, mit rechteckigen Beschlägen verzierten Gürtelgarnituren des Grabes 58 von Szeged-Kundomb und des Grabes 617 von Alattyán (Abb. 7) ab. Beide Gräber weisen auf das Ende der Benutzungszeit dieses Schnallentyps im Karpatenbecken hin, aber relativchronologisch können auch noch diese Stücke innerhalb der Mittelawarenzeit in eine frühere Periode datiert werden. ${ }^{43}$

\footnotetext{
${ }^{38}$ GARAM 2001, 137-138.

${ }^{39}$ Garam 2001, 146-147.

${ }^{40}$ GARAM 2001, 141-142.

${ }^{41}$ RÁCZ 2001, 498.
}

\author{
${ }^{42}$ Siehe MaY-SZENTHE 2015, Appendix. \\ ${ }^{43}$ Zur chronologischen Lage der beiden Gräber s. SZENTHE \\ 2012, 524-533.
}



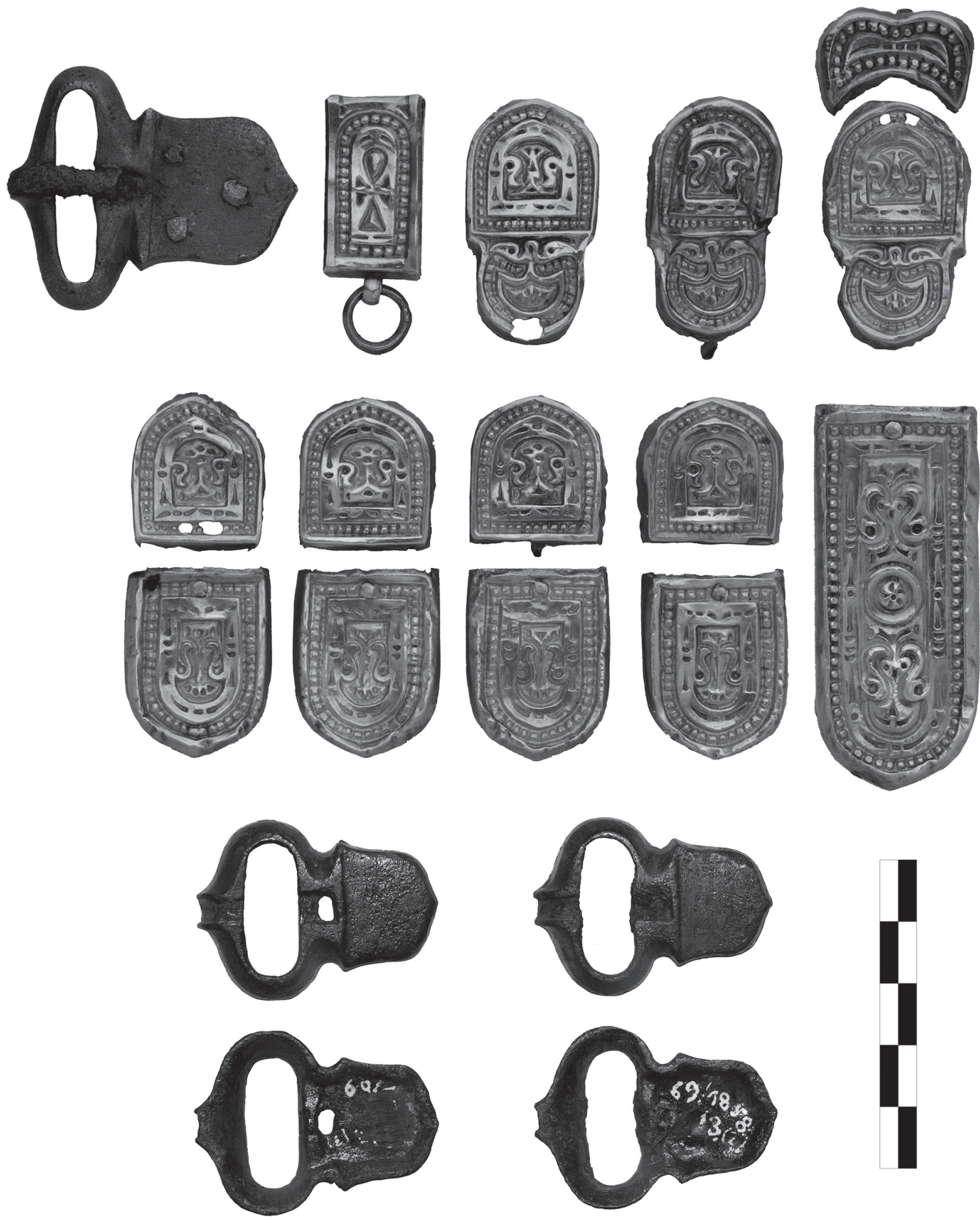

Abb. 6. Gürtelschnalle, Gürtelgarnitur und Schwertriemenschnallen, Kunágota (Ungarisches Nationalmuseum; Foto: András Dabasi) 


\section{Geographische Verbreitung}

Da die frühe und späte Gruppe eher zwei große Wellen eines kontinuierlichen Verbreitungsfeldes vertreten, können sie separat nur begrenzt kartiert werden.

Die am meisten charakteristischen Fundorte der frühen Gruppe sind Zamárdi und Környe, durch die der Schnallentyp in der FA I Periode als ein Gegenstandstyp transdanubischen Charakters bezeichnet werden kann. Andere gut datierbare Funde (Mór-Akasztódomb, Kölked A und B, Várpalota-Gymnasium) betonen diese Streuung weiter. Es ist kennzeichnend, dass die Funde, die wegen der Fundmangel der Komplexen nur allgemein in die Früha-
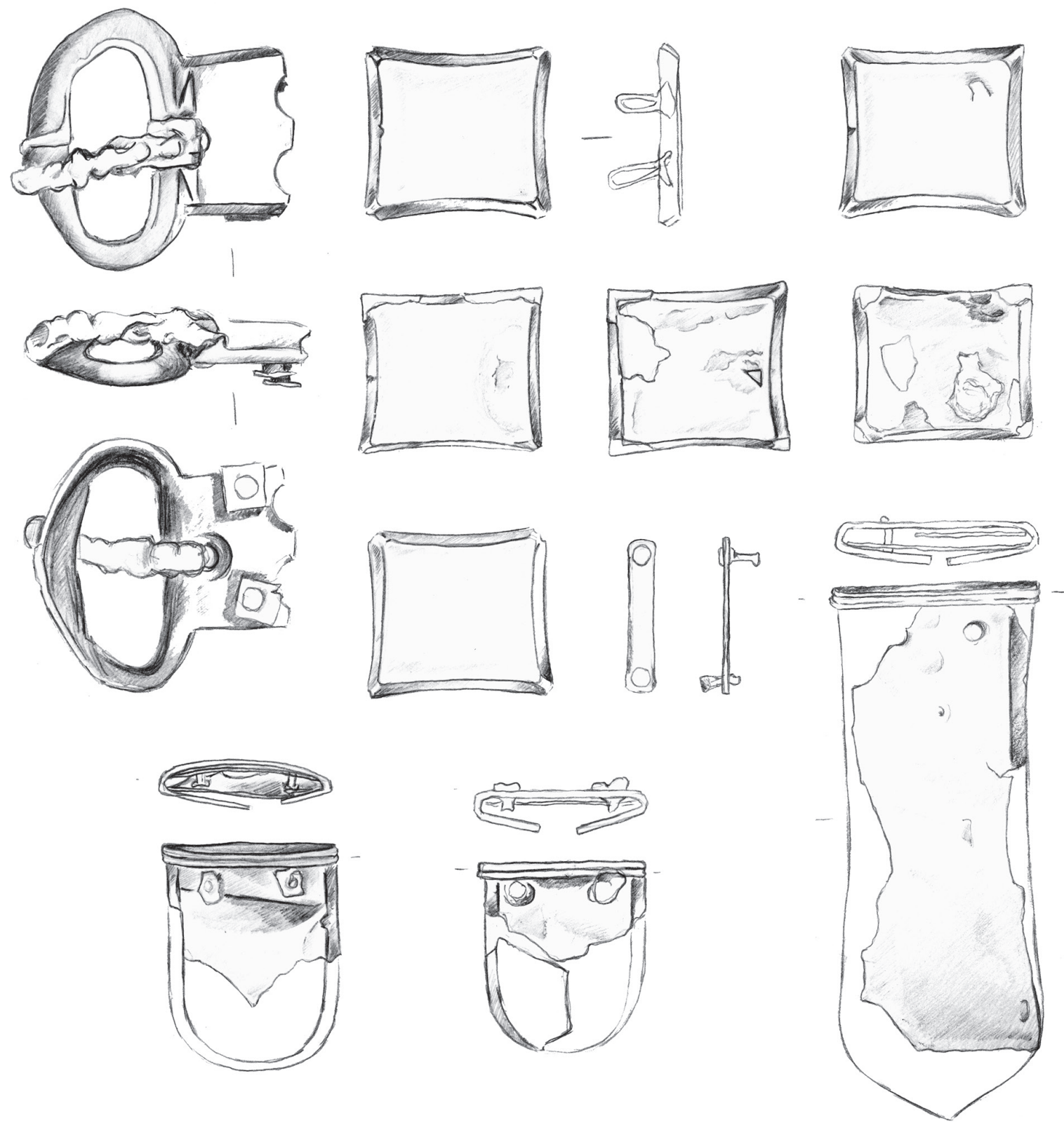

Abb. 7. Gürtelgarnitur mit gepressten Beschlägen und gegossener Schnalle osteuropäischen Typs, Alattyán-Tulát Grab 617 
warenzeit zu datieren sind, bzw. typologisch mit dem Material dieser Periode die meisten Beziehungen aufweisen, ${ }^{44}$ kommen eher in der westlichen Hälfte des Karpatenbeckens vor (Abb. 2). ${ }^{45}$

Die mit Sicherheit an das Ende der Frühawarenzeit bzw. in die Mittelawarenzeit datierbaren Komplexe haben ein anderes Verbreitungsbild. Der zumeist durch die Funde von Bócsa, Kunbábony, Kunmadaras und Kunágota bezeichnete Fundhorizont konzentriert sich ausgesprochen in der Großen Ungarischen Tiefebene (Abb. 2). Außer der Komplexen von Ozora und Pápa-Úrdomb ist der Schnallentyp vom Ende der Frühawarenzeit bzw. am Anfang der Mittelewarenzeit in Transdanubien in größerer Anzahl nur in Zamárdi bekannt. Die letzteren Stücke können aber für die Fortsetzer der frühawarenzeitlichen Tradition betrachtet werden, im Gegensatz zu den Bestattungen vom Ende der Früh- und aus der ersten Hälfte der Mittelawarenzeit im Großen Ungarischen Tiefebene, die keine örtliche Vorläufer haben. Die transdanubischen Gräber von Ozora und Pápa bilden in dieser Hinsicht - mit dem Fehlen lokaler Vorläufer - durch das in der Großen Ungarischen Tiefebene eine gemeinsame Gruppe. ${ }^{46}$

\section{DIE ENTFALTUNG DES SCHNALLENTYPS UND DIE ANALOGIEN AUßERHALB DES KARPATENBECKENS}

Zur Deutung der Eigentümlichkeiten, die in der awarenzeitlichen chronologischen und geographischen Verbreitung des Schnallentyps und dessen Montierungsweise beobachtet werden konnten, ist es nötig, ihre Zusammenhänge auch außerhalb des Karpatenbeckens zu analysieren. Hinsichtlich der Evolution des Gegenstandstyps ist sowohl (a) die Analyse der Art der Befestigung am Riemen als auch (b) die der Form wichtig.

\section{a) Analogien zur Benutzung von mitgegossenen Nieten}

Schnallen und Beschläge wurden im 5. Jahrhundert mit Hilfe von Drahtnieten angebracht, die durch Löcher durch den Körper des Gegenstandes durchgeführt wurden ${ }^{47}$ Die Anbringung durch mit dem Körper des Gegenstandes mitgegossene Nieten wurde erst im Frühmittelalter als allgemein verwendete Anbringungsweise von Maskenbeschlägen, Riemenzungen und Schnallen vom Martinovka-Typ in weitem Kreis verbreitet. ${ }^{48}$

Die überwiegende Mehrheit der Gegenstände vom Martinovka-Typ wurde durch mitgegossene Nieten oder mit Hilfe von Lochzapfen auf dem Riemen angebracht. In der zeitgenössischen mediterran-byzantinischen Kultur war die letztere Methode verbreitet. In den Fällen, wo die Publikation die Befestigungselemente dokumentiert, können beide Varianten beobachtet werden. Trotzdem scheint die Anwendung der mitgegossenen Nieten allgemeiner zu sein. Die letztere Lösung tritt im byzantinischen Mediterraneum auch auf den Beschlägen des Martinovka-Typs auf, sie ist aber in der osteuropäischen und asiatischen Steppe praktisch in jedem dokumentierbaren Fall identifizierbar. ${ }^{49}$ Beispiele für die Verwendung von Lochzapfen fand ich in der letzten Region nur selten: Es kommt auf Gegenständen mit stark profiliertem Rand und durchbrochenem Körper vor. Sie gehören meistens zu byzantinischen

${ }^{44}$ Diese Erscheinung ist in erster Linie bei den Fundkomplexen von Törökbálint und Budapest bzw. bei einigen späteren Fundensembles von Zamárdi und Környe auffällig (Tabelle Nr. 8, 35, 40, 49, 79-80, 100, 110). Außer den Exemplaren, die in die zweite Hälfte der Frühawarenzeit datierbar sind (z. B. Gegenstände mit Zahnschnittornamentik), sind Aufhängerbeschläge mit langem Hals, gepresste, unverzierte, riemenzungenförmige Beschläge, ferner die Muster vom Martinovka-Charakter kennzeichnend. Die Benutzung der Schnallen mit mitgegossenen Nieten und der erwähnten Typen hat also wegen der regionalen Verdichtung der Vorkommen eine kulturelle Bedeutung. Dieses Problem kann in der vorliegenden Studie jedoch nicht analysiert werden.

${ }^{45}$ Siehe die Gegenstände in der Tabelle mit einer allgemeinen FA-Datierung.

${ }^{46}$ Dieser Schnallentyp kommt in der Großen Ungarischen Tiefebene häufig in Einzelgräbern oder in einzelnen Bestattungen von kleinen Grabgruppen vor: Bócsa und Kecel (LÁszLó 1976), Kunbábony (H. TótH-HoRVÁTH 1993), Kiskunfélegyháza-Pákapuszta (H. TótHHorváth 1993, 113-114, Abb. 52), Kecskemét-Sallai-Str. (H. TóTHHoRvÁth 1993); ferner in Transdanubien: Ozora (zuletzt ProHÁszKA 2010), Pápa-Úrdomb (H. TótH-HoRvÁTH 1993, 115, Abb. 53).

${ }^{47} \mathrm{Zu}$ den spätrömischen Schnallentypen siehe den Katalog von SCHULZE-DÖRRLAMM 2009, 8-67.

${ }^{48}$ In den meisten Fällen, können die Befestigungselemente der Gegenstände mit glatter Oberfläche wegen der Mangelhaftigkeit der Veröffentlichngen, nicht identifiziert werden. Deswegen kann ich hier keine umfassende Analyse geben, höchstens können grundlegende Tendenzen skizziert werden.

${ }^{49}$ Siehe mehr unten; besonders bei BÁLINT 1992; ЛЕвИНА 1994; ГолдинА-ГолдинА 2010. 
Gürtelgarnituren ausgezeichneter Qualität (mit angelöteten Bandhenkeln) $;^{50}$ es gibt unter ihnen nur einige Stücke von durchschnittlicher oder schwacher Qualität. ${ }^{51} \mathrm{Im}$ Gegensatz zu den Befestigungsdornen wurden Lochzapfen anscheinend an Schnallen und Gürtelbeschlägen angewandt, die ab der zweiten Hälfte des 6. Jahrhunderts im direkten Einflussbereich der byzantinischen bzw. der spätantiken Kultur erzeugt wurden. ${ }^{52}$ Im byzantinischen Mediterraneum wurden bis zum 7. Jahrhundert bei gegossenen Gürtelzubehören (überwiegend bei Schnallen) ausschließlich Lochzapfen angewandt. Im osteuropäischen Fundmaterial blieben die Befestigungsdorne mit den Beschlägen des „heraldischen Stils“ bis ins 8. Jahrhundert in Verwendung.

\section{b) Die Form}

Die ältesten Vertreter des Schnallentyps im Karpatenbecken können mit Hilfe von Beschlägen des Martinovka-Typs datiert werden (Tolnanémedi und Kiskőrös-Városalatt Grab 9). ${ }^{53}$ Neben den frühawarenzeitlichen Exemplaren kommen relativ häufig Blechbeschläge oder Riemenzungen Martinovka-Charakters mit Masken oder geometrischer Verzierung (,Tamga“) vor. Die osteuropäischen Stücke werden konsequent in die typologischen und chronologischen Reihen der Gegenstände vom Martinovka-Typ oder vom „heraldischen Stil” eingeordnet. ${ }^{54}$ Die Fundzusammenhänge der frühesten Auftreten im Karpatenbecken, die Befestigung durch mitgegossenen Dornen, die meistens glatte, unverzierte Oberfläche des Körpers bzw. der schildförmige Schnallenkörper - obwohl der Letztere in sich in viel weiterem Kreis verbreitet war - weisen zusammen darauf hin, dass die Gegenstände des Martinovka-Typs bei der Entstehung des Schnallentyps wirklich eine entscheidende Rolle spielten. Deswegen konzentriert sich die folgende Untersuchung auf den Martinovka-Typ.

Das Verhältnissystem des Fundkreises, der im europäischen und mediterranen Milieu geographisch weit verbreitet war, ist in allen Einzelheiten noch nicht geklärt. ${ }^{55}$ Bestimmte Varianten kommen in Byzanz bzw. in dessen unmittelbarem mediterranem Einflussgebiet häufig vor, obwohl das primäre Verbreitungsgebiet sowohl nach der Menge als auch nach der Streuung der morphologischen Varianten die nördliche Steppenregion war. ${ }^{56}$ Die Fundkomplexe können meistens in die zweite Hälfte des 6. Jahrhunderts bzw. an den Anfang des 7. Jahrhunderts datiert werden. ${ }^{57} \mathrm{Im}$ Falle des Materials aus der Krim, aus Osteuropa und aus der Steppe kann man mit einer viel längeren Chronologie rechnen (bis zur zweiten Hälfte des 7. Jahrhunderts bzw. bis zum 8. Jahrhundert).$^{58}$ Die in osteuropäischem Milieu bzw. in der Krim gefundenen Exemplare werden übereinstimmend bis in die zweite Hälfte des 7. Jahrhunderts, am spätesten bis zur Wende des 7. und 8. Jahrhunderts, datiert. ${ }^{59}$ Die Chronologise der innerasiati-

${ }^{50}$ Z. B. Arcisa und Verona (Werner 1974, Abb. 8-9).

${ }^{51}$ Verhnaja Esera (zitiert bei BÁLINT 1992, Taf. 51. 1-4).

${ }^{52}$ Die frühesten massenhaft hergestellten Typen mit Lochzapfen können ab der zweiten Hälfte des 6. Jahrhunderts datiert werden. Der wahrscheinlich früheste, zugleich häufigste Sucidava-Typ erscheint ab der zweiten, vielleicht schon während der ersten Hälfte des 6. Jahrhunderts. Die Datierungsvorschläge sind bei ScHulzEDöRRLAMM 2009, 149 zusammengefasst.

${ }^{53}$ Tabelle Nr. 28 und 76-77.

${ }^{54}$ Ausführlicher s. unten.

${ }^{55}$ Nach Cs. Bálint, der die regionalen Varianten evaluierte (BÁLINT 1992, Taf. 38-50), ist die Bestimmung des genauen Beziehungssystems und der Abstammung wegen der Forschungslage nicht möglich (BÁLINT 1992, 421-422). Regionale Gruppen der Typen wurden in BÁLINT 1992, Taf. 54 abgesondert. Eine Zusammenfassung der verschiedenen Abstammungstheorien s. bei PRICHODNJUK 1994, 168; STARK 2008, 174-175.

${ }^{56}$ Ausführlich s. BÁLINT 1992; Anhäufung der Funde auch in: ДАскАЛов 2012. Aus byzantinischem Gebiet und dem Iran wurden frühe Beispiele in BÁLINT 1992, Taf. 7-8 (Syrien?) angeführt. Zu den byzantinischen bzw. im provinzial-byzantinischen Milieu vorkommenden Stücken s. : Krim: Tabelle Nr. 91-92; ANDRÁsI-AIBABIN 2008, 145, Pl. 49; Sadovec: UENZE 1992, Taf. 130; Italien: WERnER 1974,
123-125; PARoli-Ricci 2008, Tav. 35, Tav. 133; RupP 2005, Taf. 50. 9-10, Taf. 62, Taf. 71. 8-9. Aufgrund von formalen Kennzeichen werden mehrere, im Karpatenbecken vorgekommene Exemplare für Gegenstände byzantinischen Ursprungs gehalten: BALOGH 2004, 261.

${ }^{57}$ MARTIN 1990, 66-67; ausschließlich für das langobardisches Material: JÖRGENSEN 1992, Fig. 9; RUPP 2003, Taf. VIII; aufgrund des Materials aus dem Karpatenbecken: SoMOGYI 1997, 132-133. Ausführliche chronologische Beschreibung: BALOGH 2004, 258-264.

${ }^{58}$ Aibabin 2008, 145.

${ }^{59}$ Osteuropäische, im Allgemeinen in das 7. Jahrhundert datierte Funde sind: BÁLINT 1992, Taf. 353. 22-23. In der Krim: АЙБАБин 2003. Nomadischen Gruppen zugeschriebene, osteuropäische Komplexe wurden der „Siwaschowka-Gruppe“ zugeordnet: РАШЕВ 2007, 70-89. Bestimmte Gegenstandstypen s. noch bei KoMAP 2006, 188-216. Die Datierung des Grabes von Üč-Tepe und dessen Analogien wurden von Cs. Bálint ausführlich analysiert: BÁLINT 1992, 401-411. Die von A. V. Komar und seinen Mitautoren vorgeschlagene Datierung (letztes Drittel des 7. Jahrhunderts: KOMAP 2006; KOMAPКуБЫшЕВ-Орлов 2006) des „Üс̌-Tepe-Horizontes“, der innerhalb der von A. R. Rašev benutzten Sivašovka-Gruppe, als deren letzte Phase, abgesondert wurde, scheint im Licht der gut bestimmbaren absolutchronologischen Lage (um die Mitte des 7. Jahrhunderts) der aus dem Karpatenbecken stammenden Funde zu spät zu sein. 
schen Funde ist bestrittener. Das Gräberfeld von Kudyrge (Altaigegend) bzw. die in diesem Gräberfeld freigelegten Beschläge vom Martinovka-Typ wurden von A. A. Gavrilova in die Kudyrge-Phase datiert (6. Jahrhundert, Anfang 7. Jahrhundert) ${ }^{60}$ V. B. Kovalevskaia, die die chronologischen Verhältnisse der materiellen Kultur des ganzen Alttürkenzeit an großen Serien bewertete, sonderte zwei chronologische Schichten der Beschläge vom MartinovkaTyp ab. Von Gavrilova abweichend datierte sie die Bestattungen von Kudyrge mit Beschlägen Martinovka-Typs (durchbrochene Beschläge mit Palmetten- oder Tiergestalten) in eine jüngere Phase (in die zweite Hälfte des 7. Jahrhunderts, bis zum Anfang des 8. Jahrhunderts). ${ }^{61}$

Zum beschriebenen Fundkreis gehören auch die untersuchten, beinahe in jedem Fall unverzierten Schnallen mit festem schildförmigem Körper und mit mitgegossenen Nieten, die häufig von sehr einfacher Ausführung sind. Diese Variante erscheint nie in der byzantinischen materiellen Kultur. ${ }^{62}$ Sie kommt auch im Fundmaterial der Pontusgegend selten vor, wo die direkte Wirkung der mediterran-byzantinischen Kultur aufgrund anderer Funde (byzantinischer Schnallen) dominierte. Im Fundmaterial vom byzantinischen Typ der Krim sind überwiegend die kleinen Varianten des Schnallentyps bekannt (meistens als Schnallen von Schuhgarnituren), während er als große Gürtelschnalle - im Gegensatz zu den großen serien von byzantinischen Schnallentypen - eher ausnahmsweise vorkommt. ${ }^{63}$ In der Pontusgegend kommen eher jene Varianten des Schnallentyps vor deren Körper mit einfach profilierten Durchbrüchen gegliedert wurde ${ }^{64} \mathrm{Im}$ Fundmaterial der Region, der ins 7. Jahrhundert datiert ist, nimmt die Zahl der Schnallen mit glattem, schittförmigem Körper gegen die byzantinischen Schnallentypen stark ab. ${ }^{65}$

In Osteuropa und Mittelasien wurden die unmittelbaren Parallelen der Schnallen mit festem Beschlag und mitgegossenen Nieten von der zweiten Hälfte des 6. Jahrhunderts an bis zum 8. Jahrhundert in weiten Gebieten verbreitet. ${ }^{66}$ Sie wurden sowohl als Gürtelschnallen und Schnallen der Wehrgehänge als auch als andere kleine Schnallen der Bekleidung benutzt. Der Typ begleitete die Beschläge des Martinovka-Typs auch hier vorhanden. Der Schnallentyp kommt in nomadischen Bestattungen der osteuropäischen Steppe ${ }^{67}$ häufig vor, aber er tritt auch

${ }^{60}$ ГАврилова 1965, 59-61. Die Datierung wurde von R. Kenk übernommen: KENK 1982, 32-34.

${ }^{61}$ Ковалевская 1990, 45-47. Dasselbe Datierungsschema s. bei ГАвритухин-ОБломский 1996, Рис. 89. Die Hypothesen über die byzantinische, osteuropäisch-kaukasische bzw. mittelasiatische Herkunft des ,heraldischen Stils“ beeinflussen den Gegenstand der Studie nicht, deshalb kann ich von der Analyse des Problems absehen. Eine kurze Zusammenfassung der Fachliteratur der Frage s. bei STARK 2008, 174-176.

${ }^{62}$ Wegen des Charakters der archäologischen Spuren der byzantinischen gegenständlichen Kultur - die erhalten gebliebenen kleinen Gegenstände sind nämlich überwiegend Schnallen verschiedenen Typs - trägt diese Aussage kaum Risiken.

${ }^{63}$ Z. B. Krim, Lutčistoe: AJBABIN-CHAJREDINOvA 2009. Zu den byzantinischen Kontakten der Schuhwerke s. ХАЙРЕДИНОвА 2003, рис. 19, 10-12. Zur Gürtelschnalle siehe das Fundmaterial des Gräberfeldes Borisovo aus der zweiten Hälfte des 7. Jahrhunderts: АйБАБИн 2003, Тab. 78.

${ }^{64} \mathrm{Zu}$ den Funden aus dem 7. Jahrhundert aus der Krim, dem Kaukasus und der Pontusgegend s. КовалЕвСКАя 1979. Schnallenkörper mit Anbringungsdorn und kleinem rundem Durchbruch: Tab. V.1: Bakla; mit D-förmigem Durchbruch: Tab. V.2: Eski Kermen. Dasselbe s. Carciat, Kaukasus: Exemplare mit durchbrochenem Körper in den Gräbern 5 und 6 (ДзАттИАты 2006, 100-101) und Lutčistoe Grab 8 (Aibabin-ChajRedinova 2009, Taf. 41.1); Skalistoe 420 (ВЕЙМАРИАЙБАБИН 1993, Ris. 71, 14). Variante mit D-förmigem Durchbruch und spitzem Ende: Ковалевская 1979 Tab. XV.7: Bakla, Suuk Su, Konstantinovka, Tšmi, Borisovo; mit maskenförmigem Durchbruch: Tab. XVI.3-4: Tšmi, Kamunta, Kumbalta, Borisovo; dreieckförmiger Durchbruch zwischen zwei ovalen: Tab. V.7: Haznidon, Uzen-Bas, Eski Kermen. Zur inneren Chronologie des Gräberfeldes von Borisovo s. АйБАБин 2003, Tab. 78. Im erwähnten Gräberfeld von Carciat ist eine Schnalle mit unverziertem Beschlag und eine andere mit Scharnier mit den frühen Martinovka-Beschlägen im Grab 12 bekannt (ДзАттиАты 2006, 102, 104, 113). Im Gräberfeld von Lutčistoe ist auch eine unverzierte Variante außer dem Exemplar mit durchbrochenem Körper und Blechbeschlägen vom Martinovka-Typ im Grab 38 vorhanten (AIBABIN-CHAJREDINOvA 2009, Taf. 38.1-2).

${ }^{65}$ Im Fundmaterial des Gräberfeldes von Lutčisztoe aus dem 7. Jahrhundert sind ansonsten die Schnallen mit Lochzapfen vom byzantinischen, meistens Trebizond-Typ kennzeichnend (AIBABINChajRedinova 2009, Taf. 34-36, 41-42, 49, 59, 112, 115, 122, 130, $147,161,164)$. Neben den Letzteren kamen schon keine gegossenen Beschläge vom Martinovka-Typ zum Vorschein. Das ist auch im Katakombengräberfeld von Skalistoe festzustellen. Obwohl die Anbringungsweise aufgrund der Veröffentlichung nur insofern feststellbar ist, dass die durchgeschlagene Niete fehlt, ist es zu beobachten, dass das Auftreten der Schnallen mit einfachem schildförmigem oder viereckigem Körper in Vergesellschaftung von Beschlägen des Martinovka-Typs anscheinend auch hier charakteristisch ist (Gräber 164, 166, 321, 403, 420, 422, 430 - ВЕЙМАРИ-АЙБАБИН 1993, Ris. 14, 48, 65, 72, 75; ohne Beschlag im Grab 413 - ВЕЙМАРИ-АЙБАБИН 1993 , Ris. 68.7). Den oben erwähnten Beispielen ähnlich sind die Schnallen byzantinischen Typs von abwechslungsreicher Form. Lochzapfen für die sicher in das 7. Jahrhundert datierbaren Bestattungen sind auch da kennzeichnend. Die neben ihnen manchmal auftretenden Beschläge vom Martinovka-Typ sind gepresste Exemplare (Gräber 331 und 381 - ВЕЙМАРИ-АЙБАБИН 1993, Ris. 50, 60).

${ }^{66}$ Dieser Typ wurde von V. B. Kovalevskaja, die die Vertreter des Typs zusammengefasst hat, den 1.-3. Typen der lyraförmigen Schnallen zugeordnet: Ковалевская 1979, 33, Tabelle 2, Тур 3.1-3, Tab. XV.5-7, 8, 14.

${ }^{67}$ Einen Katalog der Funde s. bei PAшев 2007, Tab. 19-28, 44-50; s. noch: Komap 2006, Ris. 44-45. 
in der Kamagegend ${ }^{68}$ und in Mittelasien ${ }^{69}$ auf. Mehrmals kommt er mit Funden vor, die auch im Karpatenbecken bekannt sind (Aufhängerbeschlag mit langem Hals, ${ }^{70}$ Aufhängerbeschläge mit Haken, die in der späteren Gruppe des Schnallentyps in der Großen Ungarischen Tiefebene vorkommen, ${ }^{71}$ Aufhängerbeschläge mit zwei Vogel- oder anderen Tierköpfen ${ }^{72}$ ).

In Osteuropa und Mittelasien sind die Schnallen mit festem schildförmigem Körper und Befestigungsdornen in geschlossenen Fundkomplexen mit ornamental verzierten Gürtelbeschlägen auch noch am Anfang des 8. Jahrhunderts bekannt. ${ }^{73}$ Die Schnallen aus dem Grab $22^{74}$ von Nevolino und aus dem Grab 77 von Verh-Saia ${ }^{75}$ schlossen je einen Gürtel mit halbkreisförmigen oder breiten, schildförmigen, palmettenverzierten Gussbeschlägen. Der letztere Beschlagtyp war am Ende des 7. und am Anfang des 8. Jahrhunderts in Osteuropa bzw. besonders in der Krim verbreitet. ${ }^{76}$ Gewisse Zeichen weisen also auch in der osteuropäischen Steppe darauf hin, dass die Schnallen mit festem Beschlag und mitgegossenen Nieten von dem genetisch verwandten Martinovka-Kreis ab der zweiten Hälfte des 7. Jahrhunderts, wie im Karpatenbecken, mindestens teilweise unabhängig wurden. Hinsichtlich des frühen Verschwindens der Beschläge vom Martinovka-Typ folgt das Karpatenbecken diejenigen Trends, die in der materiellen Kultur des europäischen Mediterraneums bemerkbar sind. Dieselben Trends spiegeln sich direkt vielleicht auch in der Relativchronologie der Gegenstandstypen der krimischen, kaukasischen Gräberfelder der bzw. in den Bestattungen der Pontusgegend (siehe die seltene Schnallenform mit Befestigungsdorn in den krimischen und kaukasischen Gräberfeldern bzw. im Gegensatz dazu die Dominanz der byzantinischen Schnallen in der gleichen Region), insofern die gegossenen Martinovka-Beschläge in diesen Gräberfeldern im Laufe der ersten Hälfte des 7. Jahrhunderts verschwanden. Aufgrund ihrer materiellen Kultur gehörten die Gemeinschaften, die diese Gräberfelder benutzten, zu der byzantinischen Welt.

Die Verbreitung des Schnallentyps ohne die Beschläge des Martinovka-Typs deutet auf eine Zwischenposition der awarischen Kultur des Karpatenbeckens zwischen den Steppenkulturen und dem Mediterraneum hin, wo noch eindeutig Byzanz die zentrale Macht während der ersten Hälfte des 7. Jahrhunderts war. In dieser Hinsicht zeigt das Karpatenbecken eine gewisse Ähnlichkeit mit der Pontusgegend auf, wo der Schnallentyp am Rand der byzantinischen materiellen Kultur sporadisch ebenfalls erhalten blieb.

Da die Gegenstände des Martinovka-Kreises aus dem Karpatenbecken schon früh verschwanden, sind die awarischen Exemplare des Schnallentyps im 7. Jahrhundert wahrscheinlich keine kulturellen Reminiszenzen, sondern solche Elemente, die durch ständige osteuropäische Kontakte ins Karpatenbecken gelangten, und die sich von der lokalen, von byzantinischen Quellen dominierten materiellen Kultur abgrenzen.

\section{ZUSAMMENFASSUNG: DIE LEHREN DER VERBREITUNG EINES „HERALDISCHEN“ SCHNALLENTYPS IM KARPATENBECKEN}

Die morphologischen Merkmale, die Befestigungsweise und die Fundzusammenhänge der frühesten Vorkommen zeugen davon, dass die Entfaltung des untersuchten Schnallentyps innerhalb des Martinovka-Kreises bzw. der Zusammenhänge des ,,heraldischen Stils“ stattfand. Am nördlichen Rand des byzantinischen Mediterraneums - im Karpatenbecken, in den nördlichen und östlichen Küstengebieten des Schwarzen Meeres und im Kaukasus bilden die Exemplare des Schnallentyps (meistens mit Scharnierbeschlag) mit den gegossenen Beschlägen vom Martinovka-Typ eine Gruppe. Im Karpatenbecken kommen sie meistens mit den Aufhängerbeschlägen mit langem

${ }^{68}$ In der Kamagegend: Nevolino, Grab 22 (ERDÉLYI-OJTOZI-GENING 1969, Taf. XXV); Verh-Saia, mehrere Grabkomplexe (ГолдинА-ГолдинА 2010, Ris. 18, 23, 27, 29); Uszty-Irginsk, Streufund (Волков-ПАСтуренко 2006, Ris. 19.2).

${ }^{69}$ Mittelasien, entlang der oberen Sir-Daria unter den Funden der „Džetyasar-Kultur“ s. den Schnallentyp: Левина 1994, ris. 149.12, ris. 153.1-4; ГолдинА-ГолдинА 2010, z. B. Ris. 19.

${ }^{70}$ Z. B. Dimovka: PAшев 2007, Tab. 23.

${ }^{71}$ Bócsa (GARAM 1993, Taf. 6.6); Kunbábony (mit angelöteter Öse; H. Tóth-HoRvÁth 1993, Taf. 12, Taf. XXI.5), Kunbábony
Grab 2, aus Silber, mit durchgeschlagenen Nieten (H. TóTH-HoRVÁTH 1993, Taf. 12, Taf. XXIV.6).

${ }^{72}$ BÁLINT 1992, Taf. 31.1-10.

${ }^{73}$ Außer diesem Schnallentyp kamen Beschläge und Riemenzungen im Gräberfeld Verh-Saja vor, die ab der Wende der 7. und 8. Jahrhunderte in osteuropäischen Fundverbänden, besonders in der Krim, kennzeichnend sind (Grab 65, 77 und 81; s. ГолдинА-ГолдинА 2010, 218-220).

\footnotetext{
${ }^{74}$ ERdélyi-Ojtozi-Gening 1969, Taf. XXV.

${ }^{75}$ ГолдиНА-ГолдиНА 2010, Ris. 27.

${ }^{76}$ Datiert von АЙБАБин 1982, 172-173.
} 
Hals vor. In der byzantinischen Kultur tritt die Schnallenform in den Garnituren vom Martinovka-Typ eher mit Scharnierbeschlägen auf. Die jüngeren Gürtel mit blechernen Martinovka-Garnituren wurden im Mittelmeerbecken schon mit den weit verbreiteten byzantinischen Schnallentypen des 7. Jahrhunderts verschlossen.

In der osteuropäischen Steppe waren die gegossenen Varianten der Gegenstandstypen des MartinovkaKreises - des „heraldischen Stils“ der osteuropäischen Fachliteratur - mit mitgegossenen Nieten im 7. Jahrhundert kontinuierlich benutzt. Ihr Gebrauch war durch die Schnallen mit festem, schildförmigem Körper begleitet, die dann scheinbar unabhängig von den Garnituren des Martinovka-Typs noch eine kurze Zeit weiter in Gebrauch blieben (ca. bis zum Anfang des 8. Jahrhunderts).

Die älteren Vorkommnisse des Schnallentyps im Karpatenbecken überwiegen in Transdanubien, zum Teil als eine Folge der großen Serien in den Gräberfeldern von Zamárdi und Környe. Diese Verbreitung wird durch die Fundkomplexe von Kölked, Mór, teils Törökbálint bzw. durch solche Funde unterstützt, die nur im Allgemeinen in die Frühawarenzeit datiert werden können. Sie bilden eine regionale Gruppe, die für die westliche Hälfte des Karpatenbeckens charakteristisch ist. ${ }^{77}$

Von dieser Gruppe sondert sich ein fundreicher Horizont von Waffengräbern auch geographisch ab, der durch eine Reihe von charakteristischen Begleitfunden von datierendem Wert umschrieben werden kann. Er ist während der zweiten Hälfte, am Ende der Frühawarenzeit bzw. in der ersten Hälfte der Mittelawarenzeit für die Große Ungarische Tiefebene typisch. Schon vor dieser, die am besten durch die Funde von Kunbábony, Kunágota und Kecskemét-Sallai-Straße charakterisiert werden kann (mittleres Drittel des 7. Jahrhunderts), verlor der Schnallentyp in der materiellen Kultur Transdanubiens an Bedeutung.

Obwohl die chronologische Absonderung des frühen und späten Horizontes relativ ist, ist die Unterscheidung der beiden Gruppen aufgrund der geographischen Verbreitung und der abweichenden Begleitfunde gesichert. Ihre Unterschiede weisen an das Unterbrechen der inneren Tradition während der ersten Hälfte des 7. Jahrhunderts hin, und zwar zwischen den zwei Abschnitten der Frühawarenzeit, die mit Hilfe gegenstandstypologischer Argumente unterschieden werden können (,FA“ I und II). Das Erscheinen des Schnallentyps und von anderen Begleitfunden sprechen dafür, dass in der materiellen Kultur der Großen Ungarischen Tiefebene zwischen den Fundkomplexen der zweiten Hälfte der Frühawarenzeit (FA II) bzw. der erste Hälfte der Mittelawarenzeit datiert sind (MA I), eine beträchtliche Kontinuität bestand.

Die Einfachheit der aus Kupferlegierungen gegossenen Schnallen mit Eisendorn der späteren, überwiegend in der Großen Ungarischen Tiefebene charakteristischen Gruppe steht in einem bedeutenden Kontrast zu den byzantinischen Gegenständen oder Gegenständen byzantinischen Charakters der gleichen Grabkomplexe. Die einfachen Schnallen passen nach der Form und nach der typischen Befestigungsweise in das Gesamtbild der gepressten oder mit abwechslungsreichen Techniken aus Edelmetallen hergestellten Artefakte weder morphologisch noch technisch hinein. Deswegen ist ihr Ursprung höchstwahrscheinlich den Zusammenhängen der „langen Chronologie“ des Martinovka-Kreises in der Steppe zu erklären. Auch wenn die Benutzung des Gegenstandstyps im Karpatenbecken chronologisch wahrscheinlich ununterbrochen war, wäre dessen Fortleben zur Zeit der byzantinischen kulturellen Dominanz ohne kontinuierliche osteuropäische Kontakte des Karpatenbeckens nicht vorstellbar.

Mit den Schnallen gehört ein aus gegossenen Stücken bestehender Fundkreis aufgrund der Befestigungsweise eng zusammen. Die Aufhängerbeschläge mit langem Hals und passförmigen Endungen, ${ }^{78}$ die Beschläge mit doppelten Vogelköpfen ${ }^{79}$ und die Aufhängerbeschläge mit Haken sind typische Gegenstände in den Fundzusammenhängen, in denen die Exemplare des behandelten Schnallentyps vorkommen. (Die goldenen Schnallen von Kunbábony bilden eine Ausnahme, insofern sie nach byzantinischem Vorbild mit angelöteten Ösen an den Riemen befestigt wurden. ${ }^{80}$ ) Wie die Schnallen, verbreiteten sich die verschiedenen Aufhängerbeschläge ebenfalls überwiegend in Osteuropa und teils im Karpatenbecken. ${ }^{81}$

Es gibt noch keine Analyse über die Aufhängerbeschläge mit geschwungenen Haken und schildförmigem Körper. Im Gegensatz zu den beiden anderen Aufhängertypen, deren Vorläufer bis ins 6. Jahrhundert zurückgehen, kamen ihre frühesten Exemplare in den Fundverbänden von Bócsa ${ }^{82}$ und Kunbábony, ${ }^{83}$ in dem Ensemble von

\footnotetext{
${ }^{77}$ Eine Frage ist, ob die Bearbeitung der Gräberfelder in der Großen Ungarischen Tiefebene und am Theißgebiet, die in die früheste Phase der awarischen Ansiedlung datiert werden können, dieses Bild verändern wird.

${ }^{78}$ Diese Funde s. unter den Begleitfunden der Schnallen.
}

${ }^{79}$ BÁlint 1992, Taf. 31.

${ }^{80}$ H. TÓTH-HoRváth 1993, Taf. XXI.5.

${ }^{81} \mathrm{Zu}$ den Beschlägen mit Tierkopf s. BÁLINT 1992, Taf. 31.

${ }^{82}$ LÁsZló 1976, 94, Abb. 10. 
Kalininskaia der „Sivašovka Gruppe“ ${ }^{\text {“84 }}$ bzw. im Grab 402 von Durso vor. ${ }^{85}$ Die um die Mitte des 7. Jahrhunderts datierbaren Exemplare von Bócsa und Kunbábony sind die ältesten Stücke im Karpatenbecken. Die Analogien der Aufhängerbeschläge mit Haken, die von gleicher Form sind, aber - wie es bei den meisten Gürtelbeschlägen der Periode üblich war - mit durchgeschlagener Niete angebracht wurden, können im Karpatenbecken schon in die Mittelawarenzeit bzw. in die erste Hälfte der Spätawarenzeit datiert werden (Spätstufe I-II) ${ }^{86}$ Die Funktion des Gegenstandstyps und die Herkunft der Form sind unbekannt. Die oben erwähnten Aufhängerbeschläge mit Haken aus dem 7. Jahrhundert kamen in herausragenden Fundkomplexen zum Vorschein. Die spätawarenzeitlichen Exemplare, die in größerer Anzahl, aber im Vergleich zur hohen Zahl der gegossenen Gürtelbeschläge selten auftauchen, treten in den analysierbaren Fällen - wie die früheren Funde - in solchen Fundverbänden auf, die im awarischen Milieu atypische oder seltene morphologische Elemente, mediterran-byzantinische Verbindungen aufweisen. ${ }^{87}$ Unabhängig von der unbekannten Herkunft kann das Auftreten des Beschlagtyps im Kreis Bócsa-Kunbábony wegen der Methode der Befestigung - mit den Schnallen mit mitgegossenem Befestigungsdorn und den Aufhängerbeschlägen mit langem Hals - auf die osteuropäischen Beziehungen der zeitgenössischen Bevölkerungsgruppen hinweisen, zu denen die analysierten Waffengräber gehörten.

Nach dem Erscheinen der Schnallen mit festem schildförmigem Körper bzw. nach dem Auftreten der Gegenstände mit mitgegossenen Nieten ist darauf zu schließen, dass die nördlichen Peripherien des byzantinischen Mediterraneums im 7. Jahrhundert miteinander direkte Kontakte hatten.

Aus dieser Perspektive scheint es nicht mehr gesichert zu sein, dass die zahlreichen Übereinstimmungen der Fundverbände von Mala Pereščepino und der Fundgruppe Bócsa-Kunbábony im Karpatenbecken ausschließlich die Folgen der Kontakte der Eliten des Zentrums und der Peripherie, d. h. von Byzanz und der an dessen nördlicher Grenze liegenden Staatsgebilden, sind. Unter die Faktoren, die das Bild der awarischen materiellen Kultur gestalteten, kann auch die Kommunikation mit dem osteuropäischen Raum eingereiht werden, obwohl der Einfluss des byzantinischen Zentrums und von anderen europäischen politischen Formationen sicherlich ein Übergewicht hatte.

Solange die Einbeziehung von weiteren Quellengruppen - von naturwissenschaftlichen Analysen - einen Fortschritt nicht ermöglicht, kann die Frage nur hypothetisch beantwortet werdenb wie großen Anteil die Prodution der byzantinischen Werkstätte und die Kontakte mit den osteuropäischen Eliten-als komplementäre, mitwirkende Faktoren-in der Formation des Bócsa-Kunbábony-Fundkreises hatten.

Das gemeinsame Vorkommen „Prunkgrabhorizontes“88 weist jedenfalls auf den umfassenden Charakter der am westlichen Ende der euroasiatischen Steppe ablaufenden gesellschaftlichen Prozesse him. Die Entfaltung des Horizontes war wahrscheinlich eine Antwort auf die Veränderung der Verhältnisse zwischen der Peripherie und dem Zentrum, das bis dahin die Quelle des Reichtums für die Erste war. Die Entfaltung des Kunbábony-BócsaKreises ist also in diesem Modell ein Krisensymptom, das auf die gleichen Gründe wie die Belagerung Konstantinopels durch die Awaren zurückzuführen ist. ${ }^{89}$ Beide waren - obwohl erfolglose - Antworte der Peripherie bzw.

${ }^{83}$ Aus den beiden Funden: H. TótH-HoRváth 1993, Taf. XXI.5; mit durchgeschlagenen Nieten: Taf. XXIV.6.

${ }^{84}$ PAшеB 2007, Tab. 26.11.

${ }^{85}$ ДмитриЕв 1982, Ris. 12, 15.

${ }^{86}$ Igar-Vámszőlőhegy, Fund III, Streufund (FÜLÖP 1988, Abb. 12.2, Abb. 13.2); Kecel-Határdülő Grab 32 (Cs. Sós 1958, 8, T. XX.2; Mártély Grab B (Hampel 1905, II, 107; III, Taf. 85.4); Mosonszentpéter (unveröffentlicht, UNM), Szeged-Fehértó B Grab 69 (Madaras 1995, Pl. 13, 17); Mödling Grab 100 und Zsély Grab 335 (Typ 570, Kodenummern 33100 und 20335; ZÁвоJNíк 1991, Taf. 36). Zur Datierung siehe z. B. ZÁвојNíK 1991, Taf. 1, Seriationstabelle.

${ }^{87} \mathrm{Zu}$ den Zusammenhängen der Garnituren von Kecel und Mártély anlässlich der Riemenzungen s. SzENTHE 2013a, 141-142, $151-154$.

${ }^{88}$ KOSSACK 1974.

${ }^{89}$ In einem teils abweichenden Zusammenhang und im Kontext des Karpatenbeckens wurde die Frage von T. Vida richtig beantwortet (VIDA 2009, 110-111). Nach der Interpretation von $\mathrm{T}$. Vida stehen gesellschaftliche Veränderungen im Karpatenbecken (die mittelawarenzeitliche Verschmelzung von frühawarenzeitlichen
Kulturgruppen, der Beginn von gesellschaftlichen und kulturellen Veränderungen) im Hintergrund des Prozesses. Durch die Abnahme der Kraft der nomadischen Elite führen diese Gründe als Panikerscheinungen zum Abenteuer bei Konstantinopel bzw. danach als Krisensymptom zur Entfaltung des „Prachtgrabhorinzontes“. Im Lichte der sich an der nördlichen Peripherie in weiterem Kreis als im Karpatenbecken abzeichnenden Prozesse bzw. der dokumentierbaren Kommunikation an der Peripherie ist es wahrscheinlich, dass in der Umwandlung der inneren Strukturen des Awarischen Khaganats die Abnahme der Interessen des Zentrums, die die ganze nördliche Peripherie in gleichem Maße berührte, als auslösender Faktor eine größere Rolle spielte. Unter den Komponenten des Bedeutungsverlustes könnten unter anderen die weitere Aufwertung des östlichen Kriegsschauplatzes (Sassanidenkrieg, dann die Verteidigung gegen die muslimische Invasion) und der darauf folgende Zerfall des byzantinischen Systems determinierend sein. Die inneren Prozesse der awarischen Gesellschaft im Karpatenbecken waren wahrscheinlich sekundär. Dennoch sind die beiden Antworte im Fall des Karpatenbeckens zwei gleicherweise gültige Modelle für die Interpretation desselben Prozesses aus einer inneren und aus einer äußeren Herangehensweise. 
des awarischen Khaganats auf das abnehmende Interesse des byzantinischen Zentrums. Der deutliche Aufschwung in der Verwendung des untersuchten Schnallentyps im Karpatenbecken um die Mitte des 7. Jahrhunderts kann ein Zeichen der Belebung der Kommunikation zwischen destabilisierenden Peripherien sein, die nach dem Rückgang der Zentrum-Peripherie-Kontakte und dem daraus folgenden Ressourcenmangel an den Peripherien erfolgte. 


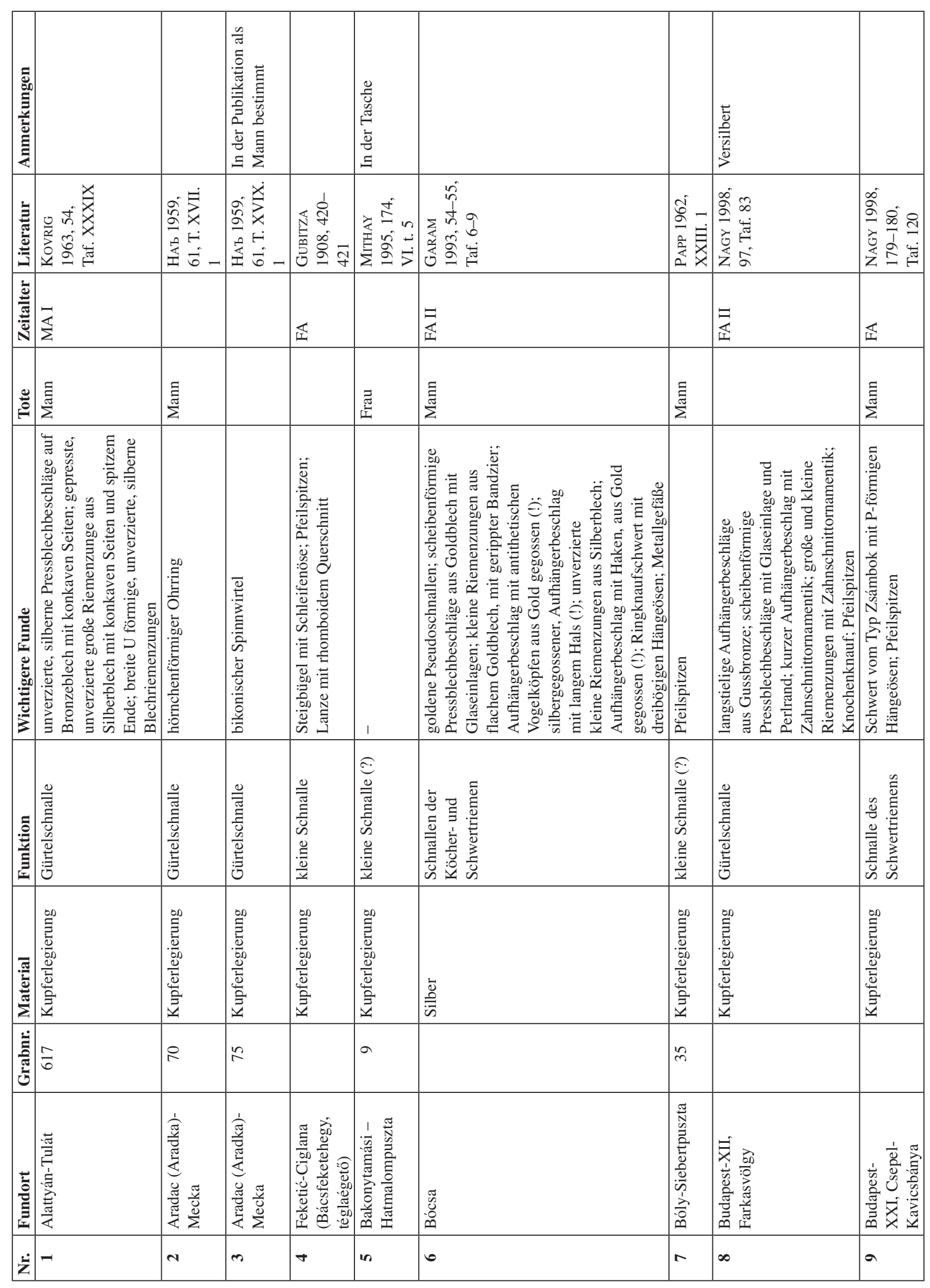




\begin{tabular}{|c|c|c|c|c|c|c|c|c|c|c|}
\hline & & & $\begin{array}{l}\mid \overline{0} \\
\overline{0} \\
0 \\
000 \\
00 \\
0\end{array}$ & & 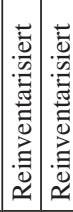 & 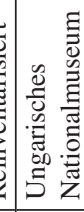 & 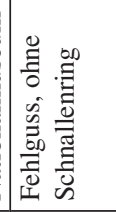 & & & 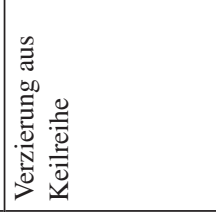 \\
\hline 紊 & 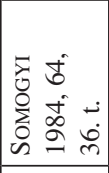 & 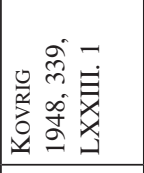 & 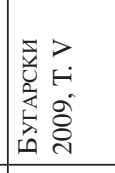 & 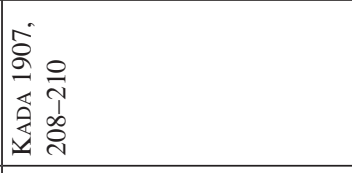 & & & 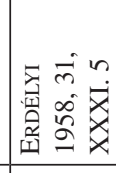 & 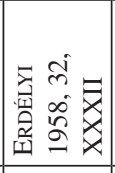 & 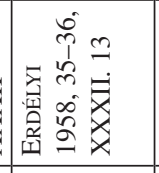 & 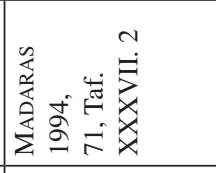 \\
\hline 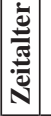 & & $\vec{\Sigma}$ & $\mathbb{|}$ & 在 & & $\underset{\Sigma}{\mathbb{2}}$ & & & 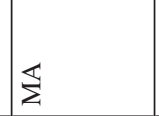 & $\bar{\Sigma}$ \\
\hline 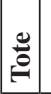 & & 洁 & & 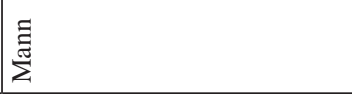 & & 䓌 & 茞 & 急 & 䓌 & 吉 \\
\hline & 1 & 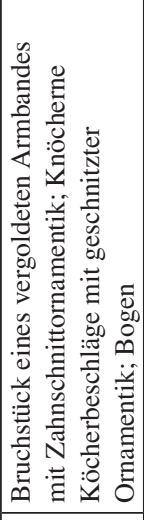 & 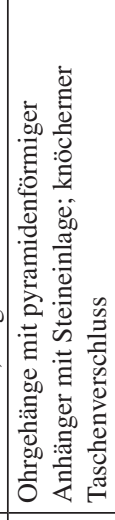 & 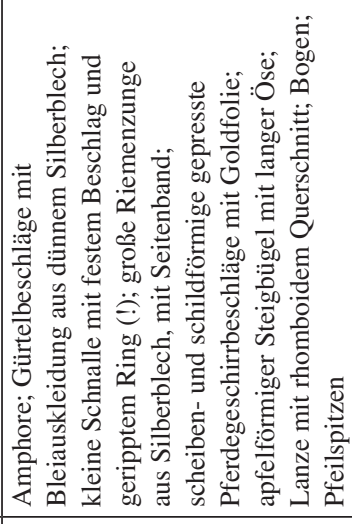 & & 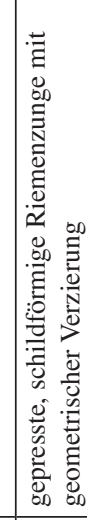 & 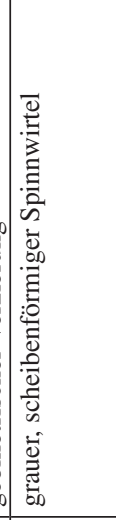 & 1 & 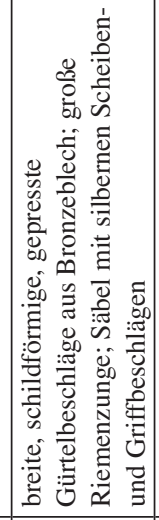 & 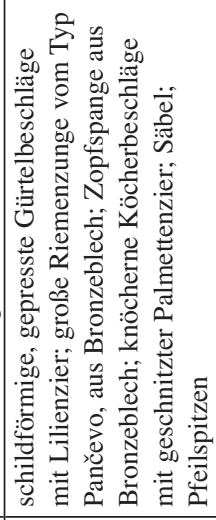 \\
\hline & 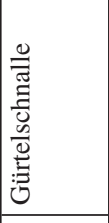 & 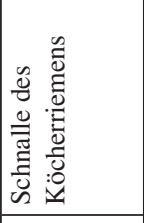 & 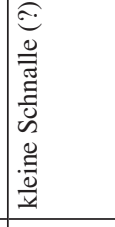 & 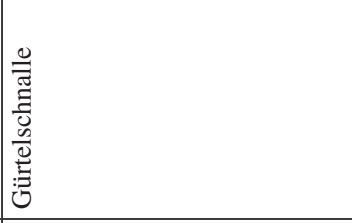 & 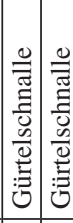 & 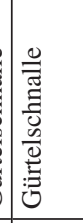 & 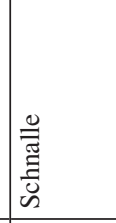 & 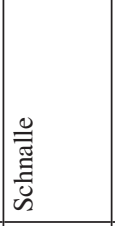 & 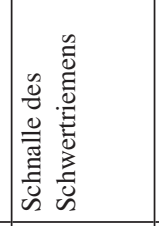 & 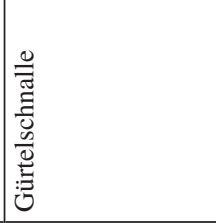 \\
\hline 胥 & 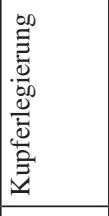 & 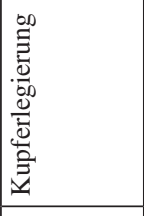 & 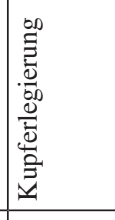 & 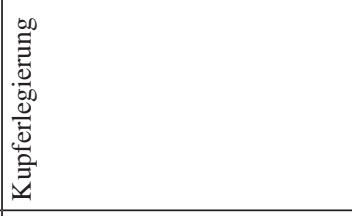 & 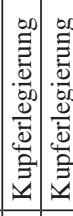 & 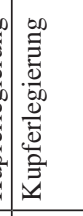 & 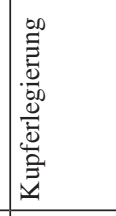 & 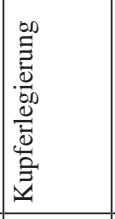 & 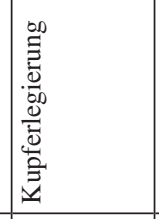 & 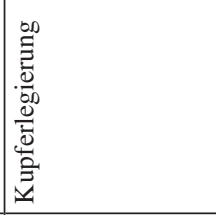 \\
\hline 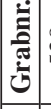 & हि & $r$ & ஜి & $\hat{\sigma}$ & & & $\stackrel{\cong}{I}$ & $\stackrel{\infty}{\infty}$ & సิ & 胥 \\
\hline 童 & 总 & 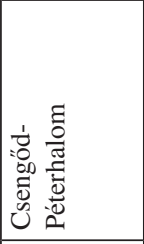 & : & 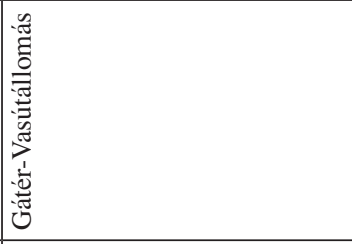 & 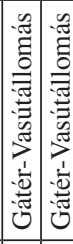 & 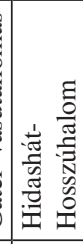 & 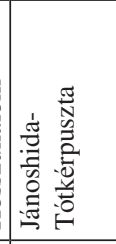 & 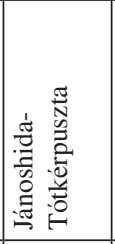 & 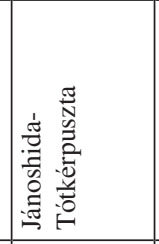 & 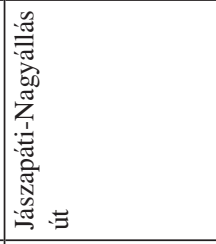 \\
\hline$\dot{\vec{z}}$ & $\varrho$ & $=$ & $\approx$ & 2 & $\pm \simeq$ & 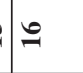 & $\cong$ & $\stackrel{\infty}{-}$ & 2 & సิ \\
\hline
\end{tabular}

Acta Archaeologica Academiae Scientiarum Hungaricae 66, 2015 


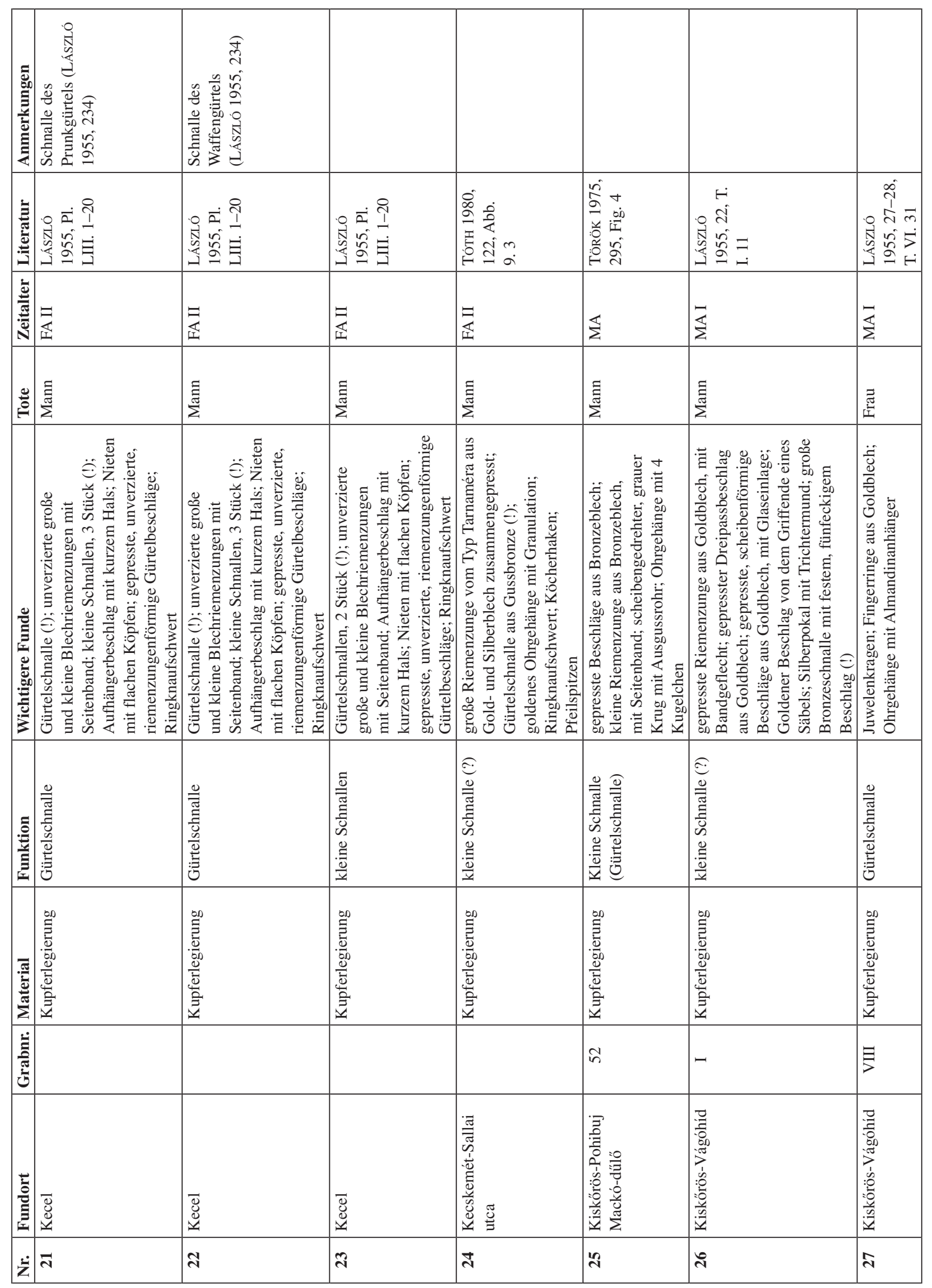




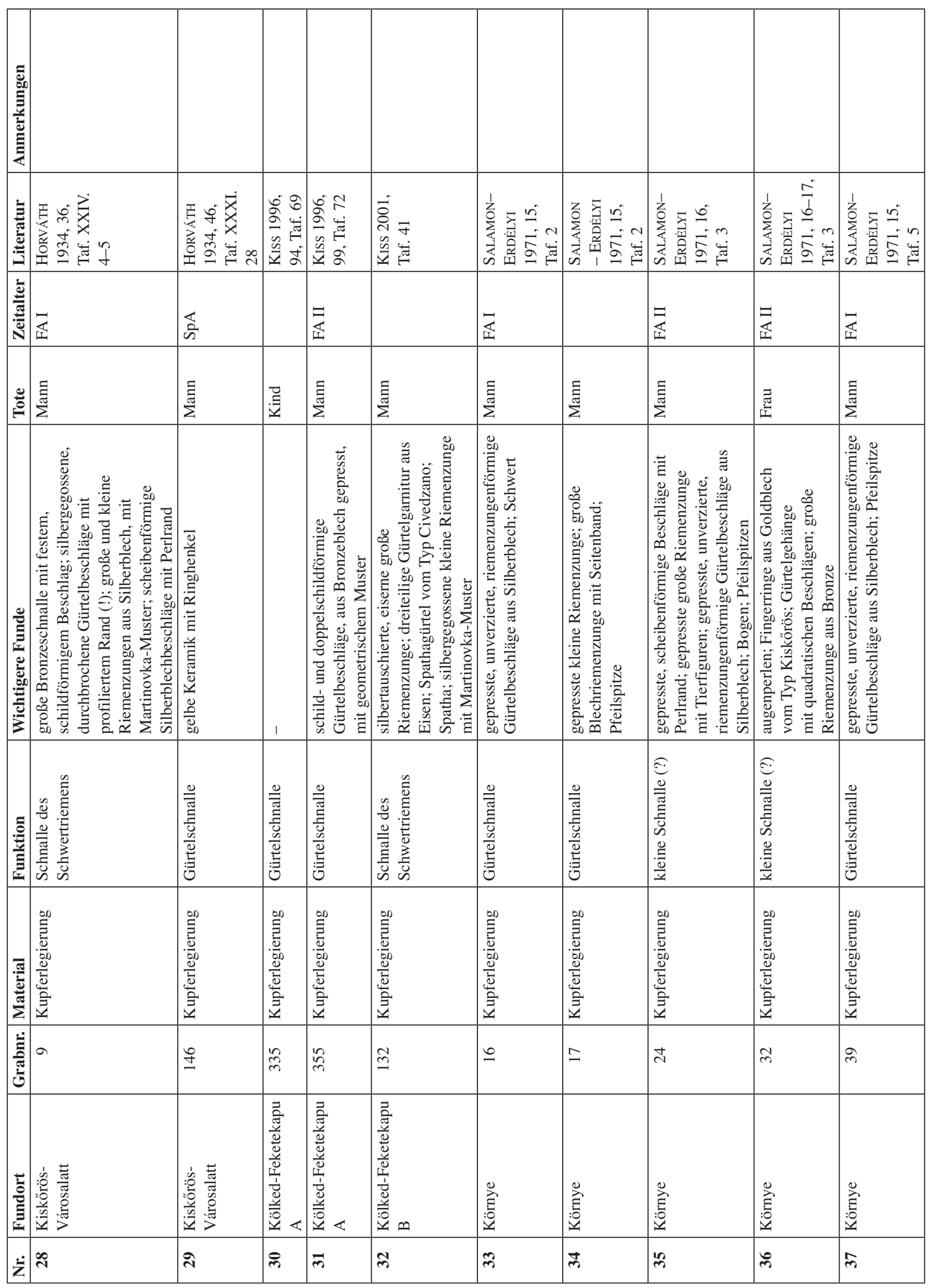

Acta Archaeologica Academiae Scientiarum Hungaricae 66, 2015 


\begin{tabular}{|c|c|c|c|c|c|c|c|c|}
\hline 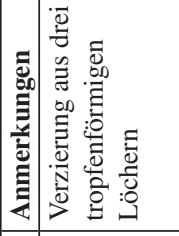 & & & & 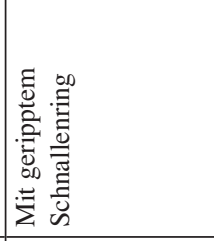 & & & & \\
\hline 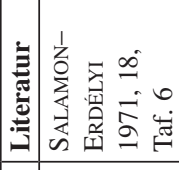 & 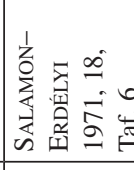 & 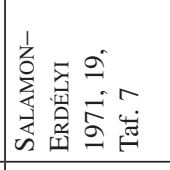 & 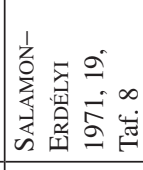 & 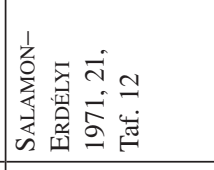 & 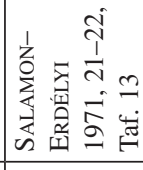 & 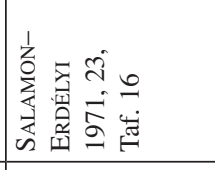 & 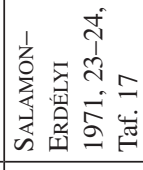 & 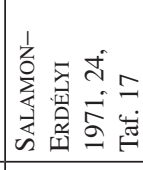 \\
\hline 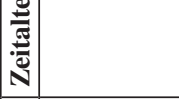 & 芷 & 居蓄 & 企 & 屋 & 原 & 胥 & 屋 & \\
\hline 言 & 言 & 言 & 言 & 長 & 咅 & 言 & 䇏 & 疍 \\
\hline 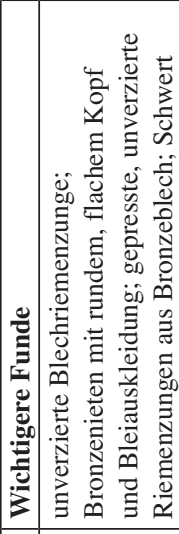 & 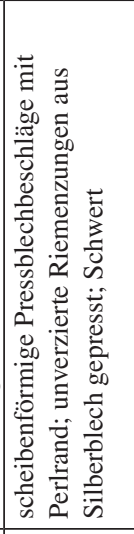 & 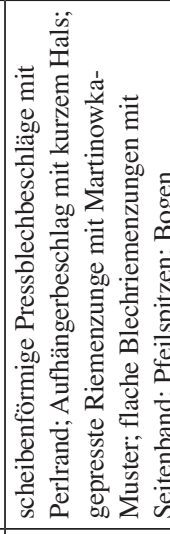 & 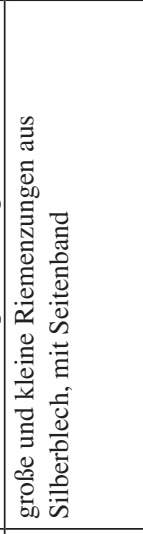 & 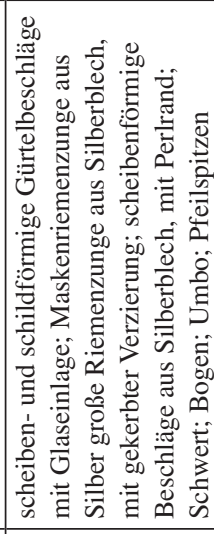 & 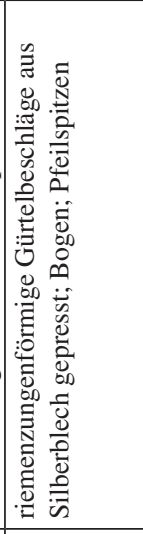 & 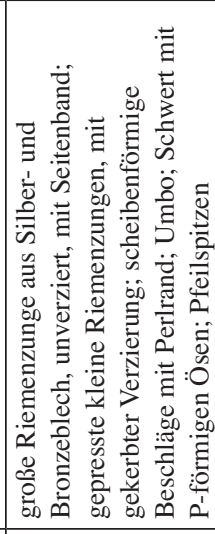 & 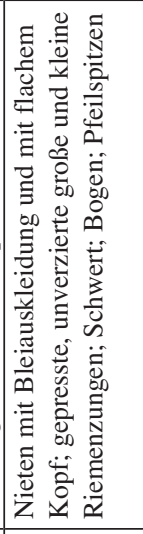 & 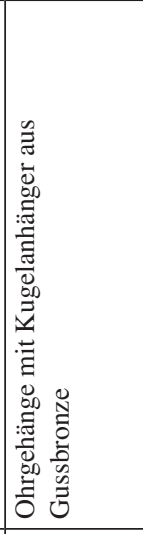 \\
\hline 毵 & 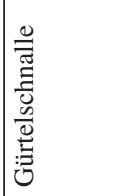 & 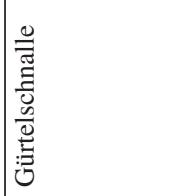 & 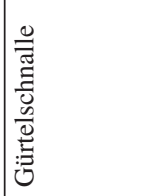 & 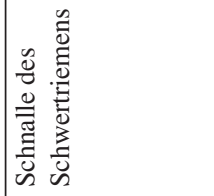 & $\mid$ & 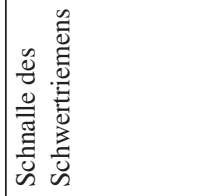 & 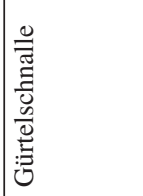 & 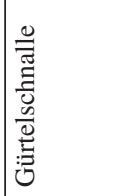 \\
\hline 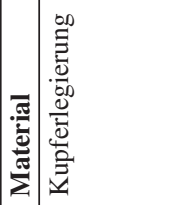 & 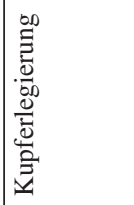 & 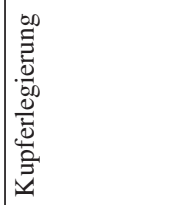 & 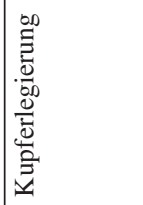 & 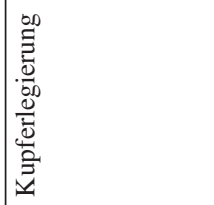 & 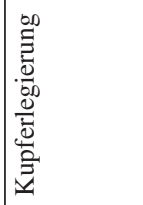 & 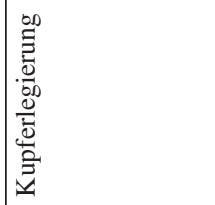 & 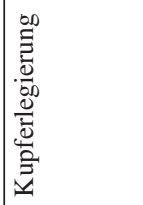 & 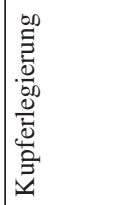 \\
\hline $\mid$ & $\vec{n}$ & 8 & $\vec{\sigma}$ & 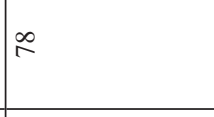 & $\infty$ & \&े & 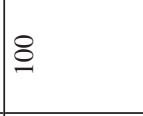 & $\stackrel{\tilde{\Xi}}{0}$ \\
\hline 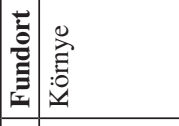 & 兽 & 产 & 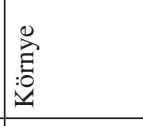 & 言 & 产 & & 产 & 产 \\
\hline$\dot{\vec{z}} \mid \infty$ & के & q & 7 & 7 & 8 & 7 & if & $\%$ \\
\hline
\end{tabular}




\begin{tabular}{|c|c|c|c|c|c|c|c|}
\hline 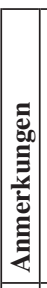 & & & & & & & 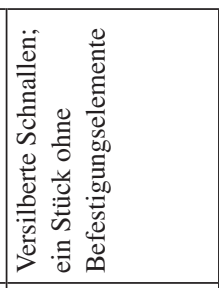 \\
\hline 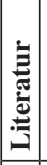 & 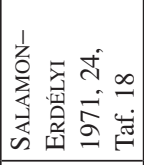 & 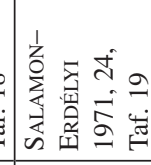 & 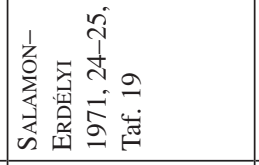 & 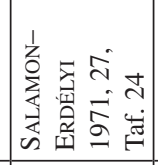 & 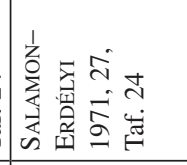 & 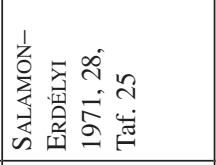 & 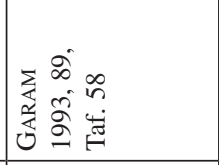 \\
\hline $\mid$ & 㜽 & $\mathbb{I}$ & $\underset{\Psi}{\mathbb{I}}$ & $\mathbb{\Phi}$ & $\mathbb{\Phi}$ & 蛋 & 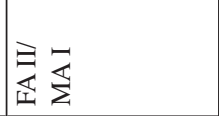 \\
\hline : & 镸 & $\stackrel{\Xi}{ }$ & 志 & 斻 & 部 & 言 & 志 \\
\hline & 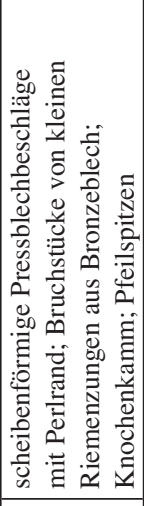 & 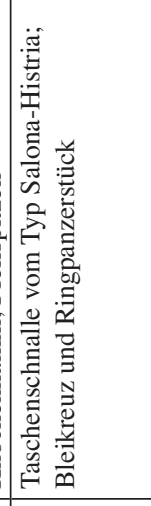 & 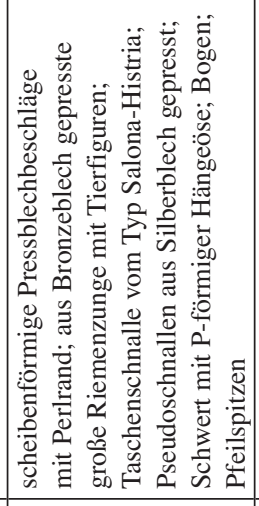 & 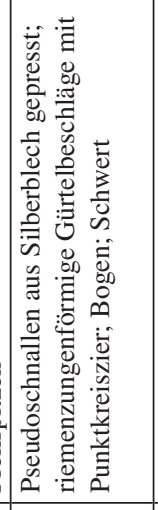 & 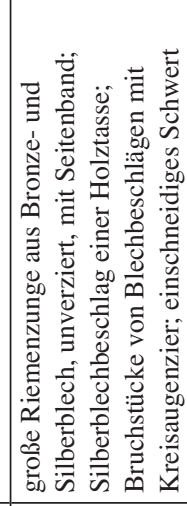 & 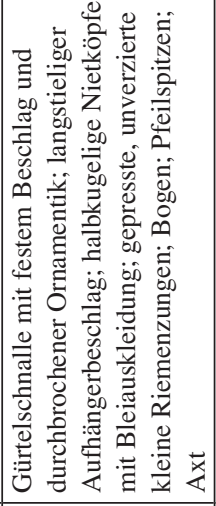 & 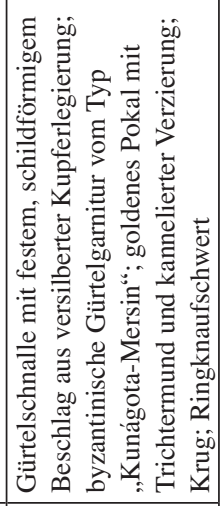 \\
\hline & 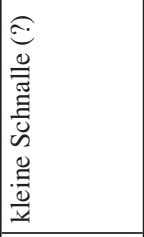 & 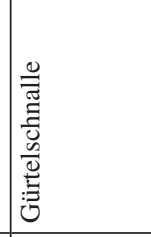 & 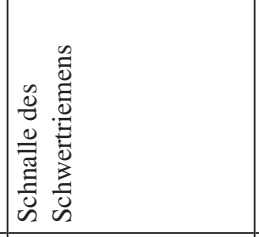 & 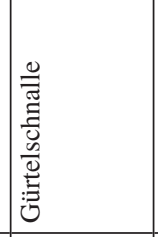 & 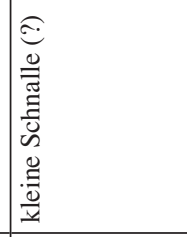 & 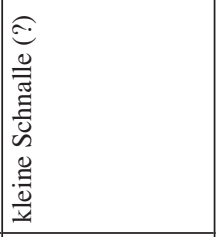 & 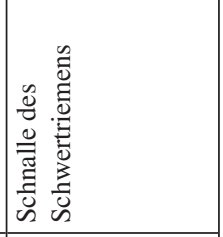 \\
\hline 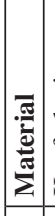 & 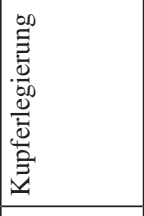 & 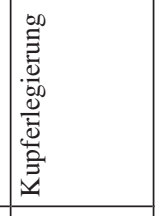 & 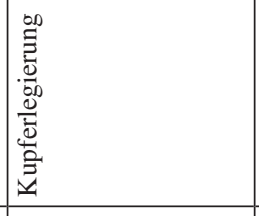 & 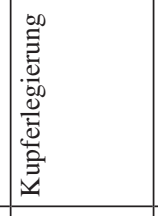 & 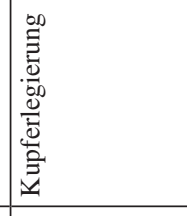 & 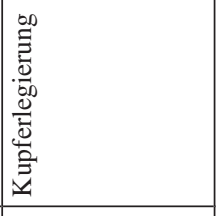 & 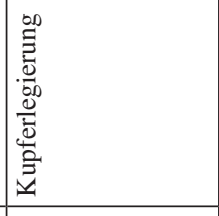 \\
\hline 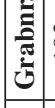 & $\varrho$ & ๕ & $\stackrel{\text { }}{ }$ & 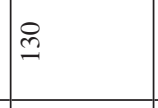 & $\cong$ & 导 & \\
\hline 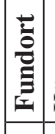 & 畜 & 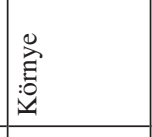 & 空 & 突 & 斊 & 离 & 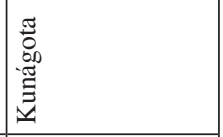 \\
\hline $\mid \dot{\vec{z}}$ & F & $\stackrel{\infty}{+}$ & $\hat{q}$ & in & in & in & in \\
\hline
\end{tabular}

Acta Archaeologica Academiae Scientiarum Hungaricae 66, 2015 


\begin{tabular}{|c|c|c|c|c|c|c|}
\hline 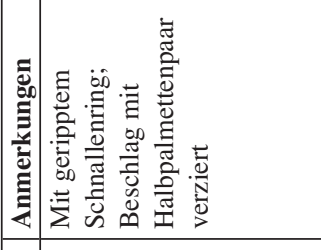 & 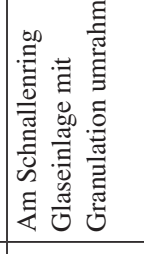 & 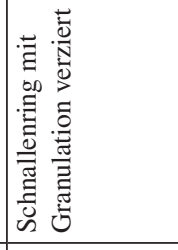 & & & 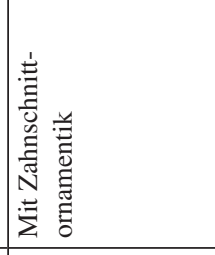 & \\
\hline 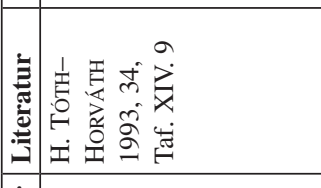 & 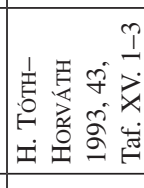 & 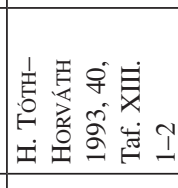 & 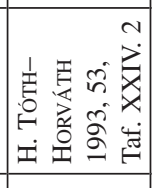 & 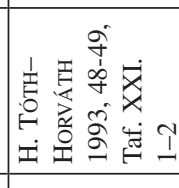 & 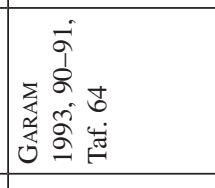 & 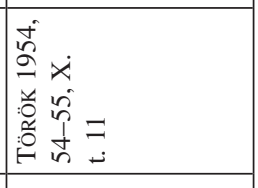 \\
\hline 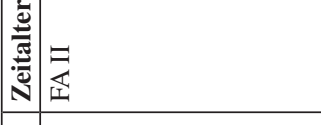 & 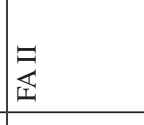 & \begin{tabular}{|l} 
\\
\end{tabular} & 胥 & 屋 & \begin{tabular}{|l} 
\\
\end{tabular} & 丞 \\
\hline 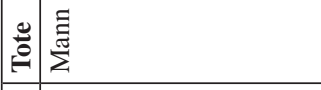 & 善 & 旄 & 镸 & 镸 & 謍 & 镸 \\
\hline 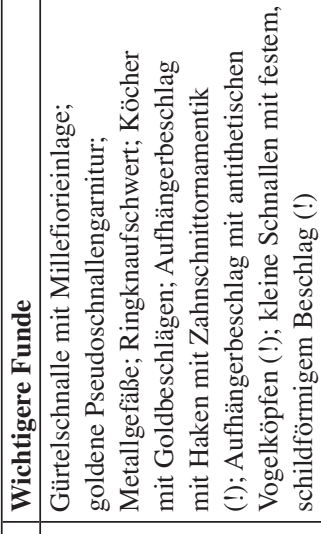 & 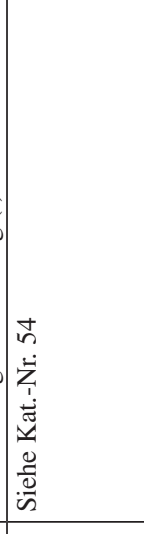 & 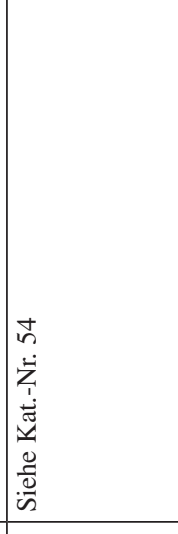 & 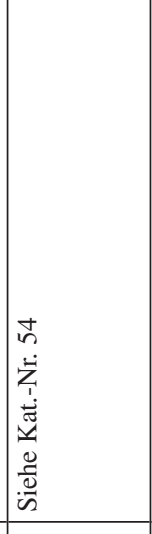 & 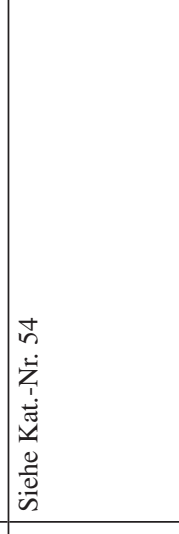 & 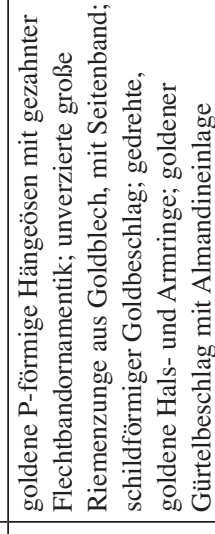 & 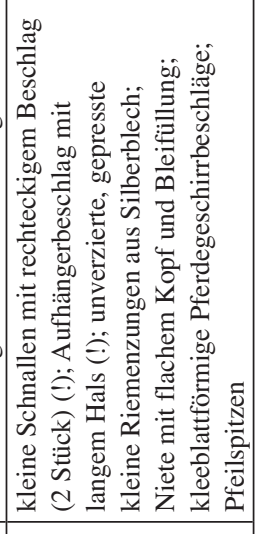 \\
\hline 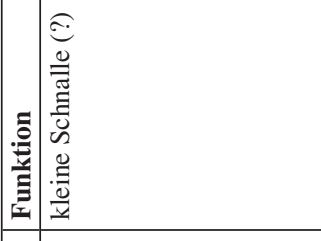 & 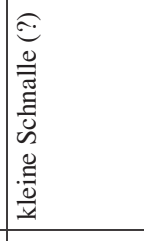 & 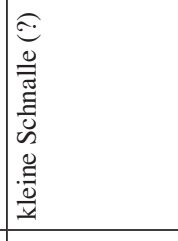 & 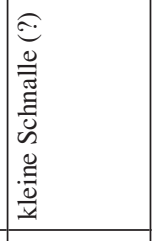 & 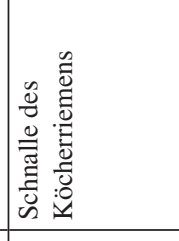 & 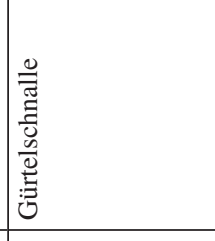 & 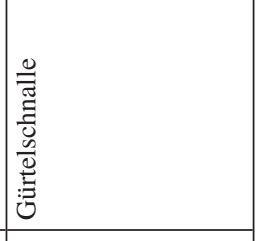 \\
\hline 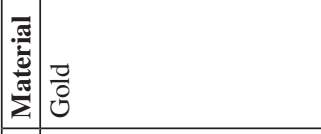 & \begin{tabular}{|l}
$\frac{7}{0}$ \\
0
\end{tabular} & \begin{tabular}{|l}
$\frac{\pi}{0}$ \\
0
\end{tabular} & 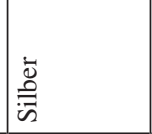 & $\begin{array}{l}\frac{\pi}{5} \\
0\end{array}$ & \begin{tabular}{|l}
$\frac{\pi}{0}$ \\
0
\end{tabular} & 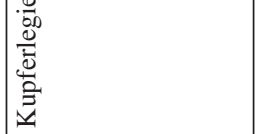 \\
\hline 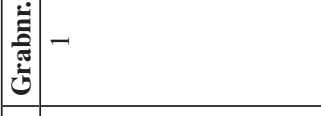 & - & - & - & - & & $\vec{a}$ \\
\hline 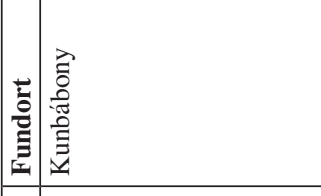 & 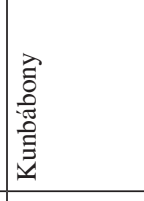 & 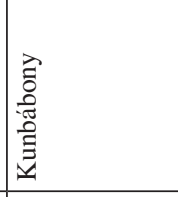 & 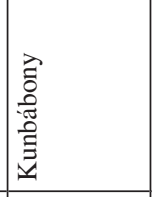 & 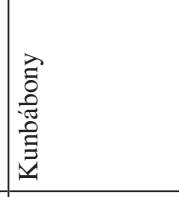 & 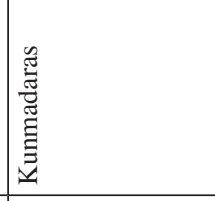 & 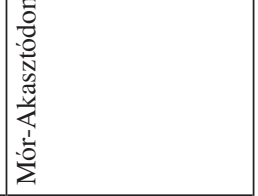 \\
\hline 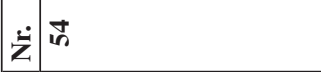 & in & in & in & in & in & 8 \\
\hline
\end{tabular}




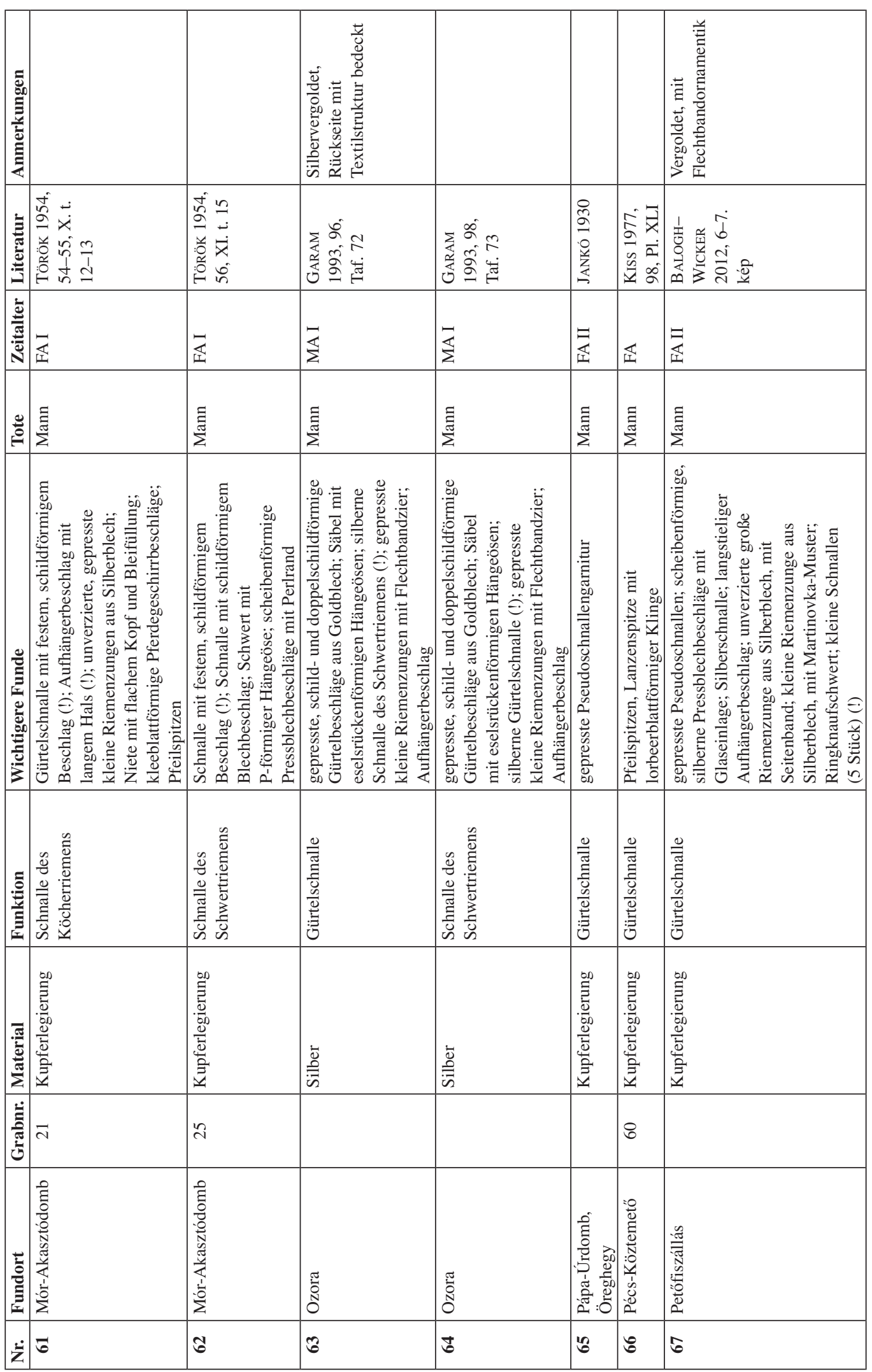

Acta Archaeologica Academiae Scientiarum Hungaricae 66, 2015 


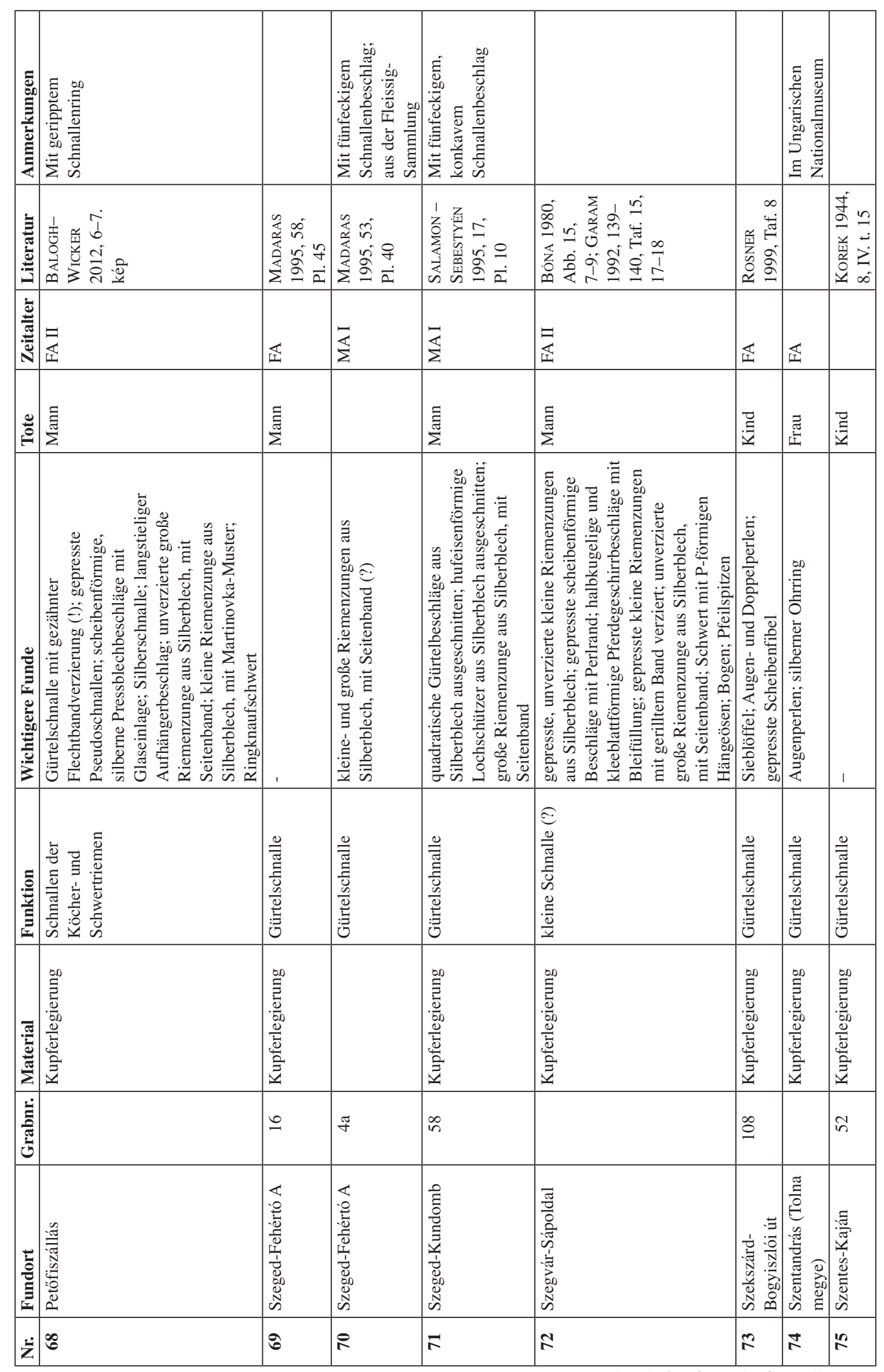




\begin{tabular}{|c|c|c|c|c|c|}
\hline $\mid$ & 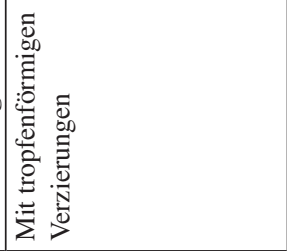 & 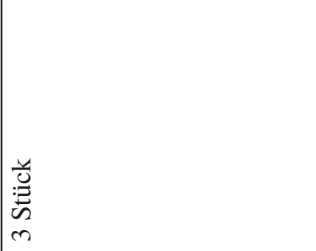 & & & \\
\hline & 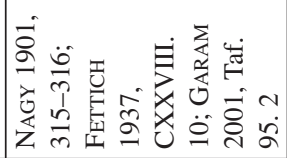 & 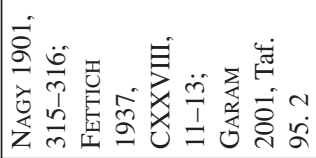 & 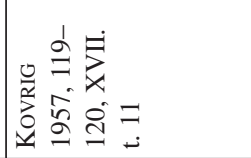 & 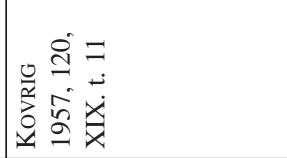 & 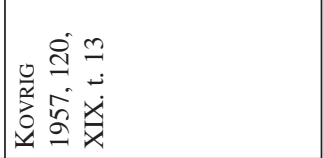 \\
\hline 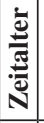 & & & 厓 & $\underset{\Phi}{\mid \vec{x}}$ & 居 \\
\hline : & & & 昙 & $\begin{array}{l}\text { 壳 } \\
\text { ¿ }\end{array}$ & 竞 \\
\hline & 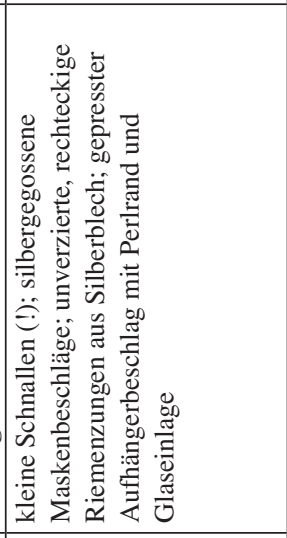 & 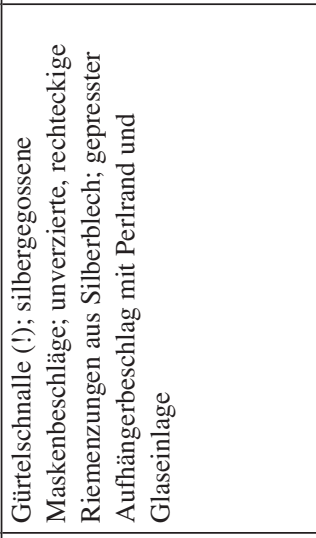 & 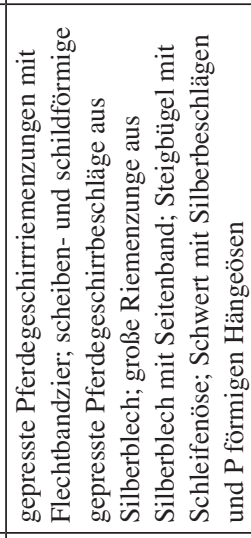 & 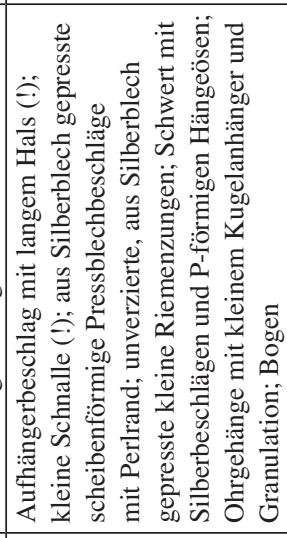 & 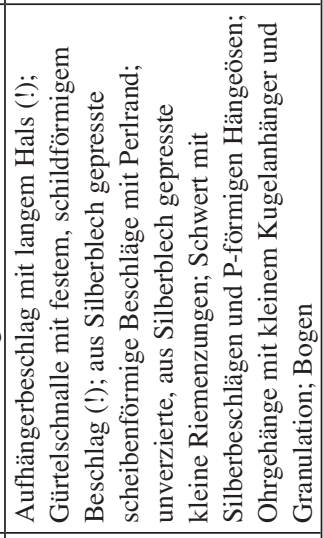 \\
\hline & 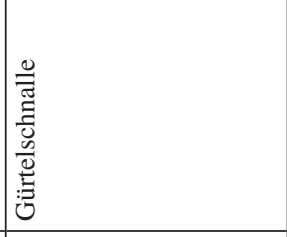 & 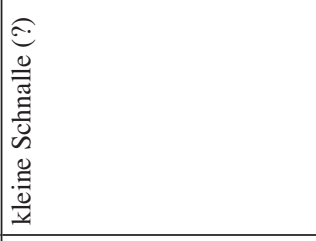 & 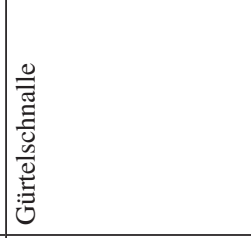 & 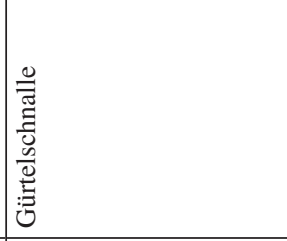 & 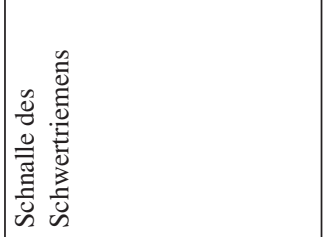 \\
\hline 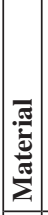 & & & 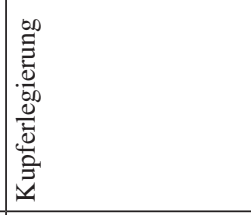 & 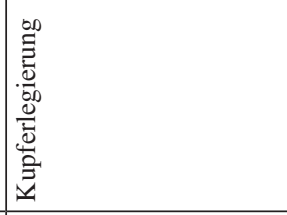 & 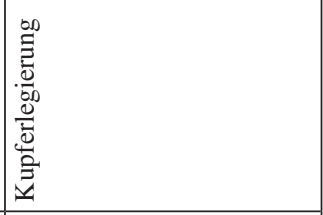 \\
\hline $\mid$ & & & - & $\mathrm{a}$ & 4 \\
\hline & 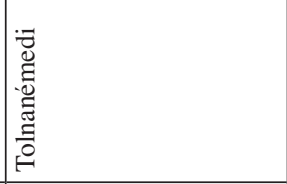 & 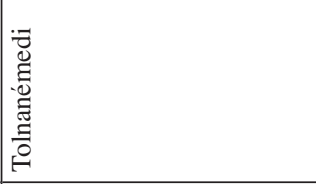 & 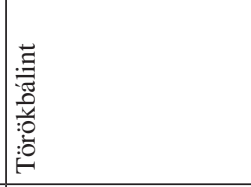 & 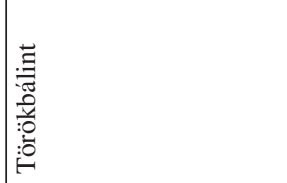 & 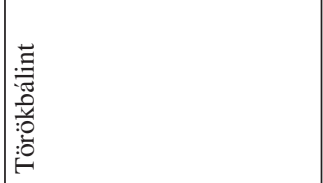 \\
\hline$\dot{\vec{z}}$ & & N & $\approx$ & $\approx$ & 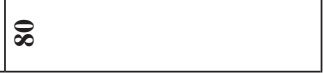 \\
\hline
\end{tabular}

Acta Archaeologica Academiae Scientiarum Hungaricae 66, 2015 


\begin{tabular}{|c|c|c|c|c|c|c|c|c|c|c|}
\hline & 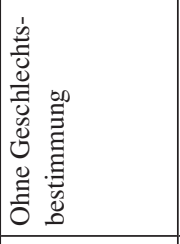 & & & & 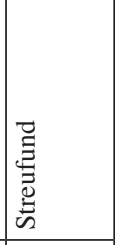 & & & & & \\
\hline 紊: & 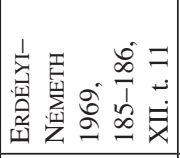 & 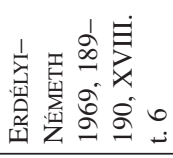 & 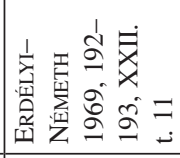 & 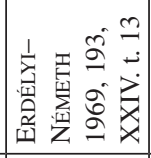 & 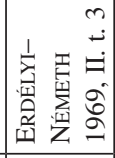 & 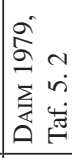 & 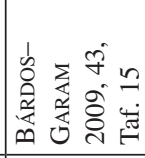 & 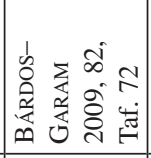 & 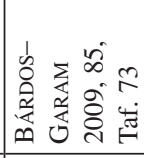 & 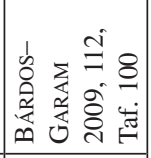 \\
\hline 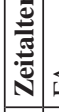 & $\varangle$ & 玨 & 厌 & 在 & & & 左 & $\mathbb{\Psi}$ & $\mathbb{\Psi}$ & 丞 \\
\hline : & 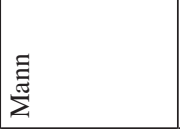 & 昰惫 & 蛋 & 胥 & & & 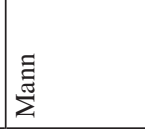 & $\begin{array}{l}\vec{\Xi} \\
\dot{\Xi} \\
\end{array}$ & 莺 & 䔍 \\
\hline : & 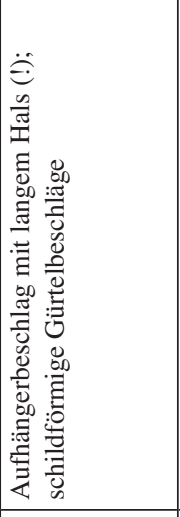 & 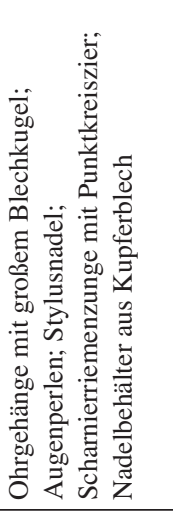 & 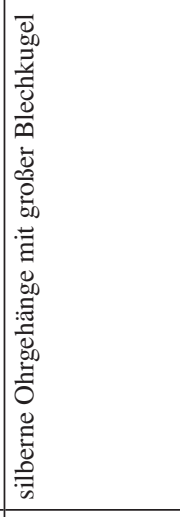 & 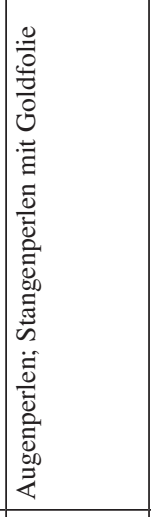 & 1 & 1 & 1 & 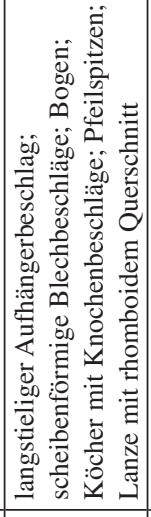 & 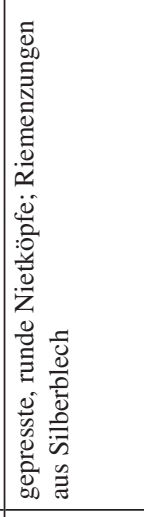 & 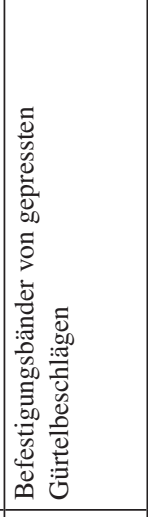 \\
\hline : & 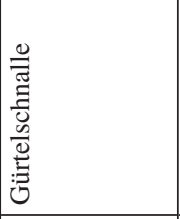 & 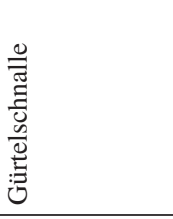 & 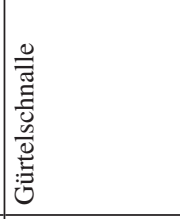 & 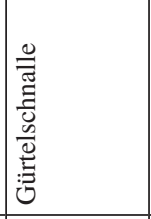 & 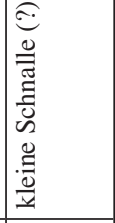 & 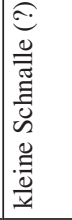 & 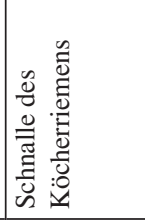 & 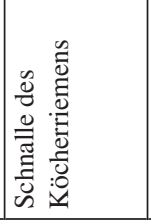 & 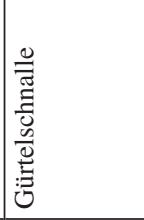 & 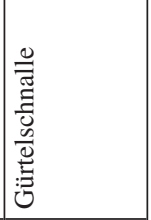 \\
\hline . & 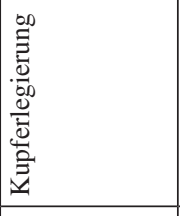 & 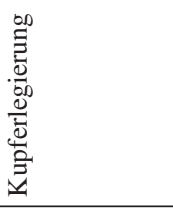 & 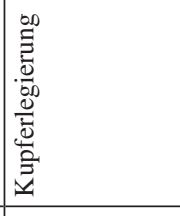 & 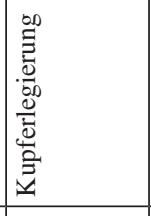 & 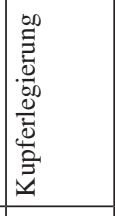 & 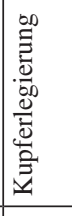 & 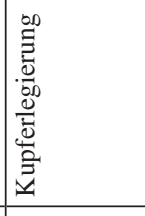 & 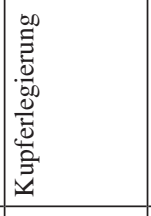 & 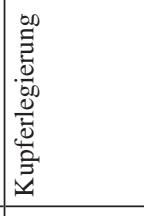 & 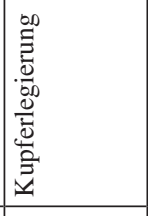 \\
\hline 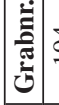 & $\stackrel{\Delta}{2}$ & $\stackrel{\infty}{\stackrel{\sim}{~}}$ & సి & $\widehat{\widehat{A}}$ & ' & & స్ర్ర & in & $\stackrel{n}{n}$ & 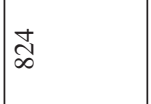 \\
\hline : & 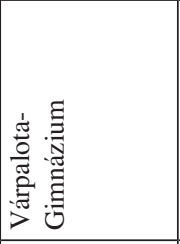 & 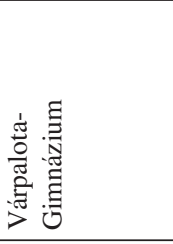 & 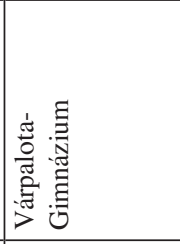 & 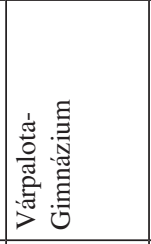 & 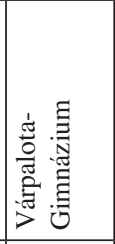 & 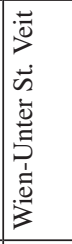 & 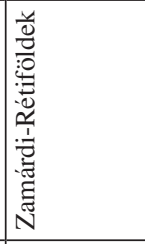 & 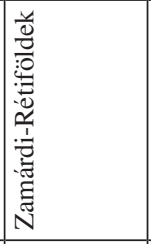 & 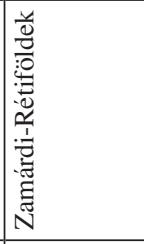 & 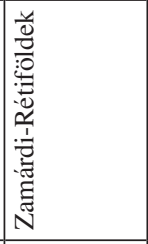 \\
\hline$\dot{\vec{z}}$ & $\bar{\infty}$ & $\infty$ & $\infty$ & $\Phi$ & $\infty$ & $\infty$ & $\infty$ & $\infty$ & के & 2 \\
\hline
\end{tabular}




\begin{tabular}{|c|c|c|c|c|c|c|c|c|c|c|}
\hline & & & 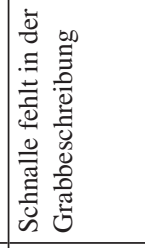 & & & & & & & \\
\hline & 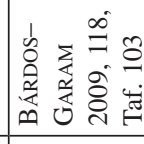 & 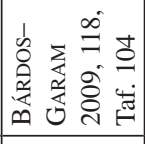 & 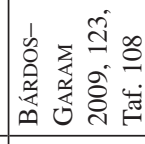 & 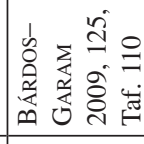 & 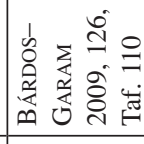 & 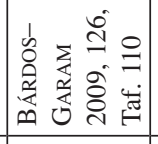 & 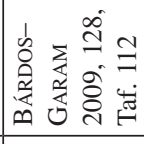 & 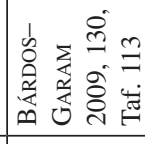 & 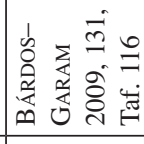 & 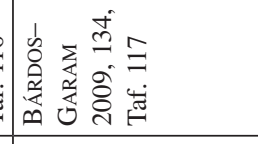 \\
\hline 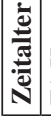 & $\underset{⿱ 乛 龰}{\exists}$ & $\mathbb{I}$ & 丞 & 左 & 左 & 疋 & 庒 & 丞 & $\underset{\Phi}{\mathbb{\Psi}}$ & 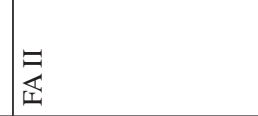 \\
\hline : & 志 & 言 & 志 & 志 & 离 & 赔 & 言 & 总 & 总 & 咅 \\
\hline & 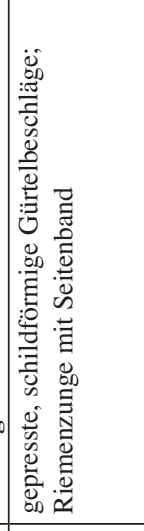 & 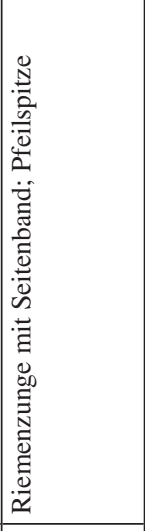 & 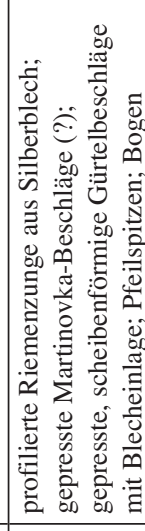 & . & 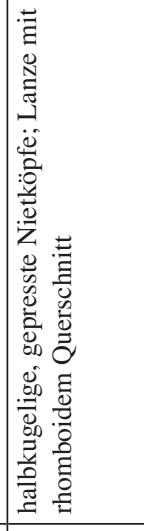 & 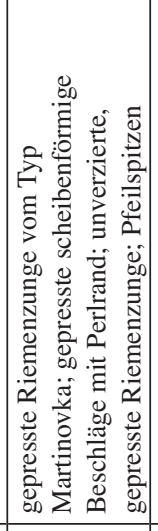 & 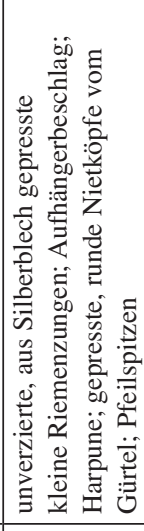 & 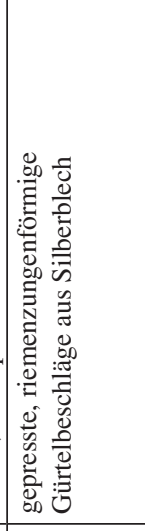 & 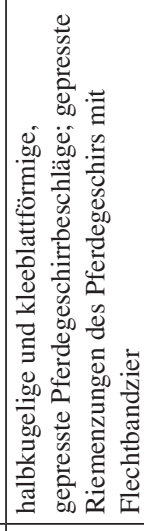 & 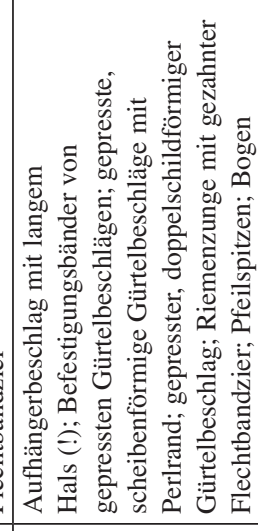 \\
\hline & 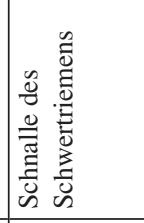 & 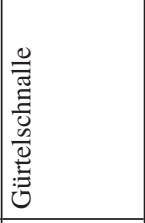 & 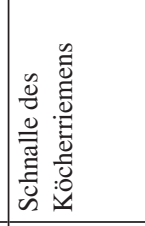 & 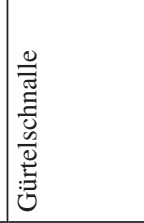 & 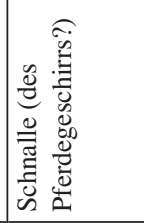 & 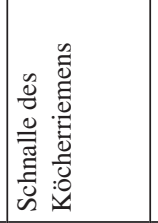 & 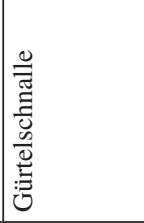 & 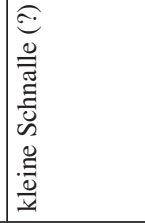 & 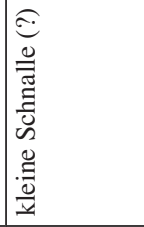 & 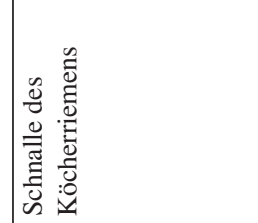 \\
\hline 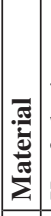 & 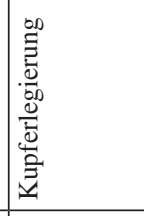 & 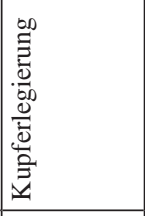 & r. & 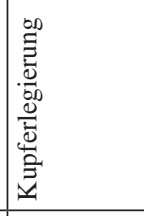 & 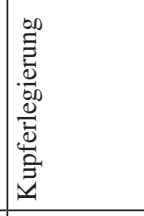 & 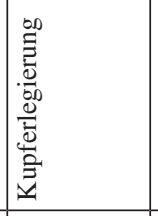 & 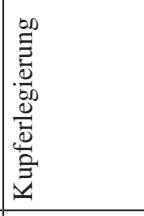 & 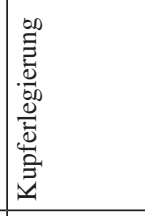 & 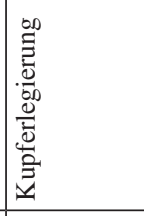 & 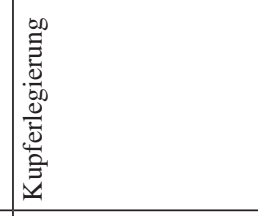 \\
\hline 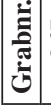 & $\hat{\infty}$ & $\underset{\infty}{t}$ & ڤૂ & 尹 & I & 我 & $\hat{a}$ & $\hat{\alpha}$ & $\stackrel{n}{\varrho}$ & 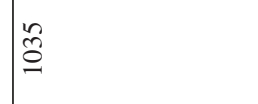 \\
\hline & 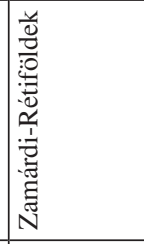 & 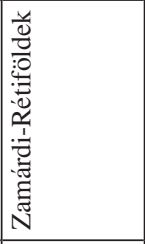 & 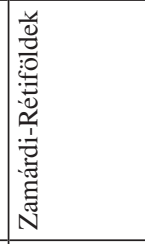 & 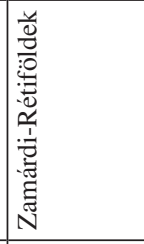 & 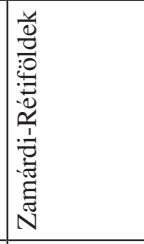 & 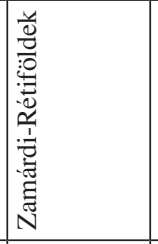 & 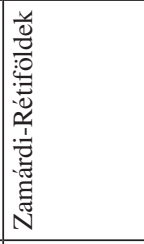 & 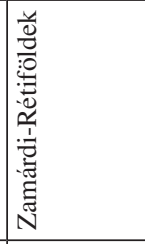 & 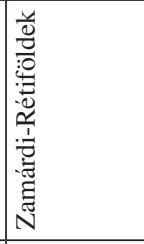 & 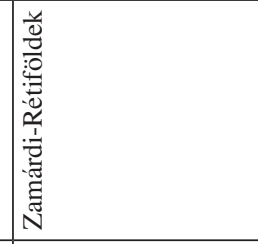 \\
\hline$\dot{\mathbf{z}}$ & $\bar{\alpha}$ & $\tilde{\alpha}$ & $\approx$ & I & $\approx 2$ & 2 & ta & 2 & 2 & $\Xi$ \\
\hline
\end{tabular}

Acta Archaeologica Academiae Scientiarum Hungaricae 66, 2015 


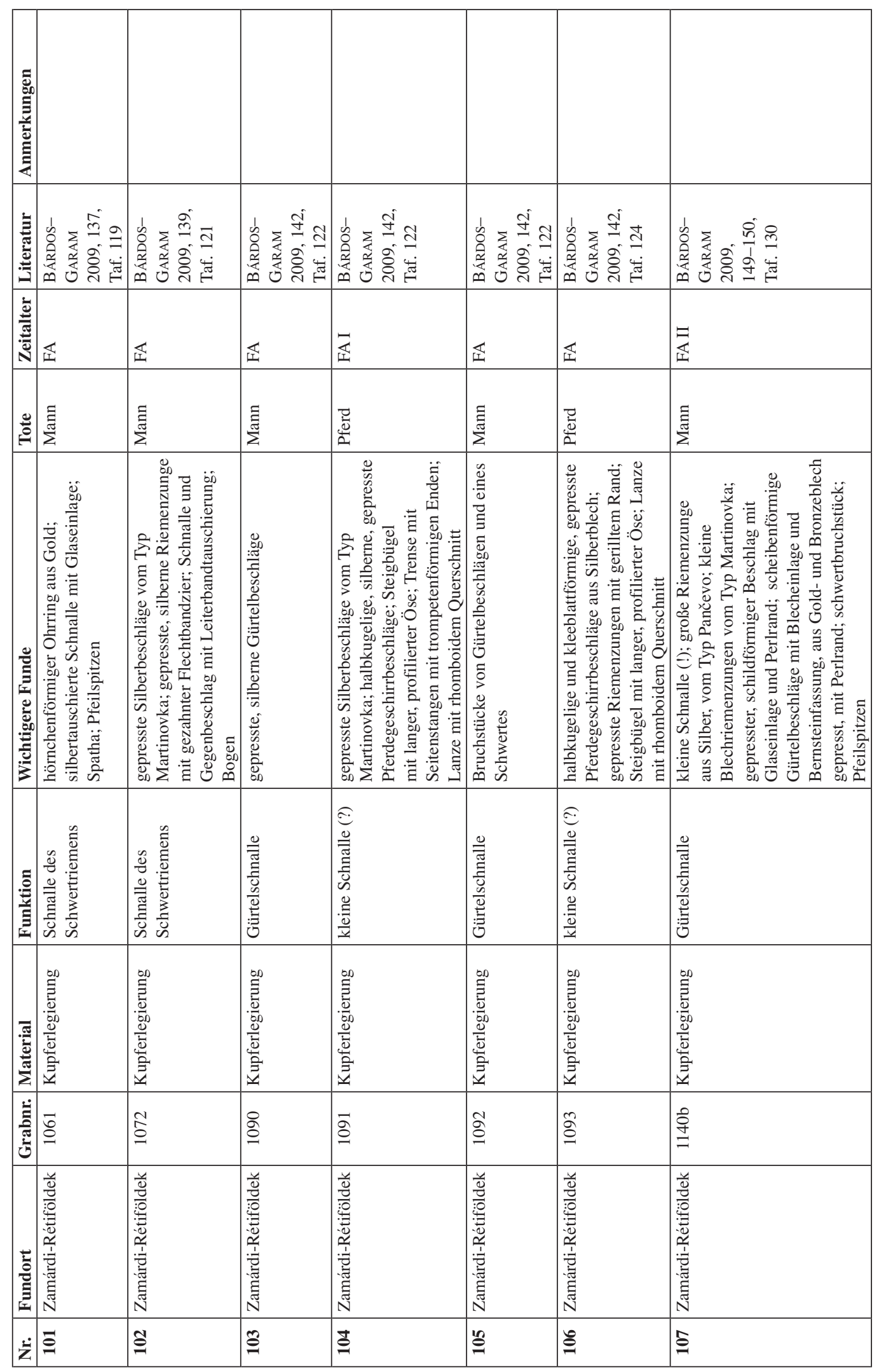




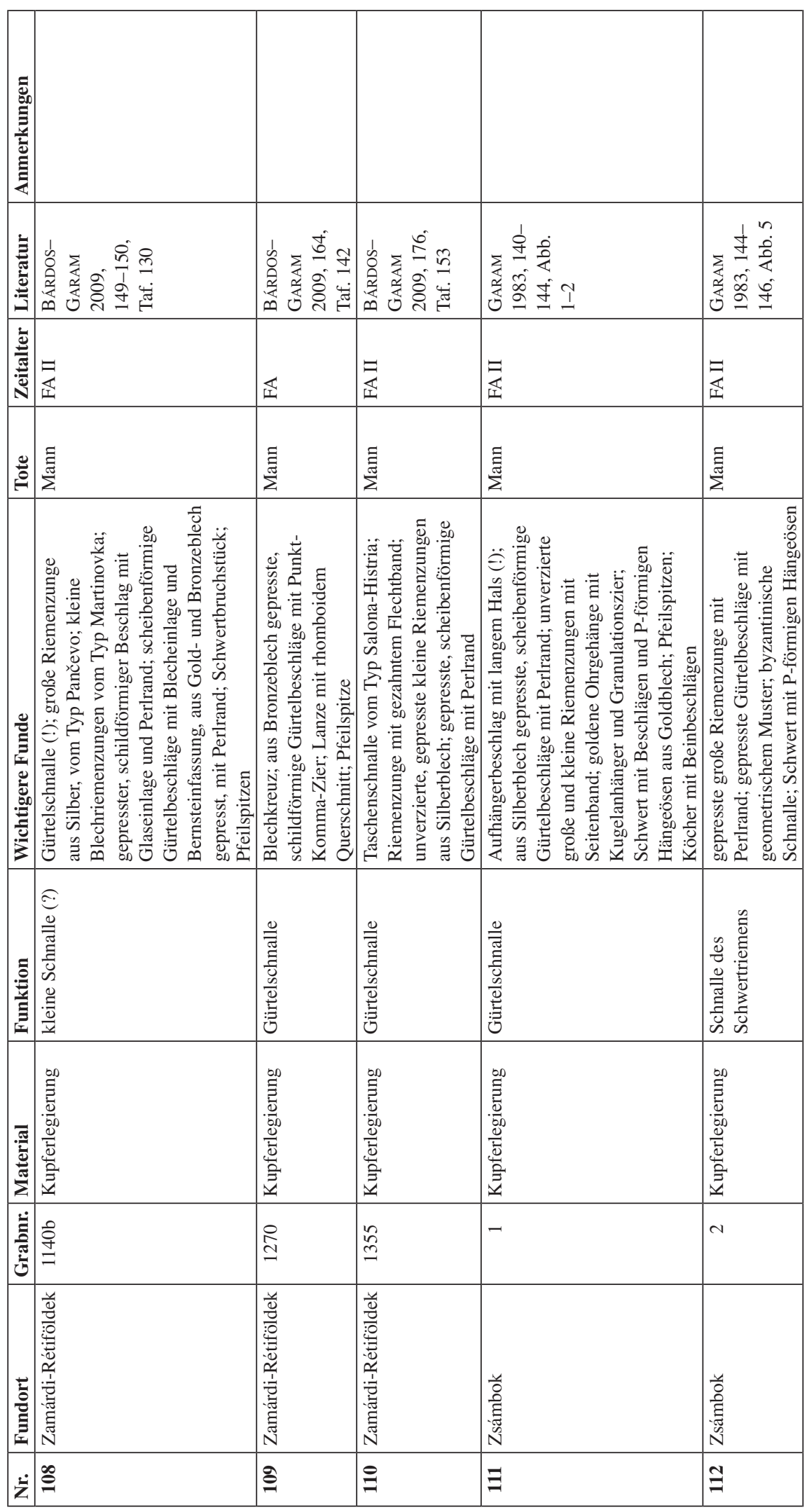

Acta Archaeologica Academiae Scientiarum Hungaricae 66, 2015 
LITERATUR

АЙБАБИН 1982

АЙБАБИН 2003

AIBABIN 2008

AJBABIN-ChAJREDINOVA 2009

ANDRÁSI-AIBABIN 2008

BÁLINT 1992

BALOGH 2004

BALOGH-WICKER 2012

BÁRDOS-GARAM 2009

BÍRÓ-SZENTHE 2011

BÓNA 1980

БУГАРСКИ 2009

BÜHLER 1999

BÜHLER 2010

DAIM 1979

DAIM 1987

DAIM 2000

ДаскАЛов 2012

ДзАТТИАТы 2006

ДМитРИЕв 1982

ERDÉLYI 1958

ERDÉLYI-NÉMETH 1969

ERdÉLYI-OJTOZI-GENING 1969
= А. И. АЙБАБин: Погребения конца VII - первой половины VIII. в. в Криму (Gräberfelder in der Krim zwischen dem Ende des 7. bis zur ersten Hälfte des 8. Jahrhunderts.) In: А. К. Амброз - И. Ф. Эрдели (ред.): Древности эпохи великого переселения народов V-VIII веков. Москва 1982, 165-192.

= А. И. АЙБАБИн: Крым, Северо-Восточное Причерноморье и Закавказье в эпоху средневековя. IV-IX. века. (Die Krim, das nordöstliche Schwarzmeergebiet und das Kaukasus-Gebiet im Mittelalter. 4.-9. Jahrhundert). Археология. Москва 2003.

= A. I. AIBABIN: Commentary on select items and groups of the Collection. In: ANDRÁSI-AiBABIN 2008, 149.

= A. I. AJBABin-Ė. A. ChaJREdinova: Das Gräberfeld beim Dorf Lučistoe. 1: Ausgrabungen der Jahre 1977, 1982-1984. Monographien des Römisch-Germanischen Zentralmuseums 83. Mainz 2009.

= J. ANDRÁSI-A. I. AIBABIN: The Berthier-Delagarde Collection of Crimean Jewellery in the British Museum and Related Material. British Museum research publications. Oxford 2008.

= Cs. BÁLINT: Der Gürtel im frühmittelalterlichen Transkaukasus und das Grab von Üč Tepe (Sowj. Azerbajdžan). In: F. Daim (Hrsg.): Awarenforschungen I. Archaeologia Austriaca Monographien 1. Studien zur Archäologie der Awaren 4. Wien 1992, 309-496.

= Cs. BALOGH: Martinovka típusú övgarnitúra Kecelről. A Kárpát-medencei maszkos veretek tipokronológiája (Gürtelgarnitur des Typs Martinovka von Kecel. Die Typochronologie der Maskenbeschläge des Karpatenbeckens). MFMÉ - StudArch 10 (2004) 241-303.

= Cs. BALOGH-E. WiCKER: Avar nemzetségfó sírja Petőfiszállás határából (Das awarenzeitliche Sippenhäuptlingsgrab von Petőfiszállás). In: T. Vida (ed.): Thesaurus Avarorum. Régészeti tanulmányok Garam Éva tiszteletére = Archaeological Studies in Honour of Éva Garam. Budapest 2007, 551-582.

= E. BÁRDOS-É. GARAM: Das awarenzeitliche Gräberfeld von Zamárdi-Rétiföldek. I. Monumenta Avarorum archaeologica 9. Budapest 2009

= Cs. BíRó-G. SzEnTHE: Öntéstechnikai vizsgálatok késő avar kori bronztárgyakon. Sorozatok modellezése és sokszorositása (Investigations of casting techniques of bronze artefacts from the Late Avar Period. Modelling and production of serial pieces). In: I. Vida-E. Tóth (ed.): Corolla museologica Tibor Kovács dedicata. Magyar Nemzeti Múzeum, Budapest 2011, 155-174.

= I. BÓNA: Studien zum frühawarischen Reitergrab von Szegvár. ActaArchHung 32 (1980) 31-95.

= И. БУГАРски: Некрополе из гоба антике и раноі̄ средньеі̄ века на локалитету Чик (Сemeteries from Antiquity and Early Middle Ages at Čik). Београд 2009.

= B. BüHLER: Untersuchungen zu Guss, Oberflächenbearbeitung und Vergoldung an frühmittelalterlichen Bunt- und Edelmetallgegenständen. ArchA 82-83 (1998-1999) 429-492.

= B. BÜHLER: Is it Byzantine metalwork or not? Evidence for Byzantine craftmanship outside the Byzantine Empire (6 ${ }^{\text {th }}$ to $9^{\text {th }}$ centuries AD). In: F. Daim-J. Drauschke (Hrsg.): Byzanz - das Römerreich im Mittelalter. 1: Peripherie und Nachbarschaft. Monographien des Römisch-Germanischen Zentralmuseums 84/1. Mainz 2010, 213-234.

= F. DAIM: Awarische Altfunde aus Wien und Niederösterreich. MAG 109 (1979) 55-101.

= F. DAIM: Das awarische Gräberfeld von Leobersdorf, Niederösterreich. Studien zur Archäologie der Awaren 3. Wien 1987

= F. DAIM: „Byzantinische“ Gürtelgarnituren des 8. Jahrhunderts. In: F. Daim (Hrsg.): Die Awaren am Rand der byzantinischen Welt. Monographien zur Frühgeschichte und Mittelalterarchäologie 7 (Mainz, 2000) 77-204

= М. ДАскАлов: Колани и коланни украси от VI-VII век (от днешна България и съседните земи) (The $6^{\text {th }}-7^{\text {th }}$ Century Belt Sets and Belt Ornaments - Based on artifacts from present-day Bulgaria and the neighbouring territories). София 2012.

= Р. Г. ДзАттиАты: Царциатские памяатники: едисское городище и могильники. (Funde aus Carciat). Владикавказ 2006

= А. В. ДмитриЕв: Раннесредневековые фибулы из могильника на р. Дюрсо. (Frühmittelalterliche Fibeln im Gräberfeld Dyrso). In: A. К. Амброз-И. Ф. Эрдели (ред.): Древности эпохи великого переселения народов V-VIII веков. Москва 1982, 69-107.

= I. ERDÉLYI: A jánoshidai avar temető [Das awarische Gräberfeld von Jánoshida]. RégFüz II/1. Budapest 1958.

= I. ERDÉLYI-P. NÉMETH: A várpalota-gimnáziumi avar temető (A Bakonyi Múzeum avar kori emlékanyagának ismertetése I). Das awarische Gräberfeld von Várpalota-Gimnázium. VMMK 8 (1969) 167-198.

= I. ERdÉlyi-E. Ojtozi-W. Gening: Das Gräberfeld von Newolino. Ausgrabungen von A. Schmidt und der archäologischen Kama-Expedition. Arch Hung Ser. Nova 46. Budapest 1969. 
FETTICH 1937

FÜLÖP 1988

GARAM 1993

GARAM 2001

ГАВРИЛОВА 1965

ГАвРИтУХИН-ОБлОмСКИй 1996

ГолдинА-ГолдинА 2010

GREENE 1994

GuBITZA 1908

HAJNAL 2012

ХАЙРЕДИНОВА 2003

HALDON 1997

HAMPEL 1905

HORVÁTH 1934

HOWARD-JOHNSTON 2010

JANKÓ 1930

JÖRGENSEN 1992

KADA 1906

KENK 1982

KISS 1977

KISS 1996

KISS 2001

KoMAP 2006

КомАР-КУБЫШЕВ-ОРЛОВ 2006

КОВАЛЕВСКАЯ 1979
= N. FEтTiCH: A honfoglaló magyarság fémmüvessége (Die Metallkunst der landnehmenden Ungarn). ArchHung 21. Budapest 1937.

= GY. FüLÖP: Awarenzeitliche Fürstenfunde von Igar. ActaArchHung 40 (1988) 151-190.

= É. GARAM: Katalog der awarenzeitlichen Goldgegenstände und der Fundstücke aus den Fürstengräbern im Ungarischen Nationalmuseum. Catalogi Musei Nationalis Hungarici, Seria archaeologica 1. Budapest 1993.

= É. GARAM: Funde byzantinischer Herkunft in der Awarenzeit vom Ende des 6. bis zum Ende des 7. Jahrhunderts. Monumenta Avarorum archaeologica 5. Budapest 2001.

= А. А. ГАвРиловА: Могильник Кудыргэ. Как источник по истории алтайских племен. (Das Gräberfeld von Kudyrge. Zur Kultur und Geschichte der Völker im Altai.) Москва-Ленинград 1965.

= И. О. ГАвритухин-А. М. ОБломский: Гапоновский клад и его культурно-исторический контекст. (Gaponovo hoard and its cultural and historical context). Москва 1996.

= Е. В. ГолдинА-Р. Д. ГолдинА: „Дальний импорт” Прикамья - своеобразное проявление процессов взаимодействия народов Евразии (VIII в. до. н. э.-IX. в. н. э.). In: Е. В. Голдина: Бусы могильников неволинской культуры (конец IV-IX вв.). "Long-distance import” to Prikamye - a unique display of interaction processes between Eurasian nations $\left(8^{\text {th }}\right.$ century BC $-9^{\text {th }}$ century AD). Ижевск 2010, 156-262.

= K. GREENE: Technology and innovation in context: The Roman background to medieval and later developments. JRA 7 (1994) 22-33.

= K. GuBitZA: A kishegyesi régibb középkori temető [Das ältere mittelalterliche Gräberfeld von Kishegyes]. ArchÉrt 28 (1908) 346-363.

= Zs. HAJNAL: A Kölked-feketekapui 'A' és 'B' temetők együttes értékelése (Die zusammenfassende Auswertung der Gräberfelder 'A' und 'B' von Kölked-Feketekapu). In: T. Vida (Hrsg.): Thesaurus Avarorum. Régészeti tanulmányok Garam Éva tiszteletére = Archaeological Studies in Honour of Éva Garam. Budapest 2012, 607-644.

= Э. А. ХАЙРЕдиновА: Обувные наборы V-VII. вв. из Юго-Западного Крыма (Footwear sets dating back to the $5^{\text {th }}-7^{\text {th }}$ centuries in the South-Western Crimea). МАИЭТ 10 (2003) 125-160.

= J. HALDON: Byzantium in the Seventh Century. The transformation of a culture. Cambridge 1997.

= J. HAMPEL: Alterthümer des frühen Mittelalters in Ungarn. Braunschweig 1905.

= T. HoRvÁth: Az üllői és a kiskőrösi avar temető (Die awarischen Gräberfelder von Üllő und Kiskőrös). ArchHung 19. Budapest 1934.

= J. HowARD-Johnston: Witnesses to a World Crisis. Historians and histories of the Middle East in the seventh century. Oxford 2010.

= L. JANKÓ: A pápai avar kori sírleletek (Grabfunde aus der Awarenzeit zu Pápa). ArchÉrt 44 (1930) 124-141, 286-287.

= L. Jörgensen: Castel Trosino and Nocera Umbra. A chronological and social analysis of family burial practices in Lombard Italy ( $6^{\text {th }}-8^{\text {th }}$ cent. A.D.). Acta Arch København 62 (1992) 1-58.

= E. KADA: Gátéri (Kun-Kisszállási) temető a régibb középkorból [Das Gräberfeld von Gátér (KunKisszállás) aus dem älteren Mittelalter]. ArchÉrt 26 (1906) 207-221.

$=$ R. KENK: Früh- und hochmittelalterliche Gräber von Kudyrgè im Altai. Materialien zur allgemeinen und vergleichenden Archäologie 3. München 1982.

= A. Kiss: Avar Cemeteries in County Baranya. Cemeteries of the Avar Period (568-829) in Hungary 2. Budapest 1977.

= A. KISS: Das awarenzeitlich gepidische Gräberfeld von Kölked-Feketekapu A. Monographien zur Frühgeschichte und Mittelalterarchäologie 2. Studien zur Archäologie der Awaren 5. Innsbruck 1996.

= A. KISs: Das awarenzeitliche Gräberfeld in Kölked-Feketekapu B I-II. Monumenta Avarorum archaeologica 6. Budapest 2001.

= А. В. КомАР: Перещепинский комплекс в контексте основных проблем истории и культуры кочевников Восточной Европы VII- нач. VIII. в. (Pereshchepina complex in context of pivotal problems of history and culture of nomads in Eastern Europe). In: А. В. Комар-А. И. Кубышев-Р. С. Орлов (ред.): Степи Европы в эпоху средневековья (The European Steppes in the Middle Ages). 5: Хазарское время. Донецк 2006, 7-244.

= А. В. КомАР-А. И. КуБЫшев-Р. С. Орлов: Погребения кочевников VI-VII вв. из СевероЗападного Приазовья (Nomad burials of $\mathrm{VI}^{\text {th }}-\mathrm{VII}{ }^{\text {th }}$ c. from North-West Azov reaches). In: A. B. Комар-А. И. Кубышев-Р. С. Орлов (ред.): Степи Европы в эпоху средневековья (The European Steppes in the Middle Ages). 5: Хазарское время. Донецк 2006, 245-374.

= В. Б. КовАЛЕвскАя: Поясные наборы Евразии IV-IX вв. Пряжки. Археология СССР. Москва 1979. 
КОВАЛЕВСКАЯ 1990

KOREK 1944

KosSACK 1974

KOVRIG 1948

KOVRIG 1957

KovRIG 1963

KÖLTŐ 1982

LÁSZLÓ 1955

LÁSZLÓ 1976

ЛЕвина 1994

MAdARAs 1994

MADARAS 1995

MARTIN 1990

MAY-SZENTHE 2015

Mithay 1995

НАъ 1959

NAGY 1901

NAGY 1998

PAPP 1962

PAROLI-RICCI 2008

PRICHODNJUK 1994

PROHÁSZKA 2010

RÁCZ 2001

РАшев 2007

ROSNER 1999

RUPP 2003

RUPP 2005
= В. Б. КовАлЕвскАя: Традиции прорезных пояасов в памятниках кудыргинского типа. (Die Gürtelbeschläge im Nachlass der Kudyrge-Gruppe). In: Археология Средней Азии, Кавказа и Сибири. Краткие Сообщения 199. Москва 1990, 39-46.

= J. KoREK: A Szentes-kajáni avarkori temető. Das awarenzeitliche Gräberfeld von Szentes-Kaján. Dolgozatok 19 (1944) 1-129.

= G. KossacK: Prunkgräber. Bemerkungen zu Eigenschaften und Aussagewert. In: G. KossackG. Ulbert (Hrsg.): Studien zur vor- und frühgeschichtlichen Archäologie. Festschrift für Joachim Werner zum 65. Geburtstag. München 1974, 3-34.

= I. KovRIG: Avarkori sírleletek Csengődröl (Avar finds from Csengőd). ArchÉrt 29-31 (1948) 339349.

= I. KovRIG: Kora-avarkori sírok Törökbálintról (Deux tombes Avares de Törökbálint). FolArch 9 (1957) 119-133.

= I. KovRIG: Das awarenzeitliche Gräberfeld von Alattyán. ArchHung 40. Budapest 1963.

= L. KöLTő: Avar kori bronztárgyak röntgenemissziós analízise (X-ray emission analysis of bronze objects from the Avar Age). SMK 5/1 (1982) 5-68.

= Gy. LÁSZLÓ: Études archéologiques sur 1'histoire de la société des avars. ArchHung 34. Budapest 1955.

= GY. LÁSZLó: A bócsai fejedelmi sír és a keceli kard (Der Fürstengrab von Bócsa und der Schwert von Kecel). Cumania 4 (1976) 89-114

= Л. М. ЛЕвинА: Джетыасарская культура. 3-4: Могильник Алтинасар 4. Низовья Сырдарьи в Древности). Die Kultur Džetyasar. 3-4: Das Gräberfeld Altinasar 4. Altertümer bei Syrdaria. Москва 1994.

= L. MADARAS: Das awarenzeitliche Gräberfeld von Jászapáti. Avar corpus füzetek 2. Debrecen-Budapest 1994.

= L. MADARAS: The Szeged-Fehértó A and B Cemeteries. Avar corpus füzetek 3. Debrecen-Budapest 1995.

= M. MARTIN: Awarische und germanische Funde in Männergräbern von Linz-Zizlau und Környe. Ein Beitrag zur Chronologie der Awarenzeit. In: F. Vadas (Hrsg.): Internationale Konferenz über das Frühmittelalter. WMMÉ 15 (1990) 65-90.

= Z. MAY-G. SzENTHE: Archaeometrical studies on some bronze buckles with portable (handheld) XRF spectroscopy. ActaArchHung 66/2 (2015) pp. 379-386.

= S. MithaY: Bronz-, avar és középkori leletek Bakonytamási-Hathalom-pusztáról (Anyagközlés). Funde aus der Bronze- und Awarenzeit bzw. aus dem Mittelalter von Bakonytamási-Hathalompuszta. Acta Musei Papensis - Pápai Múzeumi Értesítő 5 (1995) 169-184.

= ШІ. НАъ: Некропола код Арадца из раног средњег века (Ein Gräberfeld bei Aradca aus dem frühen Mittelalter). Рад Војвођанских Музеја 8 (1959) 45-99.

= G. NAGY: Sírleletek a régibb középkorból. III: Némedi, Tolna megye [Grabfunde aus dem älteren Mittelalter. III: Némedi, Kom. Tolna]. ArchÉrt 21 (1901) 314-318.

= M. NAGY: Awarenzeitliche Gräberfelder im Stadtgebiet von Budapest I-II. Monumenta Avarorum archaeologica 2. Budapest 1998.

= L. PAPP: A bólyi avarkori temető (Der awarenzeitliche Friedhof von Bóly). JPMÉ 7 (1962) 163-193.

= L. PAROLI-M. RICCI: La necropoli altomedievale di Castel Trosino. Richerci di archeologia altomedievale e medievale 32-33. Firenze 2008.

= O. M. PrichodnuUK: Der Schatz von Martynovka und seine ethnokulturelle Interpretation. In: L. V. Pekarskaja-D. Kidd: Der Silberschatz von Martynovka. Monographien zur Frühgeschichte und Mittelalterarchäologie 1. Innsbruck 1994, 163-174.

= P. ProhÁszKa: Die awarischen Oberschichtsgräber von Ozora-Tótipuszta (Kom. Tolna, H). In: F. Daim-J. Drauschke (Hrsg.): Byzanz - das Römerreich im Mittelalter. 3: Peripherie und Nachbarschaft. Monogr. RGZM 84/3. Mainz 2010, 189-276.

= Zs. RÁCZ: Kunágota. 2. Die byzantinische Gürtelgarnitur. In: RGA XVII. Berlin-New York 2001, 488-489.

= P. РАшев: Прабългарите през V-VII век (Die Protobulgaren im 5.-7. Jahrhundert). Велико Трново 2007.

= Gy. Rosner: Das awarenzeitliche Gräberfeld von Szekszárd-Bogyiszlói Straße. Monumenta Avarorum archaeologica 3. Budapest 1999.

= C. RuPP: Langobardische und romanische Grabfunde in Umbrien. In: I Longobardi dei ducati di Spoleto e Benevento. Atti del XVI. congresso internazionale di studi sull'alto medioevo. Spoleto 2003, 669-699.

= C. RuPP: Das langobardische Gräberfeld von Nocera Umbra. Ricerche di archeologia altomedievale e medievale 31. Firenze 2005. 
SACKETT 1990

SALAMON-ERDÉLYI 1971

SALAMON-SEBESTYÉN 1995

SCHULZE-DÖRRLAMM 2009

SHENNAN 1989

SHORTLAND 2004

Somogyi 1984

SOMOGYi 1997

Cs. Sós 1958

STARK 2008

SZENTHE 2012

SZENTHE 2013a

SzENTHE 2013b

SzENTHE (Manuskript)

THEUNE-GROSSKOPF 1995

Н. То́тн 1980

H. Tóth-HoRvÁTH 1993 Tо́тн 2010

TÖRÖK 1954

TÖRÖK 1975

UENZE 1992

ВЕЙМАРИ-АЙБАБИН 1993

VIDA 2009

ВОЛКОВ-ПАСТУРЕНКО 2006

WERNER 1974

WERNER 1984
= J. SACKETT: Style and ethnicity in archaeology: The case for isochretism. In: M. Conkey-C. Hastorf (eds): The Uses of Style in Archaeology. Cambridge 1990, 32-43.

= Á. SALAMON-I. ERdÉLYi: Das völkerwanderungszeitliche Gräberfeld von Környe. StudArch 5. Budapest 1971.

= Á. SAlAmon-K. Sebestyén: The Szeged-Kundomb Cemetery. Das Awarische Corpus. Avar corpus füzetek Beihefte 4. Debrecen-Budapest 1995, 8-109.

= M. SchUlzE-DÖRRLAMM: Byzantinische Gürtelschnallen und Gürtelbeschläge im Römisch-Germanischen Zentralmuseum. 1: Die Schnallen ohne Beschläg, mit Laschenbeschläg und mit festem Beschläg des 5. bis 7. Jahrhunderts. Kataloge Vor- und Frühgeschichtlicher Altertümer 30/1. Mainz 2009

= S. J. SHENNAN: Introduction: Archaeological approaches to cultural identity. In: S. J. Shennan (ed.): Archaeological Approaches to Cultural Identity. One world archaeology 10. London-New York 1989, 1-32.

= A. J. SHORTLAND: Hopeful monsters? Invention and innovation in the archaeological record. In: J. Bourriau-J. Phillips (eds): Invention and Innovation. The Social Context of Technological Change. 2: Egypt, the Aegean and the Near East, 1650-1150 BC. Oxford 2004.

= P. SomogYI: A cikói temető [Das Gräberfeld von Cikó]. In: G. Kiss-P. Somogyi: Tolna megyei avar temetök. DissPann III/2. Budapest 1984.

= P. Somogyi: Byzantinische Fundmünzen der Awarenzeit. Monographien zur Frühgeschichte und Mittelalterarchäologie 5. Innsbruck 1997.

= Á. Cs. Sós: A keceli avarkori temetők (Die awarenzeitlichen Gräberfelder in Kecel). RégFüz II/3. Budapest 1958

$=$ S. STARK: Die Alttürkenzeit in Mittel- und Zentralasien. Archäologische und historische Studien. Nomaden und Sesshafte. Sonderforschungsbereich Differenz und Integration 6. Wiesbaden 2008.

= G. SzENTHE: 7. századi ezüstlemezes övgarnitúrák. Adatok az ezüstlemezböl készült, sima felületü övveretek elterjedéséhez (Angaben zur Frage der Gürtelgarnituren aus flachem Silberblech der Mittelawarenzeit). In: T. Vida (ed.): Thesaurus Avarorum. Régészeti tanulmányok Garam Éva tiszteletére = Archaeological Studies in Honour of Éva Garam. Budapest 2012, 521-550.

= G. SzENTHE: Antique meaning - Avar significance. Complex iconographic schemes on early medieval small objects. AArch 64 (2013) 139-172.

$=$ G. SzEnTHE: Connections between the Mediterranean and the Carpathian Basin in the $8^{\text {th }}$ century AD. On the hinged strap-ends of the Late Avar Period. ActaArchCarp 48 (2013) 195-225.

$=$ G. SzENTHE: Crisis or innovation? A technological narrative on the social processes of the Carpathian Basin in the $8^{\text {th }}$ century. In: Zwischen Byzanz und der Steppe. Festschrift für Csanád Bálint für seinen 75. Geburtstag. (In Vorbereitung.)

= B. Theune-Grosskopf: Zwiebelknopffibeln und ihre Träger - Schmuck und Rangabzeichen. In: R. Würth-D. Planck (Hrsg.): Die Schraube zwischen Macht und Pracht. Sigmaringen 1995, 77-112.

= Е. Н. То́тн: Frühawarenzeitlicher Grabfund in Kecskemét, Sallaistraße. ActaArchHung 32 (1980) $143-168$.

= E. H. Tóth-A. Horváth: Kunbábony. Das Grab eines Awarenkhagans. Kecskemét 1993.

= B. L. Tóтн: The six techniques of pierced openwork jewellery in late Antiquity and their evolution. In: Ch. Entwistle-N. Adams (eds): 'Intelligible Beauty'. Recent Research on Byzantine Jewellery. London 2010, 1-12.

= GY. TÖRÖK: Kora avar sírok Móron (Frühawarenzeitliche Gräber in Mór). ArchÉrt 81 (1954) 54-60.

= Gy. TÖRÖK: The Kiskőrös Pohibuj-Mackó-dülö cemetery. In: I. Kovrig (ed.): Avar Finds in the Hungarian National Museum. Cemeteries of the Avar Period (567-829) in Hungary 1. Budapest 1975, 283-304.

= S. UENZE: Die spätantiken Befestigungen von Sadovec. Veröffentlichungen der Kommission zur Archäologischen Erforschung des Spätrömischen Raetien. München 1992.

= Е. В. ВЕЙМАРИ-А. И. АЙБАБИН: Скалистинский могильник (Das Gräberfeld von Skalistoe). Киев 1993.

= T. VIDA: „... Kérték, hogy Pannoniában lakhassanak” [,... Man hat darum gebeten, in Pannonien wohnen zu dürfen“]. In: A. Anders-M. Szabó-P. Raczky: Régészeti dimenziók. Budapest 2009, $105-122$.

= С. Волков-И. ПАСтуРенко: Исследования Усть-Иргинского могильника неволинской культуры (Untersuchungen des Gräberfeldes Usti-Irginsk der Kultur von Nevolino). Finno-Ugrica 9 (2006) 5-37.

= J. WERnER: Nomadische Gürtel bei Persern, Byzantinern und Langobarden. In: La civiltà dei Longobardi in Europa. Accademia Nazionale dei Lincei. Roma 1974, 109-139.

= J. WeRnER: Der Grabfund von Malaja Pereščepina und Kuvrat, Kagan der Bulgaren. Bayerische Akademie der Wissenschaften Phil.-Hist. Klasse Abhandlungen. Neue Folge 91. München 1984. 
ZÁBOJNík 1991

ZÁвоJNík 2000
= J. ZÁBoJNíK: Seriation von Gürtelbeschlaggarnituren aus dem Gebiet der Slowakei und Österreichs (Beitrag zur Chronologie der Zeit des Awarischen Kaganats). In: J. Zábojník (Hrsg.): K problematike osídlenia stredodunajskej oblasti vo včasnom stredoveku. Nitra 1991, 219-321.

= J. ZÁволNíк: Zur Problematik der „,byzantinischen“ Gürtelbeschläge aus Čataj, Slowakei. In: F. Daim (Hrsg.): Die Awaren am Rand der byzantinischen Welt. Monographien zur Frühgeschichte und Mittelalterarchäologie 7. Innsbruck 2000, 327-365. 